\title{
Utilizing Lipid Biomarkers To Understand The Microbial Community Structure Of Deep Subsurface Black Shale Formations
}

\author{
Rawlings Akondi \\ West Virginia University, raakondinkerh@mix.wvu.edu
}

Follow this and additional works at: https://researchrepository.wvu.edu/etd

Part of the Biogeochemistry Commons, Geochemistry Commons, and the Geology Commons

\section{Recommended Citation}

Akondi, Rawlings, "Utilizing Lipid Biomarkers To Understand The Microbial Community Structure Of Deep Subsurface Black Shale Formations" (2019). Graduate Theses, Dissertations, and Problem Reports. 4105. https://researchrepository.wvu.edu/etd/4105

This Dissertation is protected by copyright and/or related rights. It has been brought to you by the The Research Repository @ WVU with permission from the rights-holder(s). You are free to use this Dissertation in any way that is permitted by the copyright and related rights legislation that applies to your use. For other uses you must obtain permission from the rights-holder(s) directly, unless additional rights are indicated by a Creative Commons license in the record and/ or on the work itself. This Dissertation has been accepted for inclusion in WVU Graduate Theses, Dissertations, and Problem Reports collection by an authorized administrator of The Research Repository @ WVU.

For more information, please contact researchrepository@mail.wvu.edu. 


\title{
UTILIZING LIPID BIOMARKERS TO UNDERSTAND THE MICROBIAL COMMUNITY STRUCTURE OF DEEP SUBSURFACE BLACK SHALE FORMATIONS
}

\author{
Rawlings Akondi \\ Dissertation submitted \\ to the Eberly College of Arts and Sciences at West \\ Virginia University \\ in partial fulfillment of the requirements for the degree of \\ Doctor of Philosophy in \\ Geology
}

\author{
Shikha Sharma, Ph.D., Chair \\ Timothy Carr, Ph. D. \\ Amy L. Weislogel, Ph.D. \\ Jaime Toro, Ph.D. \\ Paula Mouser, Ph. D \\ Department of Geology and Geography
}

Morgantown, West Virginia

2019

Keywords: Deep Subsurface, Phospholipid Fatty Acids, Diglyceride Fatty Acids, Microbial Community Composition, Marcellus Shale 


\section{ABSTRACT \\ Utilizing Lipid Biomarkers to Understand the Microbial Community Structure of Deep Subsurface Black Shale Formations}

\section{Rawlings Akondi}

The deep subsurface environment has been known to host microbes as early as 1926 and has also been suggested to potentially account for as much as $50 \%$ of the Earth`s biomass. Researchers have shown that microbes alter their membrane lipid components in response to physiological stress, producing stress indicative lipid biomarkers. However, little effort has been made to understand the subsurface microbial community of the shale ecosystem which is increasingly being exploited and altered by addition of drilling and hydraulic fluids to meet our growing energy needs. Phospholipid fatty acids (PLFAs) are microbial lipid biomarkers and are found in all cellular membranes. Their presence in sediments has been used to provide evidence of living microbes while diglyceride fatty acids (DGFAs) are microbial lipid biomarkers which serve as indicators of non-viable microbes. PLFAs and DGFAs are some of the most important proxies used to determine the physiological state of microbes in natural environmental systems. Currently, techniques for the evaluation of subsurface microbial community have mostly been focused on shallow subsurface environments and aquifer settings. This stems from the lack of appropriate techniques that can monitor the deep subsurface ecosystem. Developing such techniques require pristine subsurface rock samples, appropriate instruments and an understanding of the geology and biogeochemistry of the subsurface.

The goal of this dissertation is to develop understanding of microbial life in subsurface (>7000 ft.) Marcellus Shale Formation in the Appalachian Basin. The study focuses on the extraction and analyses of PLFAs and DGFAs to investigate the viable and non-viable microbial 
communities in these deep geologic formations. Samples used for this research were acquired from cores owned by the Marcellus Shale Energy and Environment Laboratory (MSEEL), the Department of Geology and Geography at West Virginia University (WVU), and the West Virginia Geological and Economic Survey (WVGES). A good understanding of microbial community of deep surface black shales like the Marcellus Shale, affords enormous opportunities for improving biocides in the shale energy industry, understanding subsurface microbial colonization, and engineering efforts for enhanced gas recovery.

\section{STRUCTURE OF DISSERTATION}

This dissertation is subdivided into three research topics.

Chapter 1 investigates how buffers and biochemical amendments can improve the recovery of lipid biomarkers from the subsurface shale samples. This chapter is part of a larger investigation to optimize the yield of both viable (PLFA) and non-viable microbial (DGFA) biomarkers. The PLFA biomarkers are presented in Trexler et al. 2017 (Master's Thesis, The Ohio State University). My primary focus in the experiment was to test the performance of the different lipid extraction methods on the DGFAs. Organic amendments and buffer solutions were used to statistically account for spatial heterogeneity in geologic environments. The objective of this chapter was to optimize recovery of microbial lipid biomarkers from the deep subsurface shale ecosystem where biomass density is very low, and matrix is complex. Different extraction procedures were tested to examine their ability to improve recovery and reproducibility of lipid biomarkers in the subsurface Marcellus Shale samples. Even though the biomarker yields were highly variable within replicates for extraction treatments, the reproducibility and yield for lipid fatty acid profiles were consistent and better for the intact phospholipid amended Bligh and Dyer 
treatments $(\mathrm{mBD}+$ Phos + POPC) compared to other treatments. The results from this chapter have been published in Frontiers in Microbiology.

Chapter 2 uses the diversity and concentrations of the DGFA to interpret non-viable microbial community structure and distribution within three zones of the Marcellus Shale. This chapter is also companion to a much larger investigation of the microbial community composition of the deep subsurface shale ecosystem. The PLFA observations are presented elsewhere in Trexler et al. 2017 (The Ohio State University) while this chapter presents the DGFA observations. By differentiating the membrane lipid profiles in the shale rock samples from the drilling muds, we were able to provide evidence of rock-indigenous microbial signatures which could be indicative of native deep subsurface microbial life. The study samples were acquired from a $\sim 2.2 \mathrm{~km}$ deep Marcellus Shale well drilled as part of the MSEEL project in Morgantown, West Virginia. Using a drill mud tracer and core processing procedures that allowed for the removal of chemical and microbial contaminants from subsurface materials, pristine sidewall cores were collected from target intervals in the Marcellus Shale Formation, the overlying Mahantango Formation, and the Marcellus/Mahantango interface. The biomarkers were then extracted and the resulting DGFAs were methylated to fatty acid methyl esters (FAMEs) and analyzed using gas chromatographymass spectrometry (GC-MS). The FAME profiles consisted of normal saturated, monounsaturated, polyunsaturated, branched, oxiranes, terminally branched, hydroxyl, and dimethyl esters. The total biomass yield and variety of DG-FAME profiles were higher in the Mahantango compared to the samples from the Upper Marcellus Shale Formation and Marcellus/Mahantango interface. The lower microbial abundance in Marcellus Shale samples can be attributed to smaller pore throat sizes compared to the Mahantango Formation. The results from this chapter have been published in Environmental Science: Processes \& Impacts. 
$\underline{\text { Chapter } \mathbf{3}}$ investigates the effects of sampling and storage conditions on subsurface microbial community. We used core samples at similar intervals from two Marcellus Shale wells (WV 6 and MSEEL) collected at depths of about $2.2 \mathrm{~km}$ in Monongalia County, West Virginia. The WV 6 samples were collected and stored at room temperature for $~ 40$ years at the WVGES while the samples from MSEEL were obtained from sidewall cores that were sampled following proper microbial sampling protocols and stored at $-80^{\circ} \mathrm{C}$. Samples from both cores were processed and the PLFA and DGFA were extracted and analyzed using the same laboratory protocols. The total yield and variety of the PLFA and DGFA profiles were examined as FAMEs. The variety of individual and functional group biomarkers were higher in the freshly collected MSEEL core samples compared to the WV 6 core samples. The absence of some of the stress indicative biomarkers like keto- and oxiranes in the WV 6 after storage suggested that these biomarkers adapted to changing environmental conditions associated with sampling, handling, and storage. Our results demonstrate changes in the microbial lipid biomarkers due to variations in factors like temperature and pressure. These analyses emphasize the importance of appropriate sample collection and storage protocols for microbial studies. This chapter is draft of manuscript that will be submitted to Frontiers in Microbiology. 


\section{Acknowledgements}

The Marcellus Shale Energy and Environment Laboratory (MSEEL) research team has been instrumental in providing access to the site and samples used for this study. The MSEEL research was funded by the Department of Energy through National Energy Technology Laboratory (DOE-NETL) grant DE\# FE0024297. Funding for my dissertation research was provided by two National Science Foundation (NSF) grants to Dr. Sharma (NSF EAR \# 1205596; NSF-DEB \# 1342732). I express my profound appreciation to my Ph.D. advisor Dr. Shikha Sharma, whose professional knowledge, academic experience, patience, guidance, and mentorship have been very instrumental in my progress throughout my journey as a researcher. I also thank her for her prompt reviews and feedback on my manuscripts and dissertation. I thank my committee members including; Dr. Tim Carr, Dr. Jaime Toro, Dr. Amy Weislogel at West Virginia University and Dr. Paula Mouser at the University of New Hampshire for the help and guidance towards my research. I would like to thank Dr. Susan M. Pfiffner at the University of Tennessee for her laboratory assistance and logistic support in designing and performing the lipid extraction experiments. I thank the Department of Geology and Geography for providing the opportunity for me to pursue my Ph.D. study. I am particularly grateful for the friends that I made throughout my stay here at West Virginia University. I appreciate the faculty, staff, and all my fellow graduate students for their support and encouragement. Assistance from present and former colleagues in the Sharma Research Group like Dr. Warrier Ajay, Travis Wilson, John Pilewski, Rachel Yesenchak, Tom Paronish, Ruiqian Chen, Agrawal Vikas, Steve Henry, Izzy, Andrew McGrady and Brennan Ferguson is greatly appreciated. I will like to thank my paternal grandmother, Mama Manyi Zaza Judith Akondi, my parents; Akondi Pepema Samson and Claudia Ambit Akondi for their dedicated love and sacrifice. I also extend sincere appreciation to the family of my uncle 
Papa Foneng Alfred and my aunt Mama Chefor Magdaline. My siblings Erica, Bestine, Mandela, and Joyceline have been very supportive. 


\section{TABLE OF CONTENTS}
I. Abstract and Structure of Dissertation
II. Acknowledgement.............................................vi-vii
III. Figure Captions ...............................................xii

Chapter 1: Modified Lipid Extraction Methods for Deep Subsurface Shale

1.1.Abstract...............................................................

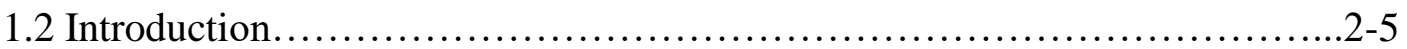

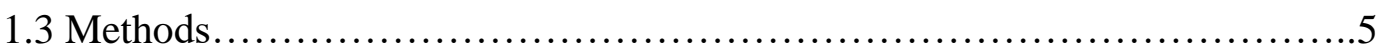

1.3.1 Reagents and Materials..................................6

1.3.2 Sample Preparation and Extraction Procedures.................7

1.3.3 Modified Bligh and Dyer (mBD) method......................8

1.3.4 Modified Folch ...........................................11

1.3.5 Microwave Assisted Extraction..............................11

1.4 Separation and Analysis

1.4.1 Silicic Acid Chromatography (SAC) .......................12

1.4.2 GC-MS Analysis, Quantification, and FAME Identification....13

1.4.3 Statistical Analysis ........................................... 14

1.5 Results

1.5.1 Quantitative FAME Yields................................16

1.5.2 Qualitative FAME Profiles.................................17

1.5.3 FAME Structural Classes and DGFA/PLFA Response..........18

1.5.4 NMDS Analysis...........................................20

1.6 Discussion

1.6.1 Influence of Extraction Treatments on Total Lipid Yield.......22

1.6.2 Amended vs. Un-amended Bligh and Dyer Procedure ...........22

1.6.3 Modified Folch and Microwave Assisted Extraction..............25

1.6.4 Lipid Reproducibility.....................................28

1.6.5 DGFA/PLFA Response................................ 30

1.7 Conclusion................................................................ 31

1.8 Acknowledgement........................................................ 31

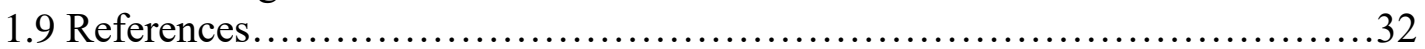

Chapter 2: Microbial Lipid Biomarkers Detected in Deep Subsurface Black Shales

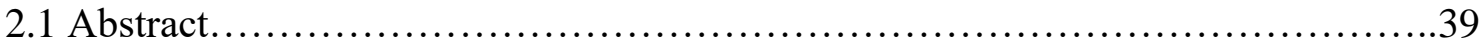

2.2 Introduction.............................................................. 40

2.3 Geologic Background....................................................43

2.4 Materials and Methods

2.4.1 Site description, drilling, and sample collection procedures...........43

2.4.2 Extraction of lipids.............................................46

2.4.3 GC-MS Analysis, Quantification, and FAME Identification..............50

2.4.4 Statistical Analysis...............................................52

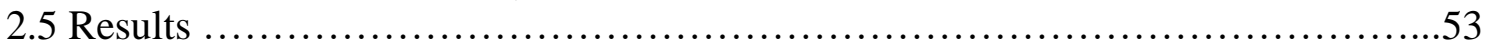


2.6 Discussion

2.6.1 Lipid Biomarkers Recovered in Drilling Muds and Core Samples .....60

2.6.2 Lipid Implications of Subsurface Microbial Life ......................61

2.6.3 Indicators of Environmental Conditions ...........................66

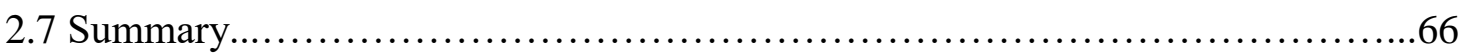

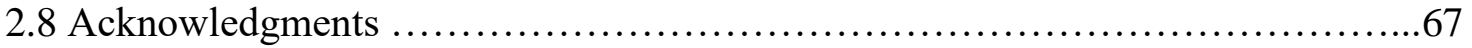

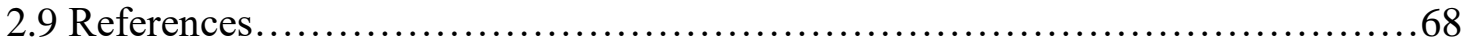

Chapter 3: Effects of Sampling and Long-Term Storage on Microbial Lipid

Biomarker Distribution in Deep Subsurface Marcellus Shale Cores

3.1 Abstract......................................................... 78

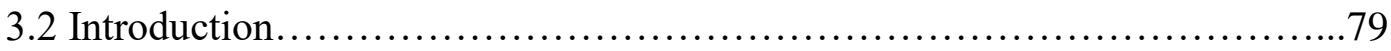

3.3 Methods.......................................................... 81

3.3.1 Site Description, Drilling, and Sample Collection Procedures...........81

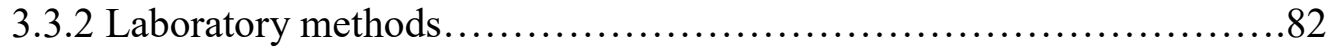

3.3.3 Lipid analyses............................................... 84

3.3.4 GC-MS Analysis, Quantification, and Lipid Identification.............85

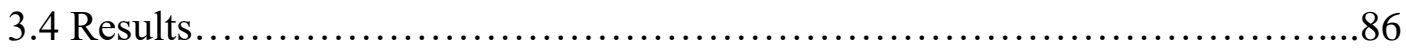

3.5 Discussion.........................................................91

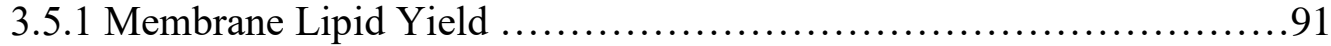

3.5.2 Environmental Adaptations and Membrane Lipid Composition..........93

3.5.3 Exclusive Subsurface Membrane Lipid Biomarkers ......................94

3.5.4 Exclusive Surface Membrane Lipid Biomarkers.....................96

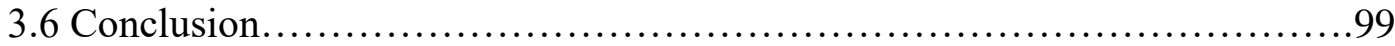

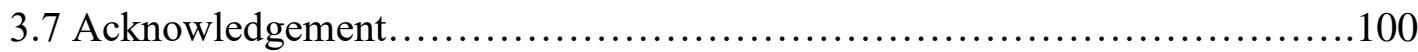

References.......................................................... 101

List of Tables..................................................... 


\section{FIGURE CAPTIONS}

\section{CHAPTER I}

Figure 1. Schematic overview of the procedures involved in the extraction and methylation of the lipid fatty acids. Light green shades show the DGFA fraction.

Figure 2. Selected typical extract ion chromatogram (EIC; for $\mathrm{m} / \mathrm{z}$ 74) obtained from modified Bligh Dyer phosphate buffered and E. coli amended treatment (mBD+Phos + E. coli).

Figure 3. Selected typical extract ion chromatogram (EIC; for $\mathrm{m} / \mathrm{z}$ 74) obtained from modified Microwave Assisted Extraction treatment (MAE).

Figure 4. Average DG-FAME yield for each extraction treatment method $(n=7)$. Error bars represent the standard deviation between triplicates. Shared letters which indicate no significant differences in mean concentration, based on ANOVA and Tukey-HSD tests $(\alpha=0.05)$, are plotted above each bar.

Figure 5. DG-FAME richness for each extraction treatment $(n=7)$. Error bars represent the standard deviation between triplicates. Levels of average means, based on ANOVA and TukeyHSD tests $(\alpha=0.05)$, are plotted above each bar.

Figure 6. Relative abundances of DG-FAME $(n=19)$ profiles based on the classes of each sample across all extraction treatments $(\mathrm{n}=7)$.

Figure 7. A comparative relative standard deviation measurement for DG-FAMEs across extraction treatment methods $(\mathrm{n}=7)$.

Figure 8. Non-metric Multi-Dimensional Scaling (NMDS) of experimental samples for DGFAMEs. Vectors representing significant $(\alpha=0.05)$ correlations of FAME relative abundance were added to reveal significant drivers between groupings. Confidence intervals (70\%) for each treatment grouping were also plotted.

Figure 9. A comparison of the ratio of DG to PL-FAMEs across extraction treatment methods $(n=7)$. PLFA biomass used in this figure is presented elsewhere in Trexler et al. 2017, Master's Thesis, The Ohio State University). 


\section{CHAPTER II}

Figure 1. Map showing the approximate location of the Marcellus Shale Energy and Environment Laboratory (MSEEL) in West Virginia, USA (A), MSEEL well design with four producing wells and scientific well (B), sidewall coring locations (C), generalized schematic of stratigraphy, total organic carbon content in the Mahantango, Marcellus Shale Top, and Upper Marcellus Shale zones (D).

Figure 2. DGFA yields (detection limit $<0.18 \mathrm{ng}$ ) in the Mahantango, Marcellus Shale Top, Upper Marcellus Shale, Mahantango Wash, Marcellus Top Wash, Upper Marcellus Wash, Drilling Mud 9-03 (2015) and Drilling Mud 8-28 (2015) samples.

Figure 3. Venn diagram illustrating the distribution of the individual and functional group DGFA biomarkers within the core samples, core washes, and drilling mud samples. The figure shows the lipid fatty acids detected only in the cores, and those shared across the drilling muds and core samples.

Figure 4. Dendrogram and heat map distribution of individual DGFA biomarkers in the Mahantango, Marcellus Shale Top, Upper Marcellus Shale, Mahantango Wash, Marcellus Top wash, Upper Marcellus Wash, Drilling Mud 8-28 (2015), and Drilling Mud 9-03 (2015) samples together with common lipid structures. Samples are sorted based on dendrogram groupings calculated from Bray-Curtis dissimilarities.

Figure 5. Relative abundance and distribution of DGFA biomarker functional groups for the Mahantango, Marcellus Shale Top, Upper Marcellus Shale zones, Mahantango Wash, Marcellus Top Wash, Upper Marcellus Wash, Drilling Mud 8-28 (2015) and Drill Mud 9-03 (2015) samples.

Figure 6. Nonmetric multidimensional scaling (NMDS) plot showing DGFA functional groups of core samples (circles), drilling muds (triangles), and core washes (squares). NMDS is performed based on Bray-Curtis dissimilarities of the DGFA and PLFA relative abundances. The vectors which correspond to DGFA classes and significantly correlate $(p<0.05)$ with the samples were plotted from the origin.

Figure 7. Biomass yields showing ratio of Gram (+)/Gram (-) lipid biomarkers and ratio of saturated/unsaturated DGFA lipid biomarkers (A and B), in the Mahantango, Marcellus Shale Top, Upper Marcellus Shale, Mahantango Wash, Marcellus Top wash, Upper Marcellus Wash, Drilling Mud 8-28 (2015), and Drilling Mud 9-03 (2015) samples. 


\section{CHAPTER III}

Figure 1. Map showing the approximate location of the WV 6 and MSEEL wells in Monongalia County in West Virginia, USA

Figure 2. Average PLFA (A) and DGFA (B) yields in the WV 6 and corresponding MSEEL core samples. The bars indicate the standard deviation between samples from same well.

Figure 3. Venn diagram illustrating the distribution of the individual lipid biomarkers for the PLFA (A) and DGFA (B) within the MSEEL and WV 6 core samples. The figure shows the lipid fatty acids detected within each core sample and those shared between the MSEEL and WV 6 cores.

Figure 4. Relative abundance and distribution of PLFA (A) and DGFA (B) biomarker functional groups for the MSEEL and WV 6 core samples. MSEEL-1 and WV 6-1=Mahantango, MSEEL-2 and WV 6-2=Marcellus Top, MSEEL-3 and WV 6-3=Upper Marcellus Shale zones. The cores from the same well had similar distribution of lipid communities.

Figure 5. Biomass yields showing ratio of Gram $(+) / \operatorname{Gram}(-)(A, B)$, ratio of saturated/unsaturated $(\mathrm{C}, \mathrm{D})$, and trans/cis lipid biomarkers $(\mathrm{E}, \mathrm{F})$ for the PLFA and DGFA in the MSEEL and WV 6 core samples.

Figure 6. A conceptual representation of common lipid fatty acid modifications of biomarkers detected in this study. In response to changes in environmental rapidly to changes in environmental conditions by modify the structure of membrane phospholipids. 


\section{LIST OF TABLES}

\section{CHAPTER I}

Table 1. Representation of reagents and materials used in the various extraction treatments. Seven treatment conditions were each tested in triplicates $(n=20)$ except the $\mathrm{mBD}+$ Phos treatment which was done in duplicate. Blanks were analyzed for each extraction treatment.

Table 2. Molar percentages of DG-FAME yield in $\mathrm{pmol} / \mathrm{g}$, and number of detected DG-FAME biomarkers recovered from the different extraction treatment methods.

\section{CHAPTER II}

Table 1. Individual DGFA concentrations and relative mole percentages in the Mahantango, Marcellus Shale top, Upper Marcellus Shale, Mahantango Wash, Marcellus Top Wash, Upper Marcellus Wash, Drilling Mud 9.03, and Drilling Mud 8.28 samples.

Table 2. Distribution of DGFA functional group biomarker in the Mahantango, Marcellus Shale top, upper Marcellus Shale, Mahantango Wash, Marcellus Top Wash, Upper Marcellus Wash, Drilling Mud 9.03, and Drilling Mud 8.28 samples.

\section{CHAPTER III}

Table 1. PLFA concentration, relative mole percentages detected in the MSEEL-1, MSEEL-2, MSEEL-3, WV 6-1, WV 6-2, and WV 6-3 samples.

Table 2. PLFA functional group biomarker distribution in the MSEEL-1, MSEEL-2, MSEEL-3, WV 6-1, WV 6-2, and WV 6-3 samples.

Table 3. DGFA concentration, relative mole percentages detected in the MSEEL-1, MSEEL-2, MSEEL-3, WV 6-1, WV 6-2, and WV 6-3 samples.

Table 4. DGFA functional group biomarker distribution in the MSEEL-1, MSEEL-2, MSEEL-3, WV 6-1, WV 6-2, and WV 6-3 samples. 


\section{Chapter 1:}

\section{Modified Lipid Extraction Methods for Deep Subsurface Shale}

\subsection{Abstract}

Growing interest in the utilization of black shales for hydrocarbon development and environmental applications has spurred investigations of microbial functional diversity in the deep subsurface shale ecosystem. Lipid biomarker analyses including diglyceride fatty acids (DGFAs) represent sensitive tools for estimating biomass and characterizing the diversity of microbial communities. However, complex shale matrix properties create immense challenges for microbial lipid extraction procedures. Here, we test three different lipid extraction methods: modified Bligh and Dyer (mBD), Folch (FOL), and microwave assisted extraction (MAE), to examine their ability of lipid biomarker recovery and reproducibility in deep subsurface shales. The lipid biomarkers were analyzed as fatty acid methyl esters (FAMEs) with the GC-MS, and the average DG-FAME yield ranged from 600 to $3000 \mathrm{pmol} / \mathrm{g}$. The intact phospholipid amended Bligh and Dyer treatments (mBD+Phos+POPC) as well as the Folch, the citrate buffered Bligh and Dyer (mBD-Cit), and the Microwave treatments all had relatively higher and statistically similar yields compared to all other extraction treatments. The biomarker yields were however highly variable within replicates for most extraction treatments although the POPC amended treatment had relatively better reproducibility in the consistent fatty acid profiles. This high variability in performance associated with the highly complex matrix of deeply buried shales further necessitates customized methodological developments for the optimized recovery of lipid biomarkers. 


\subsection{Introduction}

The microbial ecology of the deep subsurface ecosystem has received increased research attention over the last two decades (e.g. Fredrickson et al., 1997; Krumholz et al., 1997; Onstott et al., 1998; 2000; Whitman et al., 1998; D'Hondt et al., 2004; Biddle et al., 2006; Fredricks and Hinrichs, 2006; Pfiffner et al., 2006; Schippers and Neretin, 2006; McMahon and Parnell, 2014; Inagaki et al., 2016), with some studies suggesting that the deep subsurface biosphere contributes as much as $50 \%$ of the Earth`s biomass (Whitman et al., 1998; McMahon and Parnell, 2014). Consequently, the role of deep subsurface microbial communities has become increasingly important. Energy and environmental applications of black shales have also induced research interests on the microbial functional diversity in the deep subsurface shale ecosystem. Unconventional hydrocarbon production in black shales through hydraulic fracturing (Rogner, 1997; Curtis, 2002; Passey et al., 2010; Chengzao et al., 2012), has bolstered the possibility of introducing exogenous microbes which could alter the microbial community structure of the deep subsurface shale ecosystem. Accordingly, isotopic evidence of potential biogenic gas production in the Marcellus Shale (Sharma et al., 2014) and the presence of microbial signatures in produced fluids from hydraulically fractured wells (Mohan et al., 2013; Cluff et al., 2014; Gaspar et al., 2014) has further intensified the significance of microbial activities in relation to the shale ecosystem and energy applications. While unconventional hydrocarbon production has the potential of altering the deep subsurface shale ecosystem, deep subsurface microbial activity can also influence the hydrocarbon production potential and efficiency. For example, microbial metabolites can interfere negatively with hydrocarbon production by clogging hydraulically fractured formations, corroding wells, and increasing $\mathrm{H}_{2} \mathrm{~S}$ content (gas souring, Gasper et al., 2014) while also improving shale gas production potential through microbial enhanced oil recovery (Lazar et al., 
2007). Thus, the study of microbial community dynamics of deeply buried subsurface shale ecosystem becomes very essential.

Despite evidence of endogenous microbial life in the deep subsurface, the numerous challenges involved in isolating and culturing deep subsurface microbes makes it difficult to actually characterize in situ subsurface microbial communities. One molecular tool that provides a sensitive measure of in situ biomass density is the microbial lipid analysis. Upon microbial cell death, the membrane phospholipid in the DGFA breaks down leading to the formation of diglyceride fatty acid (DGFA; Kieft et al., 1994; White and Ringelberg, 1998). Thus, the PLFAs provide a sensitive molecular-based estimation of the contemporary non-viable microbial community (Kieft et al., 1994; Haldeman et al., 1993; White and Ringelberg, 1998; Fredrickson et al., 1997; Ringelberg et al., 1997). These measurements convey information into community composition, nutritional status, and other environmental stressors.

Even though lipid analysis is a very sensitive method, the informative quality of the technique can be reduced by low lipid concentrations and variations in matrix property (GomezBrandon et al., 2008). Therefore low microbial biomass and ineffective extractions will generate unreliable results. Many procedures have been developed and modified to improve the extraction of the microbial lipids from various matrices (Bligh and Dyer, 1959; Christie, 1993; BrinchIversen and King, 1990; Nielsen and Petersen, 2000; Cequier-Sanchez et al., 2008). One of the most used lipid extraction methods, especially for extraction from environmental samples, is the Bligh and Dyer single-phase extraction method (e.g, Bligh and Dyer, 1959; White et al., 1979; Guckert et al., 1985; Frostegard et al., 1991; Kieft et al., 1994; Fredrickson et al., 1997; Ringelberg et al., 1997; White and Ringelberg, 1998; Pfiffner et al., 2006). Contemporary instrumental methods have also brought about modifications to lipid extractions which have gone a long way 
to improving yields. Some of these methods include the use of pressurized or accelerated solvent extraction and microwave irradiation or ultrasonication (Vetter et al., 1998; Batista et al., 2001; Young, 1995; Lores et al., 2006; Gomez-Brandon et al., 2008). Furthermore, other lipid improvement methods have been developed to optimize the recovery of ether-linked microbial lipid biomarkers (Lengger et al., 2012; Zhang et al., 2003).

While many modifications have been made on lipid analysis for samples of various matrices, the unique properties of deeply buried shale necesitates that current extraction procedures should also be optimized in an effort to generate high quality results. Shales are characterized by complex organic matter matrix, mineralogy, and chemistry which can impede efficient lipid extraction (Shaw and Weaver, 1965; Boles and Franks, 1979; Aplin and Macquaker, 2011; Chermak and Schreiber, 2014). Clay colloids in the shale sediments also bind to the lipids, interfering with adequate lipid recovery. Additionally, the small pore sizes, low permeability (Colwell et al., 1997; Fredrickson et al., 1997; Onstott et al., 1998; Javadpour F. 2009; Sondergeld et al., 2010), and overall low biomass density (Fredrickson et al., 1997) associated with the deep subsurface shale environment may also hinder lipid extraction. More so, the extreme difficulty associated with preventing potential exogenous microbial contamination during drilling and processing of subsurface cores (Wilkins et al., 2014) also hampers molecular analysis of deep subsurface microbial communities. Given the inaccessibility of the deep surface environment and the high economic cost associated with well drilling, maximizing microbial scientific output from the already rare and precious samples becomes critical.

This chapter seeks to improve the recovery of microbial biomass and diversity for deep subsurface shale matrices with low biomass densities through the analysis of ester-linked microbial lipid biomarkers. Lipid extraction experiments based on modifications of previous extraction 
procedures were carried out to examine the combination of different extraction solvents, buffers, and biochemical amendments. Three extraction methods were tested: (i) modified Bligh and Dyer (mBD), (ii) Folch (FOL), and (iii) microwave-assisted extraction (MAE) treatments. Within the mBD method, modifications based on phosphate (White et al., 1979) or citrate buffer (Frostegard et al., 1991) were utilized. The effectiveness of three different biochemical amendments; (i) magnesium $\left(\mathrm{Mg}^{2+}\right)$, (ii) Escherichia coli biomass (E. coli), and (iii) 1-palmitoyl-2-oleoyl-snglycero-3-phosphocholine (POPC) were evaluated on their ability to enhance the yield and profile quality of the standard modified Bligh and Dyer phosphate (mBD+Phos) treatments. All samples used are deep subsurface shale samples cored from $\sim 7,000 \mathrm{ft}$. and the resultant lipids from all extraction treatments were transesterified into fatty acid methyl esters (FAMEs) and analyzed by gas chromatography-mass spectrometry (GC-MS).

\subsection{Methods}

A summarized scheme of the methodology for the lipid extraction including experimental treatments is shown in Figure 1. 


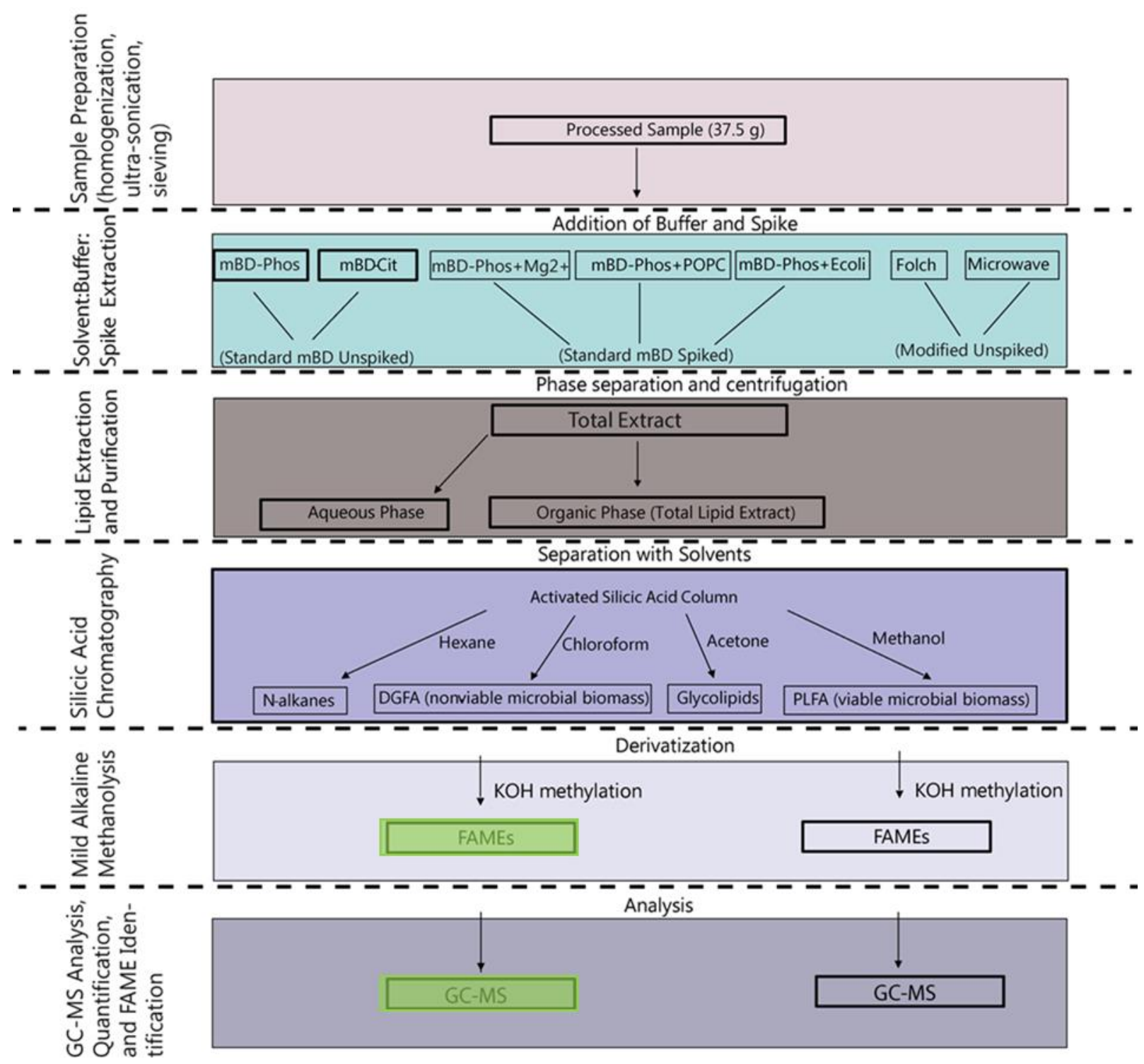

Figure 1. Schematic overview of the procedures involved in the extraction and methylation of the lipid fatty acids. Light green shades show the DGFA fraction.

\subsubsection{Reagents and Materials}

All extraction treatments and their reagents are also listed in Table 1. Critical analytical precautions were taken to ensure that materials and reagents were free of organic contaminants. 
All reagents and solvents used during the extraction and analytic experimental process were of purest grade (HPLC, Fisher Optima). Glassware were cleaned in a 10\% (v/v) micro alkaline cleaning solution (International Products Corporation, Burlington, NJ) and rinsed with 70\% methanol, 5 times with distilled water, and 5 times with Millipore water. All glassware and tools were autoclaved at $550^{\circ} \mathrm{C}$. Metal lab wares (forceps, mortar, pestle, and spatulas) were cleaned with tap water, distilled water, and finally with a solution of 1:1 chloroform:methanol. Teflonlined caps were cleaned in the same manner as the glassware and then solvent rinsed with acetone. Procedural blanks were also included in each extraction treatment to monitor laboratory contamination. With the exception of standard peaks, blanks did not have any FAME peaks. Internal standards of different concentrations ( 1 pmol, 5 pmol, $10 \mathrm{pmol}, 20 \mathrm{pmol}, 30 \mathrm{pmol}, 40 \mathrm{pmol}$, and $50 \mathrm{pmol} / \mu \mathrm{L}$ ) were prepared and analyzed on the GC-MS to determine the detection limit and to also establish the best sample dilution range. The standard curve and the regression analysis had a linear relationship (0.99). Based on the lowest dilution concentration, the detection limit for the GC-MS was $1 \mathrm{pmol} / \mathrm{uL}$.

\subsubsection{Sample Preparation and Extraction Procedures}

Non-pristine core samples taken from commercial production wells at $\sim 7,000 \mathrm{ft}$ in the Marcellus Shale in Pennsylvania and West Virginia were crushed using a sterile mortar and pestle and homogenized by stirring thoroughly (Thomas Scientific, Swedesboro, NJ). We took great care to ensure sample homogeneity by: 1) paring the outer portion of rock, ensuring any handling/storage effects were minimized; 2) crushing cores using a sterile mortar and pestle; and 3) homogenizing the samples by first stirring thoroughly then transferring the crushed samples to muffled aluminum foils and continuing to homogenize by folding, dividing, and mixing different corners of the sheet. The homogenized crushed samples were passed through a sterile brass sieve 
series (Dual Manufacturing Co., Franklin Park, IL), where we retained only the crushed core that passed a $500 \mu \mathrm{m}$ screen. After homogenization, the samples were then partitioned for subsequent extractions. Lipid extractions and analyses were performed at the Center for Environmental Biotechnology at the University of Tennessee (Knox ville, TN, USA).

Table 2: Reagents and materials used in the various extraction treatments. Seven treatment conditions were each tested in triplicates $(n=21)$ and four control were samples analyzed for quality assurance $(n=4)$.

\begin{tabular}{|c|c|c|}
\hline Extraction Type & Extraction Conditions & Treatment Name \\
\hline \multirow{4}{*}{ Modified Bligh and Dyer } & Phosphate Buffer & mBD-Phos \\
\cline { 2 - 3 } & Citrate Buffer & $\mathrm{mBD}-\mathrm{Cit}$ \\
\cline { 2 - 3 } & Phosphate Buffer + $\mathrm{Mg}^{2+}$ & $\mathrm{mBD}-\mathrm{Phos}+\mathrm{Mg}^{2+}$ \\
\cline { 2 - 3 } & Phosphate Buffer + POPC & $\mathrm{mBD}-\mathrm{Phos}+\mathrm{POPC}$ \\
\cline { 2 - 3 } & Phosphate Buffer + E. coli & $\mathrm{mBD}-$ Phos+Ecoli \\
\hline $\begin{array}{c}\text { Modified Folch Extraction } \\
\text { Microwave Assisted } \\
\text { Extraction }\end{array}$ & Chloroform: Methanol & Folch \\
\hline & Chloroform: Water & Microwave \\
\hline
\end{tabular}

\subsubsection{Modified Bligh and Dyer (mBD) method}

Samples for the mBD treatments $(\mathrm{n}=14)$ were extracted by the Bligh and Dyer procedure (Bligh and Dyer, 1959), with modifications using phosphate buffer (mBD+Phos; $\mathrm{n}=11$ ) as described in White et al. (1979) and citrate buffer (mBD+Cit; $n=3)$ as described in Frostegard et al. (1991). The following materials were used as amendments in the phosphate buffered treatments (mBD+Phos; $\mathrm{n}=9$ ) to test their suitability for optimizing recovery: 
Escherichia coli $(\boldsymbol{n}=3)$. Stock solutions for the E. coli amendment were prepared by streaking Luria Broth agar plates with an E. coli aliquot and grown overnight at $37^{\circ} \mathrm{C}$ to isolate colonies. A colony was then picked and cultured in Luria Broth liquid for 16 hours at $37^{\circ} \mathrm{C}$. Cells were counted by hemocytometers under light microscopy and via the EMD Millipore Guava Flow Cytometer (Billerica, MA). Cells were diluted to $1 \times 10^{5}$ cells $/ \mathrm{mL}$ using $1 \mathrm{X}$ phosphate buffer saline solution. $1 \mathrm{~mL}$ of the resulting stock solution was then added to each of the extraction mixtures for the phosphate-buffered E. coli treatments (mBD+Phos+E.coli).

Intact Phospholipid ( $\boldsymbol{n = 3}$ ). Stock solutions of $3.3 \times 10^{-5} \mathrm{~mol} / \mathrm{mL}$ of 1-palmitoyl-2-oleoylsn-glycero-3-phosphocholine (POPC) were diluted with chloroform to a working solution concentration of $3.3 \times 10^{-12} \mathrm{~mol} / \mathrm{mL} .1 \mathrm{~mL}$ of the solution was added to each of the extraction mixtures for the phosphate-buffered POPC treatments (mBD+Phos+POPC). The concentrations of the E. coli and POPC amendments were determined based on the PLFA-to-biomass conversion factor of $1.4 \times 10^{-17} \mathrm{~mol}$ PLFA/cell (Frostegard and Baath, 1996).

Magnesium Chloride $(\boldsymbol{n}=3)$. The magnesium $\left(\mathrm{Mg}^{2+}\right)$ amendment was prepared by adding $4.767 \mathrm{~g}$ of magnesium chloride hexahydrate $\left(\mathrm{MgCl}_{2} 6 \mathrm{H}_{2} \mathrm{O}\right)$ to a $100 \mathrm{~mL}$ aliquot of prepared phosphate buffer. $30 \mathrm{~mL}$ of the phosphate buffer-magnesium solution was then added to the extraction mixture to yield a final concentration of $1200 \mathrm{ppm} \mathrm{Mg}^{2+}$ in each of the extraction mixtures for phosphate-buffered $\mathrm{Mg}^{2+}$ treatments $\left(\mathrm{mBD}+\mathrm{Phos}+\mathrm{Mg}^{2+}\right.$ ).

Lipid extractions were carried out from $37.5 \mathrm{~g}$ of the crushed rock. The crushed rock samples were transferred to a $250 \mathrm{~mL}$ glass centrifuge bottle and then suspended in solvent extraction mixtures of chloroform-methanol-appropriate buffer, 1:2:0.8 (v/v/v, Chloroform: MeOH: Buffer). The concentration and $\mathrm{pH}$ of the buffers were as follows; citrate (0.15 m, $\mathrm{pH} 4.0)$ 
and phosphate $(0.05, \mathrm{pH} 7.4)$. The appropriate amendments were then added to the phosphate buffered treatments ( $\mathrm{n}=9$, mBD-Phos+Ecoli, mBD-Phos $+\mathrm{Mg}^{2+}$, and mBD-Phos+POPC). The remaining phosphate buffered ( $\mathrm{n}=2, \mathrm{mBD}-\mathrm{Phos})$ and citrate buffered ( $\mathrm{n}=3, \mathrm{mBD}-\mathrm{Cit})$ samples were extracted without an exogenous amendment to further compare the performance of amended samples to the un-amended extracted samples. Due to the implication of reproducibility to the extraction of microbial biomass, each extraction treatment was done in triplicates. $50 \mathrm{uL}$ of 50 $\mathrm{pmol} / \mu \mathrm{L}$ of internal standard (1, 2-dinonadecanoyl-sn-glycero-3-phosphocholine, Avanti Polar Lipids) was added to each treatment. The suspension was shaken and sonicated two times in an ultrasonicator for 30 to 45 seconds with a 30 -second interval between sonication cycles. The internal standard was used to measure extraction efficiency of the lipids. Bottles were shaken for 15 seconds and vented before incubation overnight in the dark at room temperature. After incubation, samples were held at $4{ }^{\circ} \mathrm{C}$ and centrifuged for 30 minutes at $2000 \mathrm{rpm}$. The resulting supernatant was transferred to a $250 \mathrm{~mL}$ separatory glass funnel. Chloroform and water were added to the suspension $(1: 1: 0.9$, chloroform: methanol: buffer $v / v / v)$ and the separatory funnels were shaken for 15 seconds and left to rest overnight to split phase (upper: aqueous and lower: organic containing the lipids). While the lipids were kept in the separatory funnel to separate phase, the already extracted shale samples were re-extracted with same solvents and reagents. Re-extraction allowed fresh solvent to contact and penetrate new surface area in the shale. After separation, the organic phase was collected into a $250 \mathrm{~mL}$ round bottom flask and evaporated to near dryness using a rotavap system (Buchi Corporation, New Castle, DE). The total lipid extract (TLE) was then quantitatively transferred into test tubes using three washes of $2 \mathrm{~mL}$ of chloroform, after which the solvent was evaporated with an $\mathrm{N}_{2}$ blowdown evaporator at $37^{\circ} \mathrm{C}$. The dried total lipid 
extracts (TLEs) were resuspended in $2 \mathrm{~mL}$ of chloroform and stored for silicic acid chromatography.

\subsubsection{Modified Folch method}

Apart from the modifications below, the Folch samples $(n=3)$ were extracted with same extraction mixtures and procedure as described by Folch et al. (1957). Due to volume constraints in maintaining a 20:1 ratio of solvent:sample with $37.5 \mathrm{~g}$ of homogenized shale, each sample was divided into 4 round bottom flasks during solvent incubation. For each sample subset, $125 \mathrm{~mL}$ of chloroform, $62.5 \mathrm{~mL}$ of methanol, and $9.375 \mathrm{~g}$ of homogenized shale were added to provide a ratio of 2:1 chloroform:methanol $(\mathrm{v} / \mathrm{v})$. The organic fraction from each subset was fractionated and stored for silicic acid chromatography and subsequent trans-methylation.

\subsubsection{Microwave Assisted Extraction (MAE) method}

The MAE samples $(n=3)$ also had volume constraints, and as such, each sample was divided initially into 7 subsamples. The solvent for the MAE was chloroform:methanol rather than hexane:acetone which are the most frequently used solvents in MAE (Lopez-Avila and Young, 1994; Lopez-Avila, 1999; Gomez-Brandon et al., 2008; 2010). Our modification was based on the effectiveness of chloroform:methanol as reagent solvent mixtures for lipids from environmental samples (Ewald et al., 1998; Renaud et al., 1999). To create a 9:1 (v/v) ratio of chloroform:methanol, $48.2 \mathrm{~mL}$ of chloroform, $5.35 \mathrm{~mL}$ of methanol, and $5.35 \mathrm{~g}$ of homogenized shale were added to each Teflon reaction vessel. The vessels were irradiated in a Milestone Ethos EX Microwave Extractor System (Milestone Inc., Shelton, CT) with a temperature ramp of 2.5 minutes $\left(2450 \mathrm{mHz}, 630 \mathrm{~W}, 100^{\circ} \mathrm{C}\right.$ max temperature) and held for an additional 2.5 minutes $(2450$ $\mathrm{mHz}, 630 \mathrm{~W}, 100^{\circ} \mathrm{C} \max$ temperature). Stir-bars were engaged during the irradiation period and 
vessels were allowed to cool down for 15 minutes before pouring the contents into $250 \mathrm{~mL}$ round bottom centrifuge bottles. Samples were centrifuged and transferred to separatory funnels as described for mBD samples. Once in separatory funnels, $150 \mathrm{~mL}$ of water was added to break phase. The samples were shaken for 15 seconds and allowed to rest overnight to separate phases entirely. The resulting organic fraction was fractionated and stored for silicic acid chromatography and subsequent trans-methylation.

\subsection{Separation and Analysis}

\subsubsection{Silicic Acid Chromatography (SAC)}

The extracted lipids were fractionated on an activated silicic acid column, 100-200 mesh powder (dried at $110^{\circ} \mathrm{C}$ for 1 hour; Clarkson Chromatography Products, Inc), into fractions of different polarities using hexane, chloroform, acetone, and methanol. The silicic acid columns were constructed by loading a suspension of $0.5 \mathrm{~g}$ of silicic acid in $5 \mathrm{~mL}$ of hexane on to glass pipettes. Prior to loading the silicic acid column, glass wool was placed at the bottom of the pipettes and rinsed with $2 \mathrm{~mL}$ of hexane. After loading the column with silicic acid slurry, sodium sulfate $\left(\mathrm{Na}_{2} \mathrm{SO}_{4}\right)$ was added to the top of the column to exclude the possibility of the presence of oxygen. The TLE was then suspended in $200 \mu \mathrm{L}$ of hexane and loaded onto the top of the silicic acid column. We repeated this quantitative transfer three times and care was taken to not disturb the surface of the column once the sample was loaded. A series of four solvents of increasing polarity were then used to separate the lipid classes: hydrocarbons $=5 \mathrm{~mL}$ of hexane, neutral lipids $=5 \mathrm{~mL}$ of chloroform, glycolipids $=5 \mathrm{~mL}$ of acetone, polar lipids $=10 \mathrm{~mL}$ of methanol into test tubes. We maintained silicic acid and solvent ratio of 1:10 (g silicic acid: mL eluting solvent), except for methanol. The resulting chloroform fraction was methylated into fatty acid methyl esters 
(FAMEs) by mild alkaline methanolysis and analyzed for DGFA while the methanol fraction was methylated and analyzed for PLFA (White et al., 1979; Guckert et al., 1985; Kieft et al., 1994; Ringelberg et al., 1997; White and Ringelberg, 1998).

\subsubsection{GC-MS Analysis, Quantification, and FAME Identification}

Lipid samples were then dissolved in $200 \mu \mathrm{L}$ of hexane containing $50 \mathrm{pmol} / \mathrm{uL}$ of external injection standard (docosanoic acid methyl ester; Matreya, Inc) and transferred into GC-MS vials containing $500 \mu \mathrm{L}$ glass inserts. The external standard was used to calculate the peak area of the FAME profiles. Aliquots of samples were then injected into an Agilent 6890 series gas chromatograph interfaced to an Agilent 5973 mass selective detector equipped with a non-polar cross-linked methyl silicone column (Restek RTX-1 column 60m, 0.25mm I.D. $\times 0.25 \mu \mathrm{m}$ film thickness) to be further separated, identified, and quantified. The gas chromatography operating conditions were as follows: $60^{\circ} \mathrm{C}$ for 2 minutes then ramped at a rate of $10^{\circ} \mathrm{C} /$ minutes to $150^{\circ} \mathrm{C}$ and followed by a second ramp at $3^{\circ} \mathrm{C} /$ minutes to $312^{\circ} \mathrm{C}$ for a total run time of 65 minutes(White and Ringelberg, 1998). The injector temperature was $230^{\circ} \mathrm{C}$; the detector temperature was $300^{\circ} \mathrm{C}$; and Helium was the carrier gas. The lipid standards methyl ester mixtures, Bacterial Acid Methyl Esters CP Mixture, BacFAME (1114); and Polyunsaturated FAME Mixtures, PUFA-2(1081); and PUFA-3 (1177) (Matreya LLC, State College, Pennsylvania, USA) were included in each sample run to calibrate retention times and assist with peak identification. All identified peaks were confirmed across all samples and validated independently via GC-MS spectra using the Agilent MSD ChemStation Data Analysis Software F.01.00 along with the NIST11 compound library. All identified peaks were confirmed across all samples and validated independently via GC-MS spectra confirmation. FAME identities were as described in Ringelberg et al. (1989). To validate the proportional relationship, a regression analysis of external standard concentrations and peak 
areas from the standard curve samples demonstrated a linear relationship $\left(\mathrm{R}^{2}>0.99\right)$ in the scope of 1 to $50 \mathrm{pmol} / \mathrm{uL}$.

\subsubsection{Statistical Analysis}

All extractions were carried out in triplicates, except the $\mathrm{mBD}+\mathrm{Phos}$ treatments which were done in duplicates. The equivalent concentration of the amended lipids were subtracted from the samples and the internal standard and external standards were not considered in the yield calculations. Differences in PLFA and DGFA yield, diversity, and DGFA/PLFA ratios between treatment methods were analyzed using one-way Analysis of Variance (ANOVA) tests followed by Tukey HSD posthoc tests in JMP Pro version 12.2.0 (SAS Institute, Cary, North Carolina). Analysis of Similarity (ANOSIM) test was also done for PLFA and DGFA datasets $(\alpha=0.05)$. Significant differences are reported at $\alpha=0.05$ level. Non-metric multidimensional scaling (NMDS) analysis was conducted in R statistical software version 3.2.4 using the 'stats' version 2.15.3 and ‘vegan’ version 2.3-5 (Oksanen et al., 2016) packages. Specifically, Bray-Curtis distances were calculated from absolute FAME concentrations (pmol). The resulting distance matrices were used to calculate NMDS plots. One mBD+Phos sample was removed from the PLFA and DGFA NMDS analyses as an outlier. A second Folch sample was withdrawn from the DGFA NMDS analysis because the profiles contained only two saturated FAMEs. Vectors representing the correlation (p $<0.05$ ) between samples and FAME classes were plotted to discern which types of FAMEs were driving the differences between samples. The relative abundances of FAME classes for PLFA and DGFA samples were regressed $(\alpha=0.05$, permutations $=999)$ against Bray-Curtis distances using the envfit function in the vegan package. The resulting arrow vectors were overlaid on the NMDS plot from the origin and represent the correlation of FAME class abundances to ordinated samples. 
The aim of the NMDS was to describe as closely as possible any clustering patterns based on observed FAMEs classes.

\subsection{Results}

Lipid biomarkers from all extraction treatments in mol\% and pmol/g are shown in Tables 2. Selected extract ion chromatograms (EIC; for $\mathrm{m} / \mathrm{z} 74$ ) are shown in Figures 2 and 3.

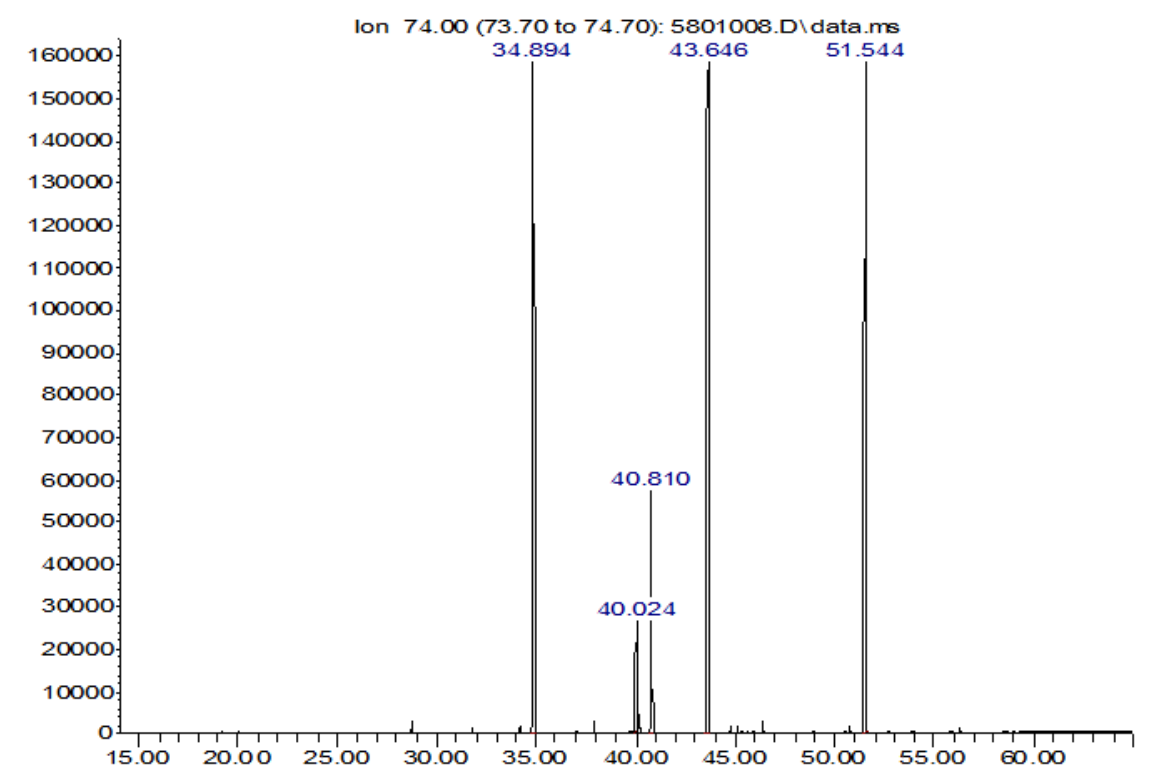

Figure 2. Selected typical extract ion chromatogram (EIC; for $\mathrm{m} / \mathrm{z}$ 74) obtained from modified Bligh Dyer phosphate buffered and E. coli amended treatment (mBD+Phos $+E$. coli).

RT 34.894 (16:0) = Hexadecanoic acid, methyl ester, $40.024(18: 1 \omega 8)=8$-Octadecenoic acid, methyl ester, $40.810(18: 0)=$ Octadecanoic acid, methyl ester, $43.646(19: 0)=$ Nonadecanoic acid, methyl ester, $51.544(22: 0)=$ docosanoic acid, methyl ester 


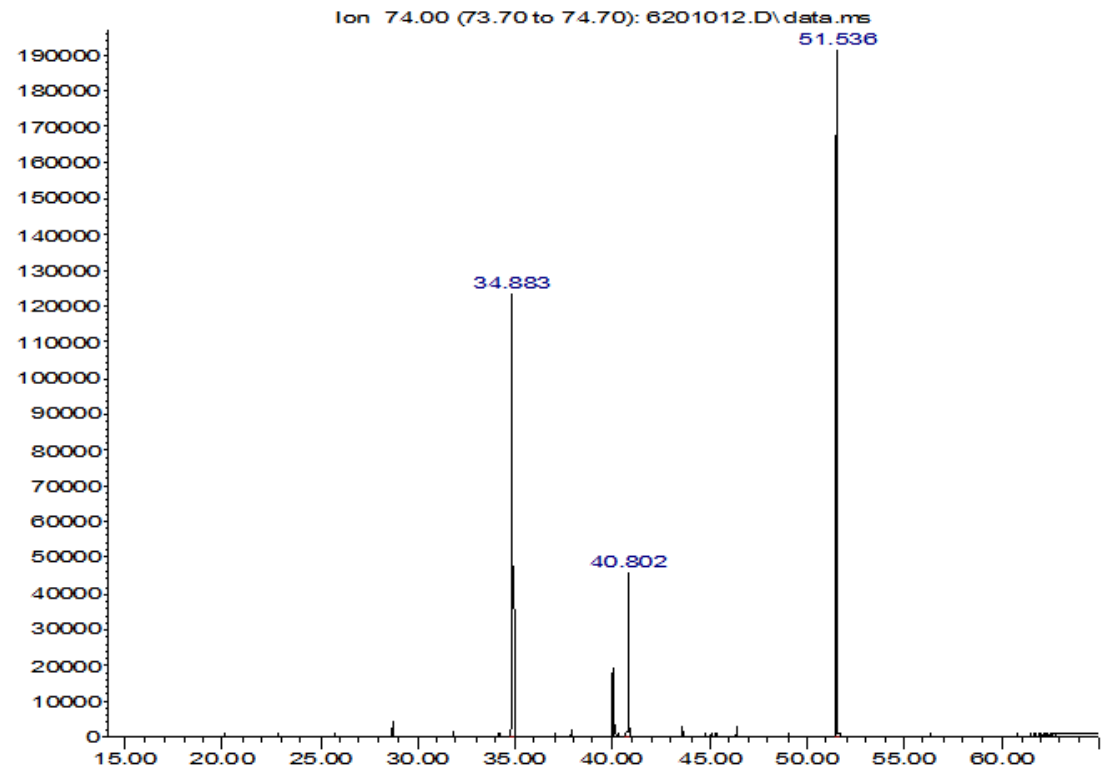

Figure 3. Selected typical extract ion chromatogram (EIC; for $\mathrm{m} / \mathrm{z}$ 74) obtained from modified Microwave Assisted Extraction treatment (MAE).

RT $34.894(16: 0)=$ Hexadecanoic acid, methyl ester $40.810(18: 0)=$ Octadecanoic acid, methyl ester $51.544(22: 0)=$ docosanoic acid, methyl ester

\subsubsection{Quantitative FAME Yields}

The average DG-FAME yields ranged from 600 to $3000 \mathrm{pmol} / \mathrm{g}$ (Figure 4). Except for the MAE and $\mathrm{mBD}+\mathrm{Phos}+\mathrm{Mg}^{2+}$ treatment methods, yields for the DG-FAMEs extraction treatment methods did not show any statistical difference (ANOVA with Tukey HSD post-hoc test, $\alpha=0.05$ ). The mBD+Phos+POPC outperformed the standard un-amended mBD+Phos extraction with a $\sim 5$ fold increase in DGFA yield compared to the mBD+Cit. (Figure 4). 


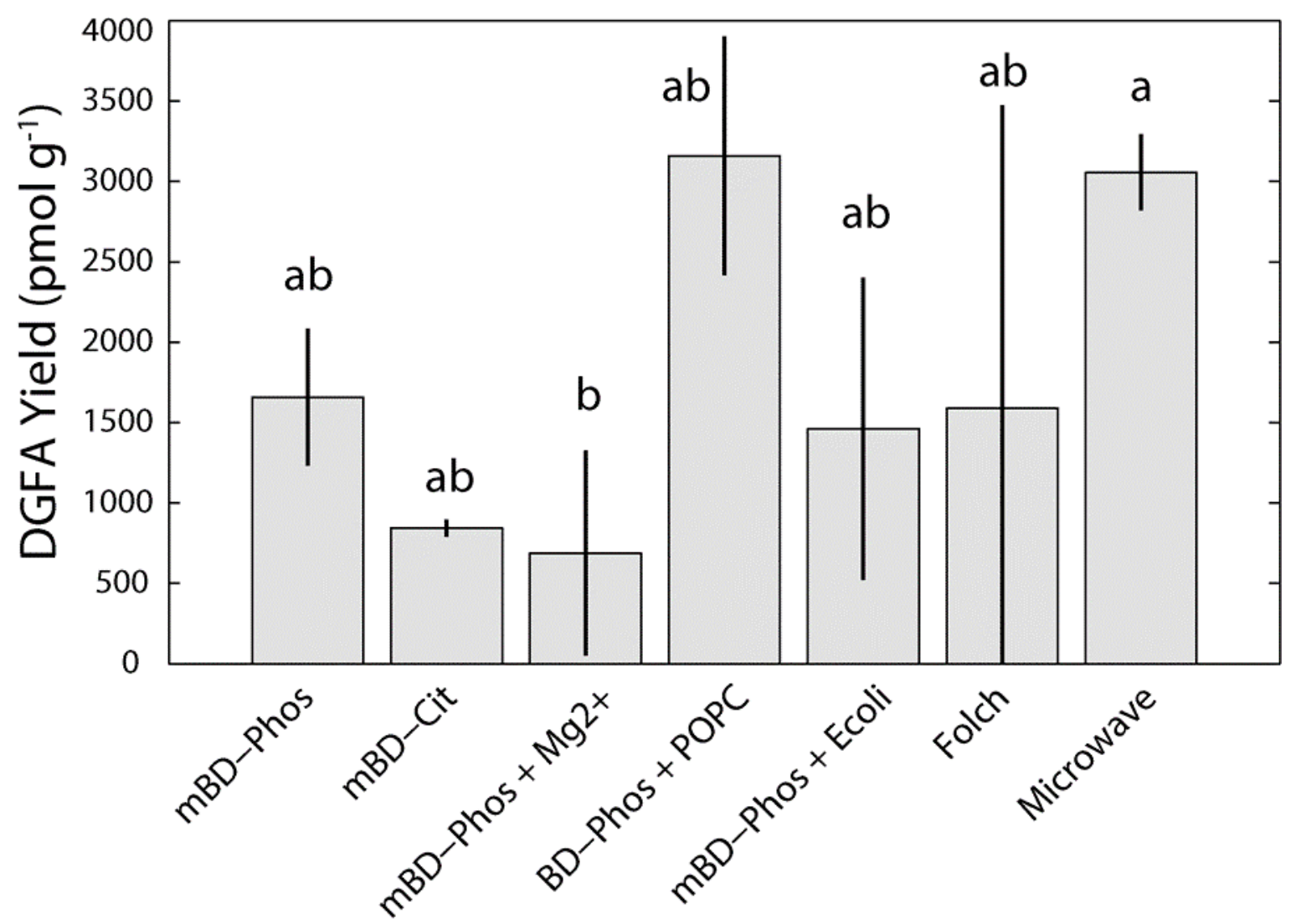

Figure 4. Average DG-FAME yield for each extraction treatment method $(n=7)$. Error bars represent the standard deviation between triplicates. Shared letters indicate no significant differences in mean concentration, based on ANOVA and Tukey-HSD tests $(\alpha=0.05)$, are plotted above each bar.

\subsubsection{Qualitative FAME Profiles}

The mBD+Phos+POPC had the highest number of detected FAMEs and was significantly different from $\mathrm{mBD}+\mathrm{Cit}$ and $\mathrm{mBD}+\mathrm{Phos}+\mathrm{Mg}^{2+}$, while all the other treatment methods were statistically indistinguishable (Figure 5). On average, mBD+Phos+POPC provided an additional 9 DG- FAMEs compared to the unamended mBD+Cit method. 


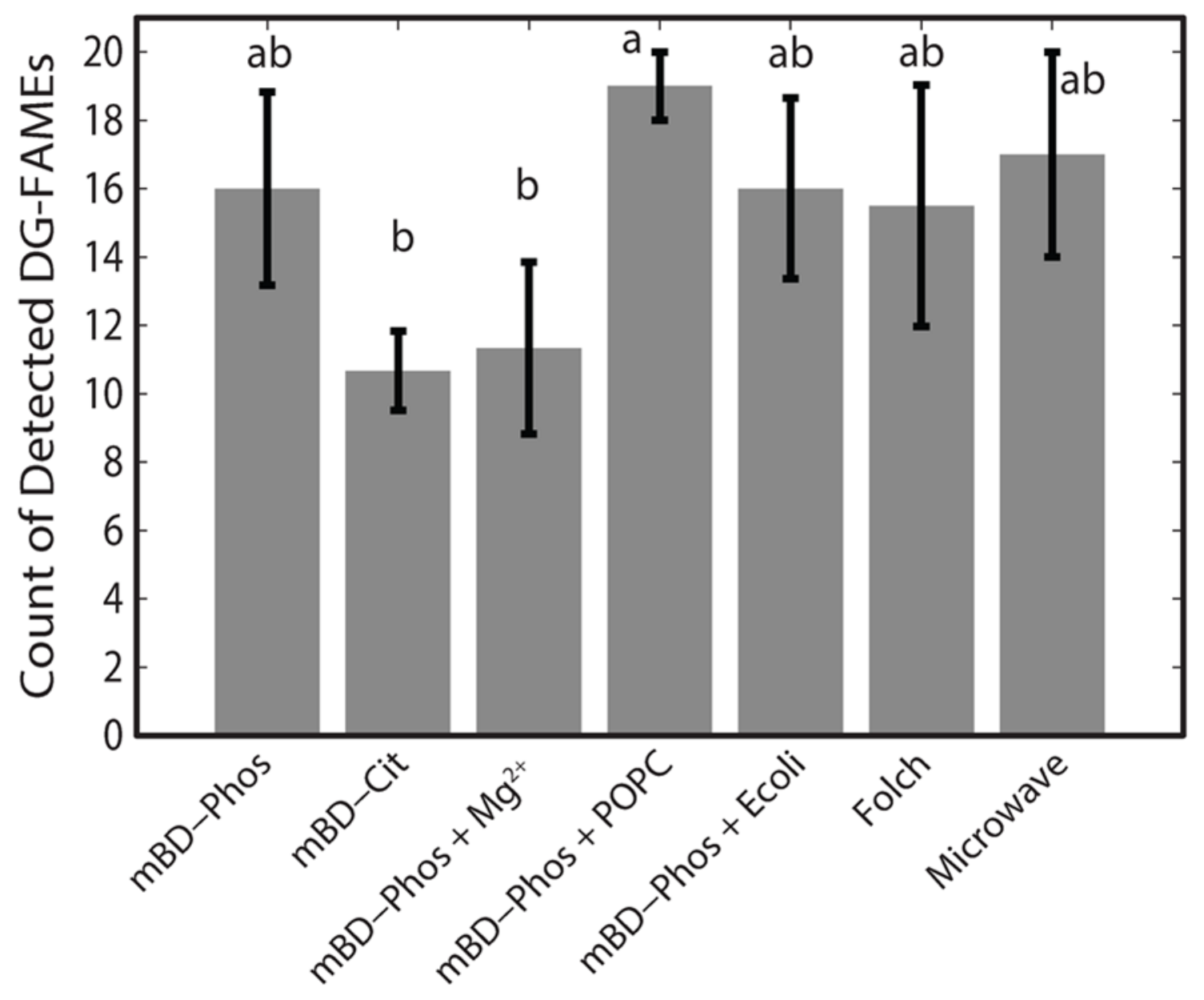

Figure 5. DG-FAME richness for each extraction treatment $(n=7)$. Error bars represent the standard deviation between triplicates. Levels of average means, based on ANOVA and TukeyHSD tests $(\alpha=0.05)$, are plotted above each bar.

\subsubsection{FAME Structural Classes and DGFA/PLFA Response}

The low abundance FAME classes ( $<10 \%$ relative abundance) exhibited the most variability between treatment methods while the high abundance FAME classes $(>10 \%$ relative abundance) were consistent both within and across treatments (Figure 5, 6). The mBD+Phos+POPC samples exhibited high reproducibility and least variability for the low 
abundant FAME classes. Other treatment methods like the mBD+Phos+E.coli and MAE also had relatively less variability for the low abundance FAME classes.

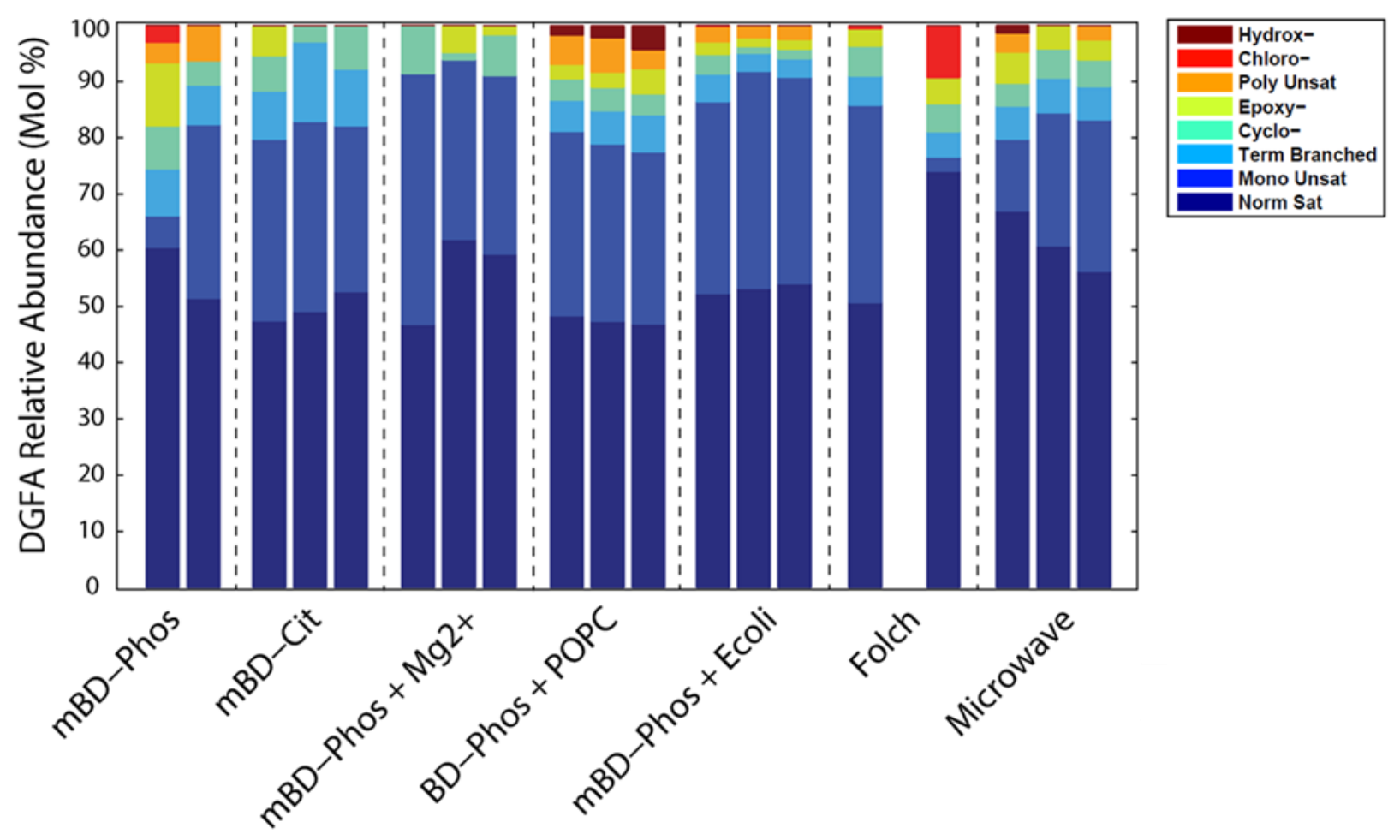

Figure 6. Relative abundances of DG-FAME $(\mathrm{n}=19)$ profiles based on the classes of each sample across all extraction treatments $(n=7)$. 


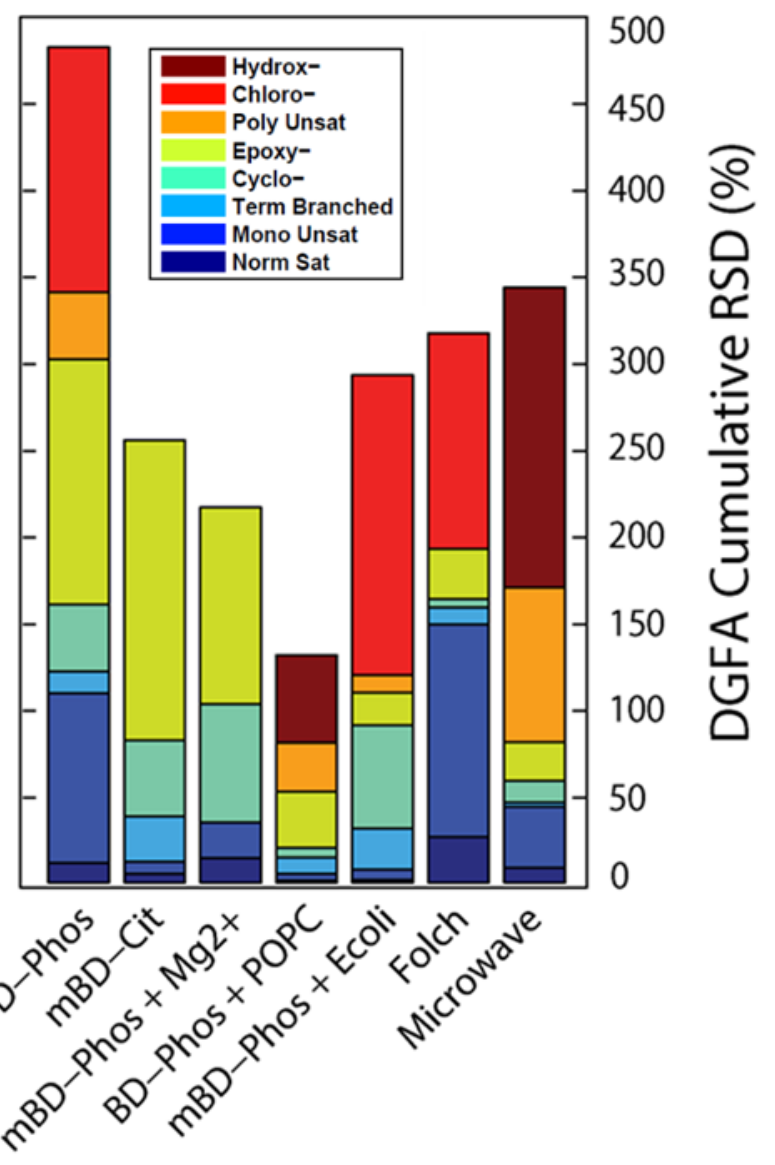

Figure 7. A comparison of Relative Standard Deviation measurements for DG-FAMEs across extraction treatment methods $(n=7)$.

\subsubsection{NMDS Analysis}

Non-metric multidimensional scaling (NMDS) was used to further illustrate the differences between extraction treatments. The samples were ordinated in Euclidean space based on BrayCurtis dissimilarities (Figure. 8). NMDS analysis showed samples clustering together based on extraction treatment type ( $\mathrm{p}=0.003$, Figure 8$)$. Rather, the low-abundance FAMEs of individual samples within treatments were responsible for the increased within-treatment variation. Comparison by NMDS analysis (Figure 8) showed samples from the same treatment methods with similar cluster patterns $(\mathrm{P}=0.003)$. The triplicates for the $\mathrm{mBD}+\mathrm{Phos}+\mathrm{POPC}, \mathrm{mBD}+\mathrm{Phos}+\mathrm{Ecoli}$, and $\mathrm{mBD}+\mathrm{Cit}$ samples were closest to each other with the smallest $70 \%$ confidence intervals. 
Extraction treatments with large 70\% NMDS confidence intervals (Figure 8) also had the highest cumulative RSDs for PL-and DG-FAME class relative abundances between the triplicates. Although some groupings had noticeable overlaps, the general trend remained the same. Physiological indicators such as the average DGFA:PLFA ratio varied between treatment methods ranging from 2 to 27 (Figure 9). The yield for PLFA biomass is presented in Trexler et al. 2017, Master's Thesis, The Ohio State University.

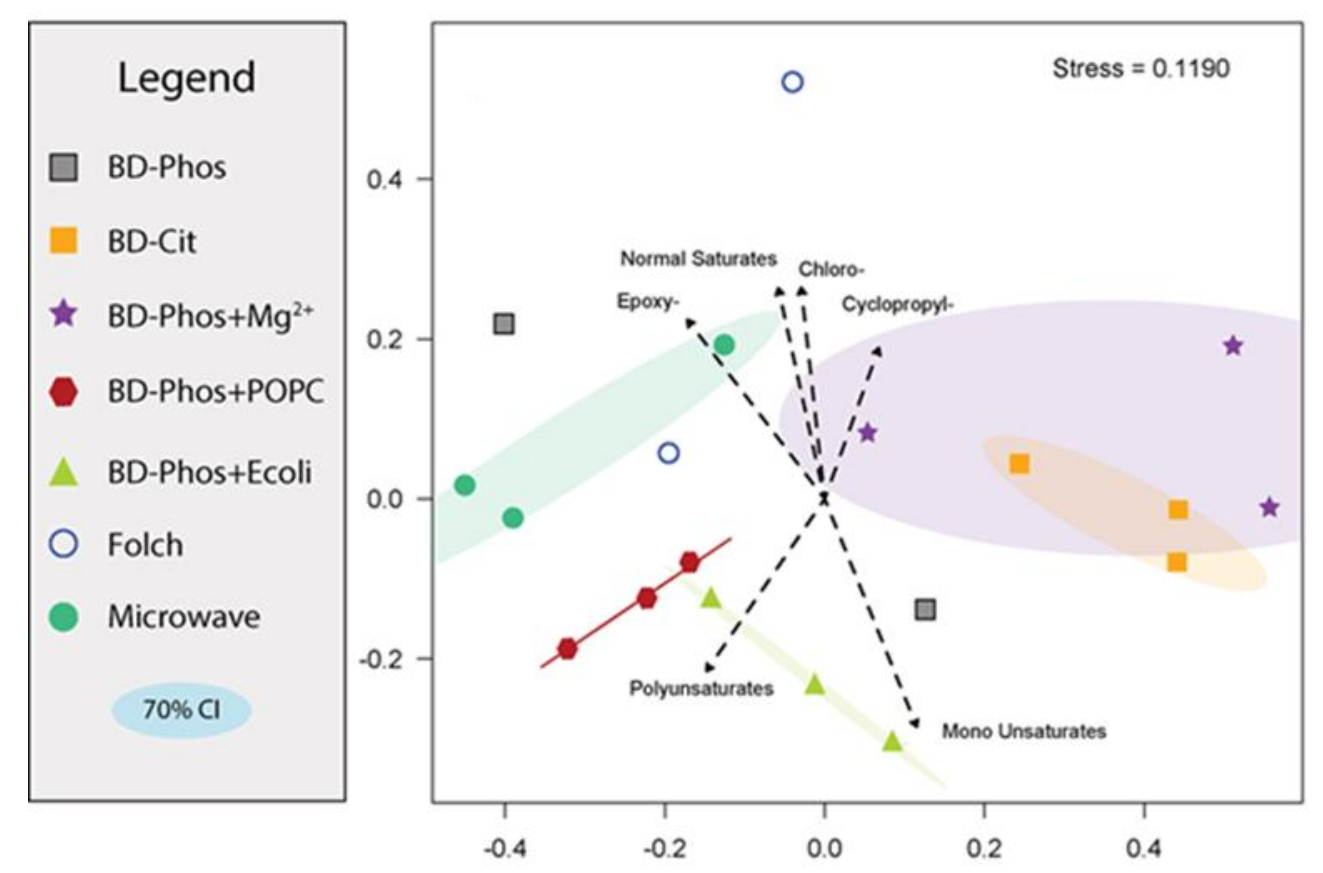

Figure 8. Non-metric Multi-Dimensional Scaling (NMDS) of experimental samples for DGFAMEs. Vectors representing significant $(\alpha=0.05)$ correlations of FAME relative abundance were added to reveal significant drivers between groupings. Confidence intervals $(70 \%)$ for each treatment grouping were also plotted. 


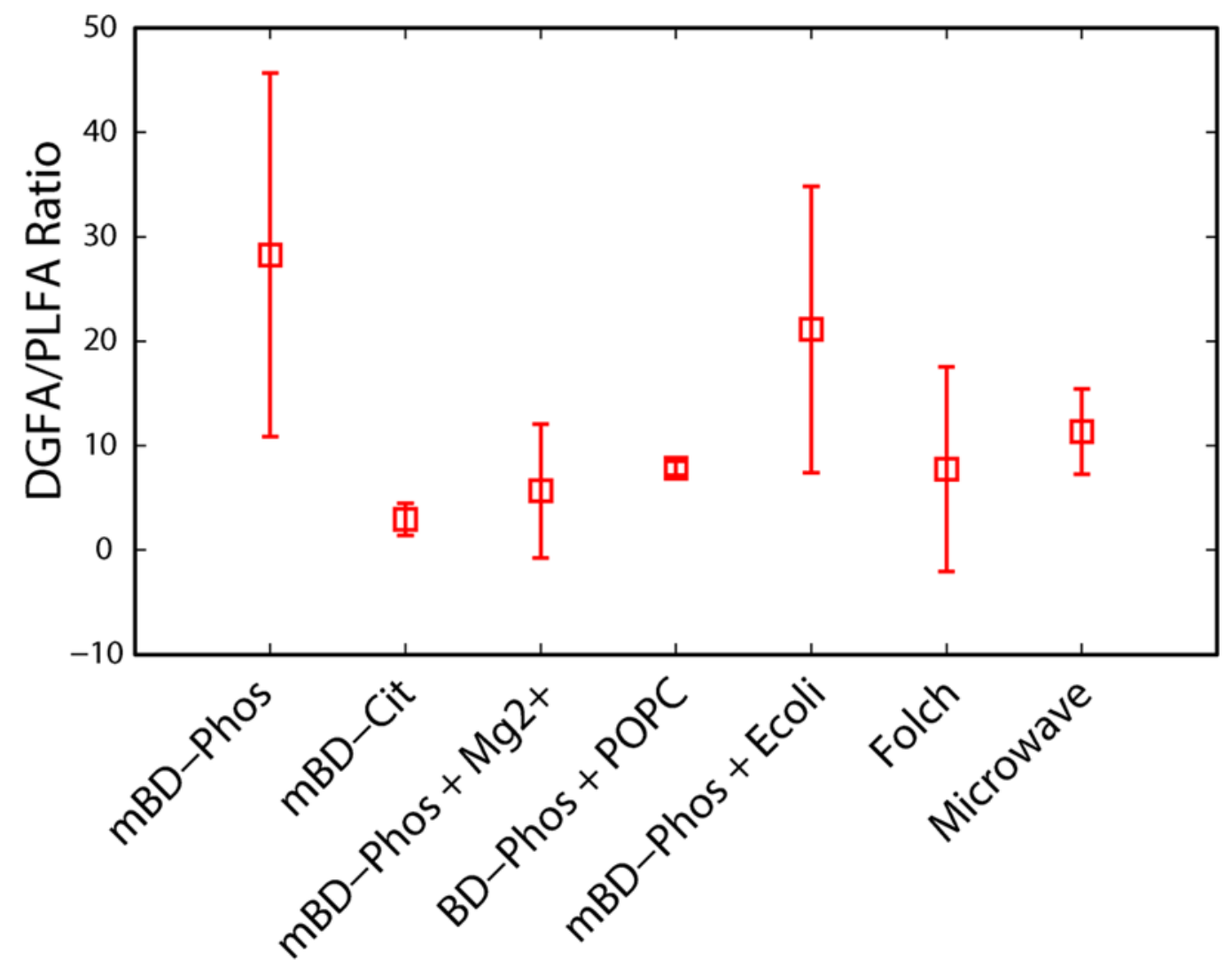

Figure 9. A comparison of the ratio of DG to PL-FAMEs across extraction treatment methods $(n=7)$. PLFA biomass used in this figure is presented in elsewhere in Trexler et al. 2017, Master's Thesis, The Ohio State University.

\subsection{DISCUSSION}

\section{1..6.1 INFLUENCE OF EXTRACTION TREATMENTS ON TOTAL LIPID YIELD (MICROBIAL BIOMASS)}

\subsubsection{Amended vs. Un-amended Standard Bligh and Dyer Procedure}

The primary aim of this chapter was to determine the efficiency of specific lipid extraction treatments and establish an optimized extraction protocol for shale core samples. When the 
standard Bligh and Dyer method using a phosphate buffer (mBD+Phos) was amended with an intact phospholipid (mBD+Phos+POPC), the shale samples yielded more lipid biomarkers and better reproducibility for the DGFA (Figure 4). Black shales are generally characterized by high amounts of clay minerals, salinity, carbonates, organic matter, and other minerals like quartz and feldspars (Shaw and Weaver, 1965; Boles and Franks, 1979; Aplin and Macquaker, 2011; Chermak and Schreiber, 2014). Studies have shown how interactions between fatty acids, clay minerals, (Meyers and Quinn, 1973; Morris and Calvert, 1975; Boles and Franks, 1979; Lahann and Campbell, 1980; Aplin and Macquaker, 2011; Chermak and Schreiber, 2014) and carbonates (Zullig and Morse, 1988; Thomas et al., 1993) could impede efficient lipid extraction. Such mineral-lipid interactions have been shown to depend on a combination of the isoelectric point of the minerals, physical adsorption, electrostatic, van der Waals, and chemical bonding (Stevens et al., 2009; Oleson and Sahai, 2010; Sahai et al., 2016). Amphipathic compounds (11mercaptoundecanoic acid, MUA and 1-dodecanethoil, DDT) have been used to minimize the interference of such mineral-lipid interactions through self-assembly of lipid molecules in solution (Lee et al., 2014). In the presence of these compounds, the lipid molecules aggregated, while in their absence the lipid molecules remained un-aggregated in solution. These observations were attributed to hydrophobic interactions, dynamic rearrangement of the biochemical compounds on the particle surfaces, and short ranged electrostatic forces on the particle surfaces.

Accordingly, surface charge adsorption of intact phospholipid ditridecanoylphosphocholine (DTPC) and 1-palmitoyl-2-oleoyl-sn-glycerol-3-phosphocholine (POPC) have been observed on common minerals present in shale (Kalb et al., 1992; Xu et al., 2009). It is therefore plausible that a similar interaction between the hydrophobic and hydrophilic segments of the POPC and the mineral matrix could be responsible for the aggregation or self- 
assembly of the lipid molecules in solution, enhancing their efficient recovery. Sahai et al. (2016), used a model and suggested that the adsorption of the added lipid molecules on the mineral surface acted as a template for the assembly of more lipid molecules in solution. As a result, we suggest that the intact POPC in our treatment was the catalyst for mediating the lipid bilayer assembly, decreasing the microbial lipid adsorption in solution and thus increasing potential for solvent recovery. The re-extraction step might have also contributed to increase the effectiveness of the added lipid (POPC) performance. Re-extraction improves the effectiveness of the extraction solution by increasing the available reactive surface areas for the interactions between the intact POPC, the shale matrix, and the shale bound lipids. Other researchers have observed 5-10\% (Wu et al., 2009) and 20\% (Papadopoulou et al., 2011) increase in lipid recovery with re-extractions. In our method, both processes (i.e. POPC addition and re-extraction) could potentially have resulted in significant amounts of lipid recovery.

It is possible that a similar interaction could occur between the internal standard $(1,2-$ dinonadecanoyl-sn-glycero-3-phosphocholine) and the shale matrix resulting in improved yields, although to our knowledge no evidence has been published. However, this effect would be applicable to all the extraction treatments, since the same amount of internal standard was added to the treatments. Studies have, however, observed that fatty acids with different structures have different interactive adsorption capacities with the minerals (Meyers and Quinn, 1973; Zullig and Morse, 1988). Consequently, it is feasible that the different intact polar lipids (the internal standard, 1, 2-dinonadecanoyl-sn-glycero-3-phosphocholine, 19:0, and the amended intact lipid, 1palmitoyl-2-oleoyl-sn-glycero-3-phosphocholine, 16:0-18:1) could have dissimilar effects on the shale matrix. Further examination will however need to be done to show if the internal standard indeed has an effect on the lipid yield. 
The $E$. coli and $\mathrm{Mg}^{2+}$ amendments were not effective in allowing more lipid recovery from the shale samples as expected (Figure 4). This was unexpected because the E. coli was calculated to provide a similar concentration of exogenous additive similar to the POPC amendment based on the conversion factor in Kieft et al. (1994). The addition of $1200 \mathrm{ppm} \mathrm{Mg}^{2+}$ was also intended to reduce the adsorption of fatty acids (Lahann and Campbell, 1980), thereby increasing the extraction efficiency. Though the actual reason for the discrepant performance is unknown, it is probable that $\mathrm{Mg}^{2+}$ ions and microbial cells from the E. coli may not be suitable for lipid recovery from complex matrices like shale, but could be suitable to improve recovery from samples of different matrices. Differential performance of extraction solutions have been observed with lipid recovery. For example, optimized extraction solution performance has been reported in samples of high mineral and salt content while samples of low mineral content did not show similar optimized recovery (Christie, 1993; Gomez-Brandon et al., 2008). The authors suggested that the buffer:reagents were effective in interacting with the high mineral and salt content of the matrices thereby improving yields, while such similar interactions were absent in the samples of simpler matrices. Frostegard et al. (1991), also examined the efficiency of extraction treatments in samples of various matrices and found that some treatments were effective in samples of high organic matter content but less effective in samples of low organic matter content. These disparities in yield among treatment methods and matrices is a confirmation that some solvent:reagent:buffer combinations might be effective in lipid recovery from samples of particular matrix properties, but not effective in samples of different matrices. While we could not establish a clear explanation for the poor performance, it is apparent that the $\mathrm{Mg}^{2+}$ and E. coli amendment interfered with the lipid recovery and further research will be needed to explain this phenomena.

\subsubsection{Modified Folch and Microwave Assisted Extraction Procedure}


While we showed an improvement in lipid recovery between the POPC amended treatment and the un-amended Bligh and Dyer phosphate buffered treatment, we did not observe any significant difference in yield between the POPC treatment, Folch, mBD+Cit, and MAE methods (Figure 4). Previous comparisons between the Bligh and Dyer phosphate buffered method (mBD+Phos), the Folch, and MAE methods from samples of different matrices (manure, compost, vemicompost, and soil) showed that the Folch method outperformed the un-amended Bligh and Dyer (mBD+Phos) which in turn outperformed the MAE method (Gomez-Brandon et al., 2008; 2010). In contrast, our observations show that both Folch and MAE outperformed the un-amended $\mathrm{mBD}+\mathrm{Phos}$ but not the POPC amended Bligh and Dyer (mBD+Phos+POPC) treatment (Figure 4). This observed improved performance of the Bligh and Dyer amended treatment compared to Folch and MAE could be directly associated with the addition of the POPC amendment. Hence, these observations corroborate the suggestion that the addition of the exogenous POPC in the extraction solvent may have improved the performance of the traditional Bligh and Dyer phosphate buffered method in lipid recovery.

Additionally, our results also show an optimized performance for the MAE treatment. Gomez-Brandon et al. $(2008 ; 2010)$, reported that the MAE method had the lowest performance in lipid recovery from samples of both high and low organic matter matrices when compared to the standard Bligh and Dyer (mBD+Phos), and Folch methods. Contrastingly, our results indicate that the MAE outperformed the mBD+Phos and performed equally well with the Folch method (Figure 6). Since the response of the MAE was higher, it is possible that this improvement could be due to the modifications made on the extraction solvents. Previous MAE extraction treatments utilized a combination of hexane:acetone as extraction solvents (Lopez-Avila and Young, 1995; Gomez-Brandon et al., 2008; 2010) while our extraction solvents were modified to 
chloroform:methanol. Although chloroform:methanol has generally been considered more effective extraction reagents for lipids from environmental samples (Ewald et al., 1998; Renaud et al., 1999), their lethality and environmental unfriendliness is the reason why most studies prefer other reagents. The effectiveness of solvents in deep subsurface samples is particularly essential as most microbes in deep subsurface aquifer settings are always attached to sediment matrix (Franzmann et al., 1996; Murphy et al., 1997; Ginn et al., 1998), and will require appropriate reagents to be efficiently released (Thomas et al., 1993). We argue that in addition to optimizing lipid recovery between the amended and un-amended phosphate buffered treatment method, our solvent modification was also responsible for the improved performance of the MAE treatment method.

In a similar fashion, the buffer type in the extraction solution also influences lipid recovery. Gomez-Brandon et al. (2010) suggested that a suitable buffer during extraction could prevent loss of lipids into the aqueous phase of the extraction mixture by reducing ionization effects. Other researchers have also proposed that interactions between organic content of samples and $\mathrm{pH}$ of the buffer could also affect lipid yield (Frostegard et al., 1991; Nielsen and Petersen, 2000). Using soil samples of high organic matter content Frostegard et al. (1991), reported higher lipid recovery with citrate buffer ( $\mathrm{pH} 4)$ as opposed to the standard phosphate buffer ( $\mathrm{pH} \mathrm{7.4).} \mathrm{Comparably,}$ Nielsen and Petersen (2000) also observed an increase in lipid recovery with citrate buffer rather than phosphate buffer. The authors suggested that the acid nature of the citrate buffer reduced organic matter interference with shale bound lipids, thereby preventing the adsorption of microbial lipids on the matrix. Citrate has also been reported to be involved in chelating cations and metals (Glusker, 1980) and as such could be responsible for the interaction between the organic matter and the microbial lipids. These findings, therefore, emphasizes the significance of citrate chelation 
in samples of high organic matter content like black shales. More so, Nielsen and Petersen (2000) proposed that organic matter interference could lead to about $20 \%$ reduction in lipid recovery. Consequently, the relatively high lipid recovery for the mBD+Cit samples compared to the standard un-amended mBD+Phos treatments (Figure 4) could be explained by the effectiveness of the citrate buffer in improving lipid recovery in samples of high organic matter content by minimizing ionic adsorption.

The total number of FAME structural classes extracted using the intact POPC additive was higher and consistent within the triplicates compared to the $\mathrm{mBD}+\mathrm{Phos}$ (Figure 5). This finding led us to interpret that the POPC amended treatment improved the effectiveness of the mBD+Phos method to obtain optimal microbial lipid diversity. Other treatment methods like the MAE and the E. coli amended treatment also recorded relatively good reproducibility for the DGFA only. Samples extracted with the Folch and MAE methods also had high total numbers of FAME structural classes, which aligned with our suggestion that the solvent modification was effective in improving recovery for the MAE method. However, considering the importance of establishing both the reproducibility and efficiency of microbial lipid biomarkers, the POPC still proved more suitable. For example, the Folch and MAE triplicate samples failed to show repeatability among the FAMEs of low abundance. When we plotted vectors representing the correlation between samples and FAME classes, we found that no high abundance FAME was responsible for determining the differences between treatments.

\subsubsection{INFLUENCE OF EXTRACTION TREATMENT ON LIPID REPRODUCIBILITY}

We observed differential performance especially with the unique FAMEs of low abundance $(<10 \%$ relative abundance) across treatment methods, but not with the high abundant 
( $<10 \%$ relative abundance) common FAMEs (Figure 6). This high proportional variation both within and across treatment methods for the low abundant FAMEs was one of the primary objectives of our study. The extraction treatment with the ability to effectively recover these low abundant FAMEs was considered to be the most efficient procedure. This is because differential interaction between extraction solvents and samples of high organic and mineral content could increase the chances of obtaining highly variable results for lipid recovery. For example, GomezBrandon et al. (2010) observed higher proportional differences between the extraction methods for the organic rich samples (compost, vemicompost, and manure) while samples of less organic matter content (soil) did not show variations across treatment methods. Concomitantly, it is likely that the physical (low porosity/permeability) and chemical (high mineral and variable organic content content) properties of these samples are the underlying reason we see such large variations across triplicates either through adsorption, sequestration, or interference leading to variation across the triplicates. The standard deviation by GC detection based on the external standard from the buffer control samples $(n=7)$ was $6.11 \%$ implying that the gas chromatograph had little influence on the variations between treatments. It is also important to note that even in well mixed subsurface samples there could still be some variability. Studies have reported that even centimeter scale changes in depth could have predominant effects on microbial variability in the communities of deep subsurface samples (Brockman et al. 1992; Zhang et al., 1998). The authors reported that the microbial communities of deep subsurface were more isolated, existing in little niches or 'islands'. Consequently, microbial examining may recover sulfate reducing bacteria (SRB) from one sample and not see it in a sample two cm away. It is therefore possible that when mixing those samples together, one may not get the community disperse. This could also partly explain the high error bars observed in the average yield of some of the extraction treatments (Figure 4). These 
challenges further necessitate the continuous customized improvement of microbial lipid extraction procedures especially for samples with complicated matrices, such as deeply buried shales which could impede, or bias findings related to microbial cell abundance and diversity.

\subsubsection{INFLUENCE OF EXTRACTION TREATMENTS ON DGFA/PLFA RESPONSE}

Besides determining the influence of extraction treatment methods on the lipid yields and reproducibility, our experimental design also allowed us to assess the variability of the interactions between the PLFA and DGFA across treatments. A DGFA to PLFA ratio provides a relative measure of nonviable to viable bacterial biomass (Kieft et al., 1994). A DGFA/PLFA ratio of 1 indicates equivalent amounts of viable and non-viable biomass. The average DGFA to PLFA ratio varied between treatment methods ranging from $\sim 2$ to 27 (Figure 9). Although most extraction treatments performed differently between the PLFA and DGFA, we did not observe any statistical difference between the treatment methods. The average yields for the DGFA were relatively higher than the PLFA across treatments methods (Trexler et al., 2016, Master's Thesis, The Ohio State University). We did not expect the yield for PLFA and DGFA biomarkers to be the same since they both represent different kinds of lipid biomarkers (Kieft et al., 1994; Haldeman et al., 1994; Haldeman et al., 1995; White and Ringelberg, 1998; Fredrickson et al., 1997; Ringelberg et al., 1997). The DGFAs are more stable and less polar while the PLFAs are fragile and polar. Therefore, it is not surprising that we might see differences in PLFA and DGFA performances. The relatively higher yields in the DGFA across most extraction treatments could be explained by the conversion of PLFA to DGFA during the concurrent breakdown of subsurface microbial cells during subsurface drilling and sampling (Haldeman et al., 1993; Haldeman et al., 1995). Also, stressful environmental conditions associated with subsurface rocks could increase the likelihood of cell dead thus leading to higher DGFA concentrations as opposed PLFAs. Additionally, the fact 
that these samples were stored under room temperature conditions could have also favored the degradation of PLFA to DGFA, thus increasing the DGFA yield. Our objective was to choose the method that could perform well for both the PLFA and DGFA biomarker profiles.

\subsection{Conclusion}

Our results showed that the choice of extraction treatment method influenced the yield of the FAMEs. The lipid recovery efficiency of the Bligh and Dyer phosphate buffered method (mBD+Phos) was improved as a result of amendment with the intact phospholipid (POPC). The mBD+Phos+POPC treatment also exhibited higher recovery of unique lipids of low abundance. When compared with previous performance to the Folch, mBD+Phos, and mBD+Cit, the MAE extraction was also improved by using chloroform:methanol as solvent extraction solution. The efficiency of the MAE was higher. Higher lipid yield was observed for the citrate buffered Bligh and Dyer method compared to the standard un-amended Bligh and Dyer phosphate treatment (mBD+Phos). The $\mathrm{Mg}^{2+}$ and E. coli amendments did not prove to be efficient in the recovery of lipid biomarkers from the shale samples. Due to observed variations in performance of extraction treatments, we thus suggest that each extraction procedure should always be guided by both the sample matrix as well as the choice of targeted lipid biomarker. These methodological developments will thus provide better assessment of the microbial abundance of deep surface as well as the role of environmental and energy applications on the deep subsurface microbial community.

\subsection{Acknowledgement}

This research was financed by grants from the National Science Foundation (NSF-DEB \#1342732/1342701 to SS/PJM) and Early Career instrumentation grant NSF EAR \#1205596 to 
SS. Laboratory assistance from Brittny Detienne in the University of Tennessee, Knoxville, other members of Ohio State University Environmental Engineering laboratory and West Virginia University isotope laboratory is greatly appreciated. We would like to thank Andrea J. Hanson for helpful suggestions. Anna Sofia Andeskie and other members of the Technical Writing in Geology class are also appreciated for their help in revising the manuscript. The West Virginia Geologic and Economic Survey was invaluable for providing the shale samples. We also thank Dr. Tommy Phelps for valuable discussions. 


\subsection{References}

Aplin, A.C., and Macquaker, J.H.S. (2011). Mudstone diversity: Origin and implications for source, seal, and reservoir properties in petroleum systems. Aapg Bulletin 95, 2031-2059. doi: $10.1306 / 03281110162$.

Batista, A., Vetter, W., Luckas, B. (2001). Use of focused open vessel microwave-assisted extraction as prelude for the determination of the fatty acid profile of fish-a comparison with results obtained after liquid-liquid extraction according to Bligh and Dyer. European Food Research and Technology, 212(3), 377-384.

Biddle, J. F., Lipp, J. S., Lever, M. A., Lloyd, K. G., Sørensen, K. B., Anderson, R., ... \& Sogin, M. L. (2006). Heterotrophic Archaea dominate sedimentary subsurface ecosystems off Peru. Proceedings of the National Academy of Sciences of the United States of America, 103(10), 3846-3851.

Bligh, E.G., and Dyer, W.J. (1959). A Rapid Method of Total Lipid Extraction and Purification. Canadian Journal of Biochemistry and Physiology 37, 911-917.

Boles, J.R., and Franks, S.G. (1979). Clay Diagenesis in Wilcox Sandstones of Southwest Texas Implications of Smectite Diagenesis on Sandstone Cementation. Journal of Sedimentary Petrology 49, 55-70.

Brinch-Iversen, J; King, G. M. (1990). Effects of substrate concentration, growth state, and oxygen availability on relationships among bacterial carbon, nitrogen and phospholipid phosphorus content. FEMS Microbiology Letters, 74(4), 345-355.

Brockman, F. J., Kieft, T. L., Fredrickson, J. K., Bjornstad, B. N., Li, S. M. W., Spangenburg, W., Long, P. E. (1992). Microbiology of vadose zone paleosols in south-central Washington state. Microbial Ecology, 23(3), 279-301.

Cequier-Sánchez, E., RODRiguez, C. O. V. A. D. O. N. G. A., Ravelo, A. G., Zarate, R. A. F. A. E. L. (2008). Dichloromethane as a solvent for lipid extraction and assessment of lipid classes and fatty acids from samples of different natures. Journal of Agricultural and Food Chemistry, 56(12), 4297-4303.

Chengzao, J., Zheng, M., Zhang, Y. (2012). Unconventional hydrocarbon resources in China and the prospect of exploration and development. Petroleum Exploration and Development, 39(2), 139-146.

Chermak, J.A., and Schreiber, M.E. (2014). Mineralogy and trace element geochemistry of gas shales in the United States: Environmental implications. International Journal of Coal Geology 126, 32-44. doi: 10.1016/j.coal.2013.12.005.

Christie, W. W. (1993). Preparation of lipid extracts from tissues. Advances in lipid methodology, 2, 195-213.

Cluff, M. A., Hartsock, A., MacRae, J. D., Carter, K., Mouser, P. J. (2014). Temporal changes in microbial ecology and geochemistry in produced water from hydraulically fractured Marcellus Shale gas wells. Environmental science \& technology, 48(11), 6508-6517.

Colwell, F.S., Onstott, T.C., Delwiche, M.E., Chandler, D., Fredrickson, J.K., Yao, Q.J., McKinley, J.P., Boone, D.R., Griffiths, R., Phelps, T.J., Ringelberg, D., White, D.C., LaFreniere, L., Balkwill, D., Lehman, R.M., Konisky, J., and Long, P.E. (1997). Microorganisms from deep, high temperature sandstones: Constraints on microbial colonization. Fems Microbiology Reviews 20, 425-435. doi: Doi 10.1016/S0168- 
Curtis, J. B. (2002). Fractured shale-gas systems. AAPG bulletin, 86(11), 1921-1938.

D'hondt, S., Jørgensen, B. B., Miller, D. J., Batzke, A., Blake, R., Cragg, B. A., Holm, N. G. (2004). Distributions of microbial activities in deep subseafloor sediments. Science, 306(5705), 2216-2221.

Ewald, G., Bremle, G., Karlsson, A. (1998). Differences between Bligh and Dyer and Soxhlet extractions of PCBs and lipids from fat and lean fish muscle: implications for data evaluation. Marine pollution bulletin, 36(3), 222-230.

Folch, J., Lees, M., and Stanley, G.H.S. (1957). A Simple Method for the Isolation and Purification of Total Lipides from Animal Tissues. Journal of Biological Chemistry 226, 497-509.

Franzmann, P. D., Patterson, B. M., Power, T. R., Nichols, P. D., Davis, G. B. (1996). Microbial biomass in a shallow, urban aquifer contaminated with aromatic hydrocarbons: analysis by phospholipid fatty acid content and composition. Journal of applied bacteriology, 80(6), 617-625.

Fredrickson, J.K., McKinley, J.P., Bjornstad, B.N., Long, P.E., Ringelberg, D.B., White, D.C., Krumholz, L.R., Suflita, J.M., Colwell, F.S., and Lehman, R.M. (1997). Pore-size constraints on the activity and survival of subsurface bacteria in a late cretaceous shalesandstone sequence, northwestern New Mexico. Geomicrobiology Journal 14, 183-202.

Frostegard, A., and Baath, E. (1996). The use of phospholipid fatty acid analysis to estimate bacterial and fungal biomass in soil. Biology and Fertility of Soils 22, 59-65. doi: Doi 10.1007/Bf00384433.

Frostegard, A., Tunlid, A., Baath, E. (1991). Microbial Biomass Measured as Total Lipid Phosphate in Soils of Different Organic Content. Journal of Microbiological Methods 14, 151-163. doi: Doi 10.1016/0167-7012(91)90018-L.

Gaspar, J., Mathieu, J., Yang, Y., Tomson, R., Leyris, J. D., Gregory, K. B., \& Alvarez, P. J. (2014). Microbial dynamics and control in shale gas production. Environmental Science \& Technology Letters, 1(12), 465-473.

Ginn, T. R, Scheibe, T.D, Murphy, E.M, DeFlaun, M.F, Onstott, T.C., (1998) Effects of chemical heterogeneity on subsurface fate and transport involving biotic reaction systems: two examples. In: American Geophysical Union Fall Meeting, San Francisco, December 1998. Eos Trans 79(45):F294

Glusker, J. P. (1980). Citrate conformation and chelation: enzymic implications. Accounts of Chemical Research, 13(10), 345-352.

Gomez-Brandon, M., Lores, M., and Dominguez, J. (2008). Comparison of extraction and derivatization methods for fatty acid analysis in solid environmental matrixes. Analytical and Bioanalytical Chemistry 392, 505-514. doi: 10.1007/s00216-008-2274-7.

Gómez-Brandón, M., Lores, M., Domínguez, J. (2010). A new combination of extraction and derivatization methods that reduces the complexity and preparation time in determining phospholipid fatty acids in solid environmental samples. Bioresource technology, 101(4), $1348-1354$.

Guckert, J.B., Antworth, C.P., Nichols, P.D., and White, D.C. (1985). Phospholipid, Ester-Linked Fatty-Acid Profiles as Reproducible Assays for Changes in Prokaryotic Community Structure of Estuarine Sediments. Fems Microbiology Ecology 31, 147-158. doi: Doi 10.1111/J.1574-6968.1985.Tb01143.X.

Haldeman, D. L., Amy, P. S., Ringelberg, D., White, D. C., 1993. Characterization of the microbiology within a $21 \mathrm{~m} 3$ section of rock from the deep subsurface. Microbial ecology, 26(2), 145-159. 
Haldeman, D. L., Amy, P. S., White, D. C., Ringelberg, D. B., 1995a. Changes in bacteria recoverable from subsurface volcanic rock samples during storage at $4 \mathrm{C}$. Applied and environmental microbiology, 60(8), 2697-2703.

Haldeman, D. L., Amy, P. S., Ringelberg, D., White, D. C., Garen, R. E., Ghiorse, W. C., 1995 b. Microbial growth and resuscitation alter community structure after perturbation. FEMS Microbiology Ecology. 17 (1) 27-37; DOI: 10.

Inagaki, F., Hinrichs, K.-U., Kubo, Y., and the IODP Expedition 337 Scientists: IODP Expedition 337: Deep Coalbed Biosphere off Shimokita - Microbial processes and hydrocarbon system associated with deeply buried coalbed in the ocean, Sci. Dril., 21, 17-28, doi:10.5194/sd-21-17-2016, 2016.

Javadpour, F. (2009). Nanopores and apparent permeability of gas flow in mudrocks (shales and siltstone). Journal of Canadian Petroleum Technology, 48(08), 16-21.

Kalb, E., Frey, S., Tamm, L. K. (1992). Formation of supported planar bilayers by fusion of vesicles to supported phospholipid monolayers. Biochimica et Biophysica Acta (BBA)Biomembranes, 1103(2), 307-316.

Kieft, T.L., Ringelberg, D.B., and White, D.C. (1994). Changes in Ester-Linked Phospholipid Fatty-Acid Profiles of Subsurface Bacteria during Starvation and Desiccation in a PorousMedium. Applied and Environmental Microbiology 60, 3292-3299.

Lahann, R.W., and Campbell, R.C. (1980). Adsorption of Palmitic Acid on Calcite. Geochimica Et Cosmochimica Acta 44, 629-634. doi: Doi 10.1016/0016-7037(80)90152-0.

Lazar, I., Petrisor, I. G., Yen, T. F. (2007). Microbial enhanced oil recovery (MEOR). Petroleum Science and Technology, 25(11), 1353-1366.

Lee, H. Y., Shin, S. H. R., Drews, A. M., Chirsan, A. M., Lewis, S. A., Bishop, K. J. (2014). Selfassembly of nanoparticle amphiphiles with adaptive surface chemistry. ACS nano, 8(10), 9979-9987.

Lengger, S. K., Hopmans, E. C., Sinninghe Damsté, J. S. Schouten, S. (2012). Comparison of extraction and work up techniques for analysis of core and intact polar tetraether lipids from sedimentary environments. Organic Geochemistry 47, 34-40.

Lopez-Avila, V., Young, R., Beckert, W. F. (1994). Microwave-assisted extraction of organic compounds from standard reference soils and sediments. Analytical Chemistry, 66(7), 1097-1106.

Lopez-Avila, V. (1999). Sample preparation for environmental analysis. Critical reviews in analytical chemistry, 29(3), 195-230.

Lores, M., Gómez-Brandón, M., Pérez-Díaz, D., Domínguez, J. (2006). Using FAME profiles for the characterization of animal wastes and vermicomposts. Soil Biology and Biochemistry, 38(9), 2993-2996.

McMahon, S., Parnell, J. (2014). Weighing the deep continental biosphere. FEMS microbiology ecology, 87(1), 113-120.

Meyers, P.A., and Quinn, J.G. (1973). Factors Affecting Association of Fatty-Acids with Mineral Particles in Sea-Water. Geochimica Et Cosmochimica Acta 37, 1745-1759. doi: Doi 10.1016/0016-7037(73)90160-9.

Mohan, A. M., Hartsock, A., Hammack, R. W., Vidic, R. D., \& Gregory, K. B. (2013). Microbial communities in flowback water impoundments from hydraulic fracturing for recovery of shale gas. FEMS microbiology ecology, 86(3), 567-580. 
Morris, R.J., and Calvert, S.E., 1975. Fatty-Acid Uptake by Marine Sediment Particles. Geochimica Et Cosmochimica Acta 39, 377-381. doi: Doi 10.1016/0016-7037(75)902021.

Murphy, E. M., Ginn, T. R., Chilakapati, A., Resch, C. T., Phillips, J. L., Wietsma, T. W., Spadoni, C. M., 1997. The influence of physical heterogeneity on microbial degradation and distribution in porous media. Water Resources Research, 33(5), 1087-1103.

Nielsen, P., and Petersen, S.O. (2000). Ester-linked polar lipid fatty acid profiles of soil microbial communities: a comparison of extraction methods and evaluation of interference from humic acids. Soil Biology \& Biochemistry 32, 1241-1249. doi: Doi 10.1016/S00380717(00)00041-9.

Oleson, T. A., Sahai, N., Pedersen, J. A. (2010). Electrostatic effects on deposition of multiple phospholipid bilayers at oxide surfaces. Journal of colloid and interface science, 352(2), 327-336.

Onstott, T.C., Phelps, T.J., Colwell, F.S., Ringelberg, D., White, D.C., Boone, D.R., McKinley, J.P., Stevens, T.O., Long, P.E., Balkwill, D.L. (1998). Observations pertaining to the origin and ecology of microorganisms recovered from the deep subsurface of Taylorsville Basin, Virginia. Geomicrobiology Journal 15, 353-385.

Oksanen F. J., Guillaume Blanchet, Roeland Kindt, Pierre Legendre Peter R. Minchin, R. B. O'Hara Gavin L. Simpson Peter Solymos M. Henry H. Stevens Helene Wagner vegan: Community Ecology Package. R package version 2.3-5 Year: 2016 URL: https://CRAN.Rproject.org/package $=$ vegan

Papadopoulou, E.S., Karpouzas, D.G., and Menkissoglu-Spiroudi, U. (2011). Extraction Parameters Significantly Influence the Quantity and the Profile of PLFAs Extracted from Soils. Microbial Ecology 62, 704-714. doi: 10.1007/s00248-011-9863-2.

Passey, Q. R., Bohacs, K., Esch, W. L., Klimentidis, R., \& Sinha, S. (2010, January). From oilprone source rock to gas-producing shale reservoir-geologic and petrophysical characterization of unconventional shale gas reservoirs. In International oil and gas conference and exhibition in China. Society of Petroleum Engineers.

Pfiffner, S. M., Cantu, J. M., Smithgall, A., Peacock, A. D., White, D. C., Moser, D. P., ... \& van Heerden, E. (2006). Deep subsurface microbial biomass and community structure in Witwatersrand Basin mines. Geomicrobiology Journal, 23(6), 431-442.

Rapuano, R., Carmona-Ribeiro, A. M. (2000). Supported bilayers on silica. Journal of Colloid and Interface Science, 226(2), 299-307.

Renaud, S. M., Thinh, L. V., Parry, D. L. (1999). The gross chemical composition and fatty acid composition of 18 species of tropical Australian microalgae for possible use in mariculture. Aquaculture, 170(2), 147-159.

Ringelberg, D.B., Sutton, S., and White, D.C. (1997). Biomass, bioactivity and biodiversity: microbial ecology of the deep subsurface: analysis of ester-linked phospholipid fatty acids. Fems Microbiology Reviews 20, 371-377. doi: Doi 10.1016/S0168-6445(97)00019-3.

Ringelberg, D. B., Davis, J. D., Smith, G. A., Pfiffner, S. M., Nichols, P. D., Nickels, J. S., Read, H. W. (1989). Validation of signature polarlipid fatty acid biomarkers for alkane-utilizing bacteria in soils and subsurface aquifer materials. FEMS Microbiology Ecology, 5(1), 3950.

Rogner, H. H. (1997). An assessment of world hydrocarbon resources. Annual review of energy and the environment, 22(1), 217-262. 
Sahai, N. (2002). Biomembrane phospholipid-oxide surface interactions: Crystal chemical and thermodynamic basis. Journal of colloid and interface science, 252(2), 309-319.

Sahai, N., Kaddour, H., Dalai, P., Wang, Z., Bass, G., Gao, M. (2017). Mineral Surface Chemistry and Nanoparticle-aggregation Control Membrane Self-Assembly. Scientific Reports, 7.

Schippers, A., \& Neretin, L. N. (2006). Quantification of microbial communities in near-surface and deeply buried marine sediments on the Peru continental margin using real-time PCR. Environmental Microbiology, 8(7), 1251-1260.

Sharma, S., Mulder, M. L., Sack, A., Schroeder, K., \& Hammack, R. (2014). Isotope approach to assess hydrologic connections during Marcellus Shale drilling. Groundwater, 52(3), 424433.

Shaw, D.B., and Weaver, C.E., 1965. The Mineralogical Composition of Shale. Journal of Sedimentary Petrology 35, 213-222.

Sondergeld, C. H., Ambrose, R. J., Rai, C. S., Moncrieff, J. 2010. Micro-structural studies of gas shales. In SPE Unconventional Gas Conference. Society of Petroleum Engineers.

Stevens M. J., Donato L. J., Lower S. K. \& Sahai N. Oxide-dependent adhesion of the jurkat Line of T Lymphocytes. Langmuir 25, 6270-6278 (2009).

Thomas, M.M., Clouse, J.A., and Longo, J.M. (1993). Adsorption of organic compounds on carbonate minerals. Chemical Geology 109, 201-213. doi: http://dx.doi.org/10.1016/00092541(93)90070-Y.

Vetter, W., Weichbrodt, M., Hummert, K., Glotz, D.,Luckas, B. (1998). Combined microwaveassisted extraction and gel permeation chromatography for the determination of chlorinated hydrocarbons in seal blubber and cod livers. Chemosphere, 37(9), 2439-2449.

Wiegart, L., O'Flahert, S. M., Struth, B. (2005). Nanocrystal induced organization of a langmuir phospholipid monolayer. Langmuir, 21(5), 1695-1698.

White, D.C., Davis, W.M., Nickels, J.S., King, J.D., Bobbie, R.J. (1979). Determination of the Sedimentary Microbial Biomass by Extractable Lipid Phosphate. Oecologia 40, 51-62. doi: Doi 10.1007/Bf00388810.

White, D. C., Ringelberg, D. B. (1998). Signature lipid biomarker analysis(Vol. 255, p. 272). Oxford University Press: New York.

Whitman, W. B., Coleman, D. C., Wiebe, W. J. (1998). Prokaryotes: the unseen majority. Proceedings of the National Academy of Sciences, 95(12), 6578-6583.

Wilkins, M.J., Daly, R.A., Mouser, P.J., Trexler, R., Sharma, S., Cole, D.R., Wrighton, K.C., Biddle, J.F., Denis, E.H., Fredrickson, J.K., Kieft, T.L., Onstott, T.C., Peterson, L., Pfiffner, S.M., Phelps, T.J., and Schrenk, M.O. (2014). Trends and future challenges in sampling the deep terrestrial biosphere. Front Microbiol 5, 481. doi: 10.3389/fmicb.2014.00481.

Wu, Y., Ding, N., Wang, G., Xu, J., Wu, J., Brookes, P. C. (2009). Effects of different soil weights, storage times and extraction methods on soil phospholipid fatty acid analyses. Geoderma, 150(1), 171-178.

Xu, L., Davis, T. A., Porter, N. A. (2009). Rate constants for peroxidation of polyunsaturated fatty acids and sterols in solution and in liposomes. Journal of the American Chemical Society, 131(36), 13037-13044.

Young, J. C. (1995). Microwave-assisted extraction of the fungal metabolite ergosterol and total fatty acids. Journal of Agricultural and Food Chemistry,43(11), 2904-2910.

Zhang, C., Palumbo, A. V., Phelps, T. J., Beauchamp, J. J., Brockman, F. J., Murray, C. J., Swift, D. J. (1998). Grain size and depth constraints on microbial variability in coastal plain subsurface sediments. Geomicrobiology Journal, 15(3), 171-185. 
Zhang, C. L., Pancost, R. D., Sassen, R., Qian, Y., Macko, S. A. 2003. Archaeal lipid biomarkers and isotopic evidence of anaerobic methane oxidation associated with gas hydrates in the Gulf of Mexico. Organic Geochemistry, 34(6), 827-836.

Zullig, J.J., Morse, J.W. (1988). Interaction of Organic-Acids with Carbonate Mineral Surfaces in Seawater and Related Solutions .1. Fatty-Acid Adsorption. Geochimica Et Cosmochimica Acta 52, 166: Doi 10.1016/0016-7037(88)90235-9 


\section{CHAPTER 2}

\section{Microbial Lipid Biomarkers Detected in Deep Subsurface Black Shales}

\subsection{Abstract}

Evidence for microbes has been detected in extreme subsurface environments as deep as $2.5 \mathrm{~km}$ with temperatures as high as $90^{\circ} \mathrm{C}$, demonstrating that microbes can adapt and survive extreme environmental conditions. Deep subsurface shales are increasingly exploited for their energy applications, thus characterizing the prevalence and role of microbes in these ecosystems essential for understanding biogeochemical cycles and maximizing production from hydrocarbonbearing formations. Here, we describe the distribution of bacterial ester-linked diglyceride fatty acids (DGFA) in sidewall cores retrieved from three distinct geologic horizons collected up to 2,275 m below ground surface in a Marcellus Shale well, West Virginia, USA. We examined the abundance and variety of DGFA before energy development within and above the Marcellus Shale Formation into the overlying Mahantango Formation of the Appalachian Basin. Lipid biomarkers in the cores suggest the presence of microbial communities comprising Gram (+), Gram (-) as well as stress indicative biomarkers. More abundant and diverse DGFA membrane profiles were associated with the Mahantango Formation. The stress indicative biomarkers like the transmembrane fatty acids, oxiranes, keto-, and dimethyl lipid fatty acids were present in all cores, potentially indicating that the bacterial communities had experienced physiological stress or nutrient deprivation during or after deposition. These findings suggest the probable presence of indigenous microbial communities in the deep subsurface shale and also improves our understanding of microbial survival mechanisms in ancient deep subsurface environments. 


\subsection{Introduction}

The ongoing search for microbial life in the subsurface has been a subject of research interest as early as 1926 (Bastin et al., 1926). Subsequent microbiological studies have demonstrated the possibility of microbial adaptation and survival in extreme subsurface environments spanning deep terrestrial and marine ecosystems (e.g.; Fredrickson et al., 1991; Brockman et al., 1992; Haldeman et al, 1993; Kieft et al., 1994; Colwell et al., 1997; Frederickson et al., 1995b; Fredrickson et al., 1997; Krumholz et al., 1997; Onstott et al., 1998; 1999; Martini et al., 2003; Biddle et al., 2006; Fredricks and Hinrichs, 2007; Pfiffner et al., 2006; Edwards et al., 2012; Colwell and D'Hondt, 2013; Inagaki et al., 2016). In addition, it has been suggested that the deep surface ecosystem may account for as much as 30\% of the Earth`s biomass (Fisk et al., 1998; Whitman et al., 1998; McMahon and Parnell, 2014). Researchers have either examined the microbial survival ability over geological time (Kennedy et al., 1994) or have reported the likelihood of potentially indigenous microbial communities in deep rocks (Murphy et al., 1992; Colwell et al., 1997; Fredrickson et al., 1995b; 199; Krumholz et al., 1997). Increased interest in energy extraction and environmental applications of deep subsurface shales has further reinforced microbial research in the deep shale ecosystem (Colwell et al., 1997; Fredrickson et al., 1997; Edwards et al., 2012; Hinrichs and Inagaki, 2012; Colwell and D’Hondt, 2013). The recovery of microbial DNA and biogenic natural gas (Sharma et al., 2013), as well as the temporal shifts in microbial communities of produced fluids from unconventional wells (Mohan et al., 2013; 2014; Cluff et al., 2014; Gaspar et al., 2014; Vikram et al., 2014; Mouser et al., 2016; Daly et al., 2016) are also evidence of pre- or post-production microbial life in shale systems.

Even though microbes have been shown to exhibit extraordinarily tenacious abilities to survive in extreme environments, questions about the role of microbes in the subsurface remain a 
scientific challenge. For example, we do not yet know the in situ microbial survival mechanisms in the subsurface and how they have been/were affected by the prevailing geologic and environmental conditions. It is also difficult to establish whether the microbes detected in the deep subsurface represent environmental conditions at the time of deposition or if they reflect changes that took place after deposition (Fredrickson et al., 1995b; 1997; Fichtel et al., 2015; Inagaki et al., 2015). This is further complicated by the fact that drilling and fracturing fluids used during development, introduces large quantities of labile carbon, nutrients, and exogenous organisms into the subsurface (Ferrer \& Thurman, 2015; Lester et al., 2015; Gaspar et al., 2014; Mouser et al., 2016) making it unclear whether indigenous communities exist in these shale formations. These challenges highlight the need for a better understanding of subsurface microbial communities and the microbial role in global biogeochemical processes (Hinrichs and Inagaki, 2012). Examining the role of microbes in these systems before and after shale gas drilling, and the potential influence of geologic and environmental conditions further provides opportunities to better understand the role of deep subsurface microbial communities.

Phospholipids are essential components of microbial cellular membranes which rapidly degrade upon cell death and therefore have been used to provide modern evidence of living microbes in the environment (e.g.; White et al., 1979; Baird et al., 1985; White, 1988; Haldeman et al., 1993; White and Ringelberg, 1998; Ringelberg et al., 1997; Petsch et al., 2003; Pfiffner et al., 2006). When the microbial cell dies, phospholipase enzymes break the glycerol backbone of the phospholipid fatty acid (PLFA), creating a diglyceride (DGFA) which contains the same fatty acid as the parent phospholipid (White et al., 1979; Kieft et al., 1994; White and Ringelberg, 1998). DGFAs are the breakdown products of PLFAs and indicate the presence of non-viable microbial communities. Lipid biomarkers in sediments are thus excellent proxies for understanding 
microbial communities and providing insight into the environmental conditions and postdepositional history (Brassell and Eglinton, 1986; Brassell, 1993; Peters et al., 2005). However, microbes can adopt different states of dormancy for survival in the deep subsurface and this could change or modify the biological or chemical definition of "viable" or "non-viable" microbial cells (Haldeman et al., 1995; Barer and Harwood, 1999). This is more important in the subsurface where the turnover rate of PLFA (removal of a phosphate group) is not known (Fredrickson et al., 1997). Generally, the PLFAs have been established as a biomarker for viable microbes while DGFAs as biomarkers for non-viable microbes (White et al., 1979; Baird and White, 1985; Baird et al., 1985; White, 1988; White and Ringelberg, 1996; Ringelberg et al., 1997). They also serve as one of the most sensitive and suitable molecular approaches to investigate in situ microbial biomass and community (Bobbie and White, 1980; White et al., 1988).

Here, we utilize the DGFA signatures to (i) to evaluate trends in biomarker yield and variety across three geologic horizons, and (ii) to identify signature lipid biomarkers (SLB) and potential microbial groups within the subsurface rock cores. We hypothesized that zones with higher organic carbon content would have higher biomarker composition and variety since organic carbon can serve as both a carbon and energy source for microbial activities in the deep biosphere (McMahon and Chapelle, 1991; Murphy et al., 1992; Kieft et al., 1995; D’Hondt et al., 2004; Biddle et al., 2005; Shrenk et al., 2009). Based on previous studies we also hypothesized that the transition zone between the extremely low permeability Marcellus Shale and the more permeable Mahantango Formation would have higher lipid abundance and diversity. We thus collected deep subsurface core samples from Marcellus Shale Top, upper Marcellus Shale zones, and the overlying Mahantango Formation to examine DGFA membrane lipid profiles across these zones. 
We also evaluated the differences between the lipid profiles in the cores, drilling mud, and core washes to discern what fraction (if any) was unique to the cores.

\subsection{Geologic Background}

The geologic units sampled in this study all belong to the Hamilton Group and were deposited in the Appalachian Basin during the Acadian Orogeny of the Middle Devonian (Ettensohn, 1985; 2011). The Marcellus Shale is a thinly-laminated, gray- to black-colored organic-rich shale and is overlain by the Mahantango Formation which is predominantly a gray, thickly laminated, interbedded silty mud, and sandstone unit (Dennison and Hasson, 1976; Soeder et al., 2014). The Marcellus Shale and the Mahantango Formations are both composed primarily of mud rock, although the rocks of the Marcellus Shale Formation are more organic-rich (Figure 1). Recent studies on the Hamilton Group in this part of the basin have indicated that variations in paleoenvironmental conditions and sources of sediment influx were responsible for the differences in lithological composition, age, mineralogy, and geochemistry of the different formations (Wang and Carr, 2013; Wang et al., 2014; Chen et al., 2015; Chen and Sharma, 2016; Hupp, 2017). All these units were deposited in the shallow to the deep marine environment, however, the Marcellus

Shale was deposited in relatively deeper anoxic conditions compared to the Mahantango Formation (Boyce et. al., 2010; Yanni, 2010; Chen and Sharma 2016).

\subsection{MATERIALS AND METHODS}

\subsubsection{Site Description, Drilling, and Sample Collection Procedures}

The study site is the Marcellus Shale Energy and Environment Laboratory (MSEEL), located two miles southeast of Morgantown, West Virginia. The MSEEL site contains four producing wells (MIP 3H, MIP 4H, MIP 5H, MIP 6H) and a scientific well (MIP SW) each 
penetrating more than 2,250 $\mathrm{m}$ into the Marcellus Shale (Figure 1). The funding for MSEEL is provided by the Department of Energy's National Energy Technology Laboratory (NETL) with the goal of improving the efficiency of unconventional hydrocarbon production while minimizing adverse environmental impacts. The site is developed and managed by the Department of Geology and Geography at West Virginia University (WVU), in collaboration with Northeast Natural Energy (NNE), NETL and The Ohio State University (OSU). The samples for this study were side wall cores collected from MIP-3H. A total of five formations were targeted for sidewall cores ranging in depth from $2,175 \mathrm{~m}$ to $2,306 \mathrm{~m}$. For this study, sidewall core samples collected at selected intervals from the Mahantango Formation, Marcellus Shale top, and the upper Marcellus Shale zones were chosen for analysis (Figure 1) and transported to OSU for decontamination and processing. Prior to obtaining field core samples, rigorous decontamination methods and small batch core processing protocols were developed to ensure all core samples were free of exogenous microbial signatures (Wilkins et al., 2014). The cores were subsequently collected in a manner to ensure minimal contamination from the drilling process or sample collection. Specifically, drilling mud tracers (i.e. fluorescent microspheres; Lehman et al., 1995) were added to the drilling mud to track any microbial contamination. In total $2.8 \times 10^{13}$ particles of Fluoresbrite, Carboxylate YG 0.50 micro microspheres (Polysciences Inc., Warrington, PA) were added to the input drilling muds. Samples of the drilling muds (Drilling Mud 9-03 (2015) and Drilling Mud 8-28 (2015)) were then collected in sterile 1 liter Nalgene bottles (stored on ice) to serve as a control for confirming lipid profiles indigenous to cleaned cores.

In order to remove contamination that may have resulted from drilling, sample collection and/or handling, each core was placed in a sterile saline bath $(1.5 \mathrm{M} \mathrm{NaCl})$ and the outer portion was abraded with autoclaved steel wool (Wilkins et al., 2014). Cores were next placed in 
successive saline baths to remove contamination, with wash fluids retained to evaluate potential contaminants. After the cores were cleaned, the outer portion was flame sterilized. The cores were then crushed with a Plattner mortar and pestle (Humboldt Mfg. Co., Elgin, IL) and then ground in a ceramic mortar and pestle using sterile technique. The ground core samples were passed through a series of autoclave-sterilized brass sieves with mesh sizes of $2000 \mu \mathrm{m}, 1000 \mu \mathrm{m}$, and $500 \mu \mathrm{m}$ (Dual Manufacturing Co., Inc., Franklin Park, IL). Powdered samples were continuously ground until all samples could pass through a $500 \mu \mathrm{m}$ sieve. Three out of the five cores from each depth were homogenized and stored in autoclaved wide-mouthed, amber glass jars with Teflon-coated lids at $-80^{\circ} \mathrm{C}$ (Thermo Fischer Scientific, Waltham, MA). To ensure that the lipid biomarkers were representative of the microbial community of the deep subsurface cores and not introduced during drilling, samples of saline decontamination baths from each core depth were also collected for lipid analyses. The samples were stored at $-80^{\circ} \mathrm{C}$ until extraction. 

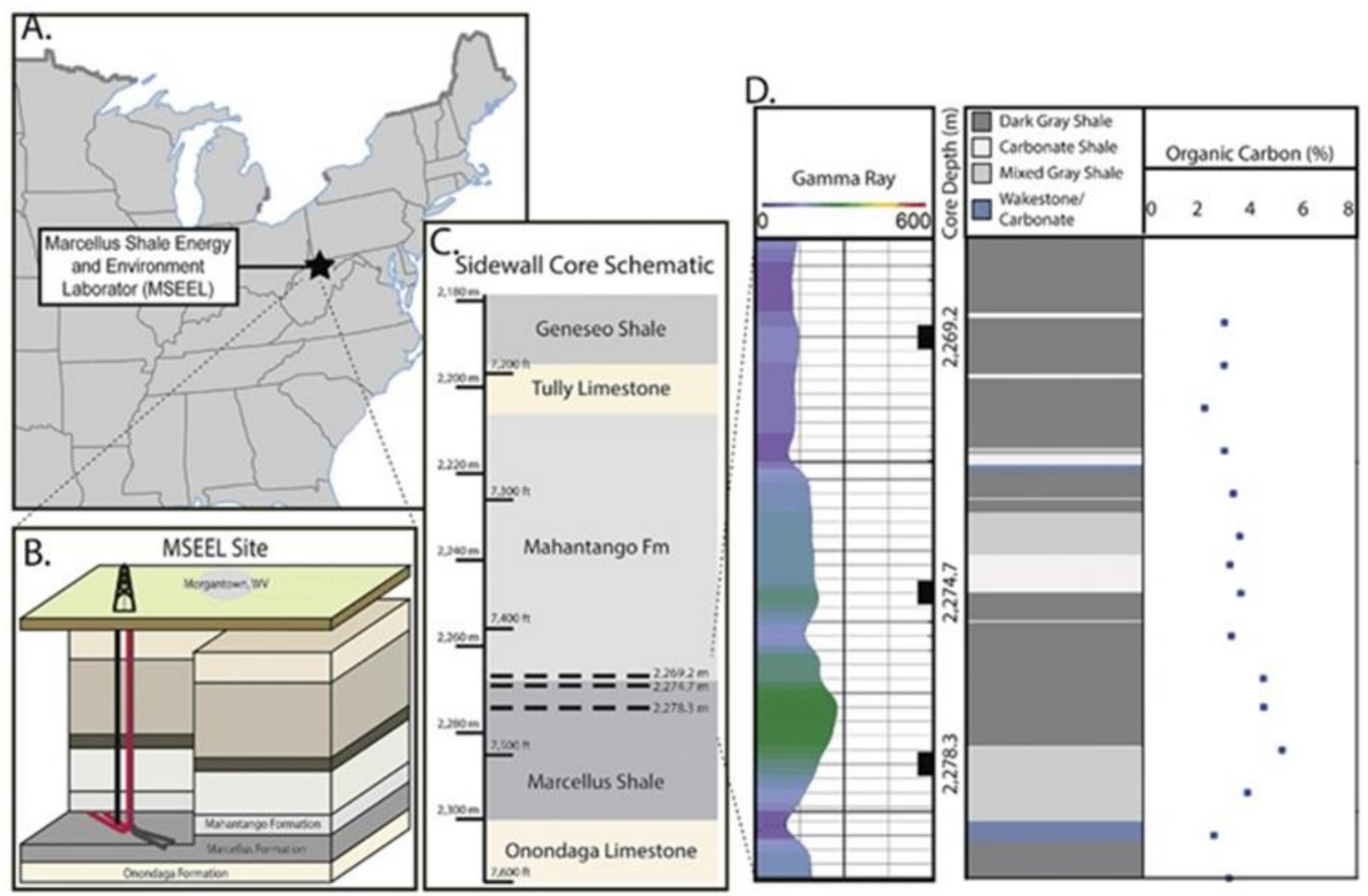

Figure 1. Map showing the approximate location of the Marcellus Shale Energy and Environment Laboratory (MSEEL) in West Virginia, USA (A), MSEEL well design with four producing wells and scientific well (B), sidewall coring locations (C), generalized schematic of stratigraphy, total organic carbon content in the Mahantango, Marcellus Shale Top, and Upper Marcellus Shale zones (D).

\subsubsection{Lipid Extraction}

Lipid extraction and analysis were performed in the Pfiffner lab at the Center for Environmental Biotechnology at the University of Tennessee (Knoxville, TN, USA). A modified summarized scheme of the methodology for the lipid extraction is shown in Akondi et al. (2017). All glassware were cleaned in a 10\% (v/v) micro alkaline cleaning solution (International Products Corporation, Burlington, NJ) and 5 times with distilled water and 5 times with Millipore water before being combusted in a muffle furnace at $550^{\circ} \mathrm{C}$ for 6 hours. Metal lab ware (forceps, mortar, pestle, and spatulas) were cleaned with tap water and then with distilled water and finally with a solution of 1:1 chloroform: methanol. Teflon-lined caps were cleaned in the same manner as the 
glass-wares and then solvent-rinsed with acetone. All reagents and solvents used during the extraction and analytic experimental process were of high grade (HPLC, Fisher Optima). The samples were lyophilized and weighed before extraction, which provides better adheres to the solvent ratios used by removing the water in the sample.

Samples were extracted ultrasonically according to the modified Bligh and Dyer procedure (Bligh and Dyer, 1959; White et al., 1979), with an intact polar lipid (Phosphate Buffer + phosphatidylcholine; POPC) amendment following the approach described by Akondi et al. (2017). To make sure the added POPC was not a contaminant in the total lipid concentrations, we subtracted the equivalent concentration of the amended lipids from the PLFA yield. The amended POPC was meant to improve lipid extraction efficiency in deep subsurface formations characterized by extremely low biomass, complex shale matrices, and mineralogy (Akondi et al., 2017). Procedural blanks and experimental controls (drilling muds and core washes) were also analyzed to monitor any laboratory contamination and the possibility of contamination during drilling and extraction process. The procedural blanks and experimental controls were prepared and analyzed identically as the samples. Lipid extractions were carried out on $37.5 \mathrm{~g}$ of the powdered rock sediments. Solvent extraction mixtures of chloroform-methanol-phosphate buffer, 1:2:0.8 (v/v/v, Chloroform:MeOH:Buffer) were used to suspend the powdered rock sediments in a $250 \mathrm{~mL}$ glass centrifuge bottle. Phosphate buffer $(0.05 \mathrm{M})$ was prepared by adding $8.7 \mathrm{~g}$ of dibasic potassium phosphate $\left(\mathrm{K}_{2} \mathrm{HPO}_{4}\right)$ with 1 liter of HPLC-grade water and neutralized with $1 \mathrm{~N}$ HCL to $\mathrm{pH}$ of 7.4. The buffer was washed with chloroform (5\% of buffer volume) by vortexing and storing at room temperature overnight. $50 \mathrm{uL}$ of $50 \mathrm{pmol} / \mu \mathrm{L}$ of internal standard (1, 2dinonadecanoyl-sn-glycero-3-phosphocholine; Avanti Polar Lipids) was added, and the suspension was shaken and sonicated twice in an ultrasonicator for 30 to 45 seconds with a 30- 
second interval between sonication cycles to aid in cell lysis. Bottles were shaken vigorously for 15 seconds and vented before incubation overnight in the dark at room temperature. The samples were centrifuged for 30 minutes at $2000 \mathrm{rpm}$ at $4^{\circ} \mathrm{C}$ after incubation and transferred into a $250 \mathrm{ml}$ glass separatory funnel. Our extraction, separation, and analysis were based on traditional lipid extraction procedures.

Chloroform and water were added to the suspension to achieve a ratio of 1:1:0.9, chloroform:methanol:buffer (v/v/v) and the separatory funnels were shaken vigorously for 15 seconds and let to rest overnight to split phase (upper: aqueous phase, lower: organic phase containing the lipids). The organic phase was collected into a $250 \mathrm{~mL}$ round bottom flask and evaporated to near dryness using a rotavap system (Buchi Corporation). The total lipid extract (TLE) was then transferred quantitatively into test tubes by the use of three washes of $2 \mathrm{~mL}$ of chloroform, after which the solvent was evaporated with a $\mathrm{N}_{2}$ blowdown evaporator at $37^{\circ} \mathrm{C}$. The dried TLEs were re-suspended in $2 \mathrm{~mL}$ of chloroform and sequentially fractionated on an activated silicic acid column, $100-200$ mesh powder (dried at $110^{\circ} \mathrm{C}$ for 1 hour; Clarkson Chromatography Products, Inc), into fractions of different polarities using hexane, chloroform, acetone, and methanol (Kates, 1986; Bateman and Jenkins, 1997; Ruiz-Gutiérrez, and Pérez-Camino, 2000). Silicic acid column chromatography uses solvents of increasing polarity (hexane<chloroform $<$ acetone $<$ methanol) to selectively elute the lipid classes from the silicic acid stationary phase. The active sites on the silicic acid (silanols) contain $-\mathrm{OH}$ groups directly bound to the silicon atom which interact with the polar groups of the lipid classes. As the polarity of the solvents increases, the lipid classes are selectively eluted from the silanols, thereby effecting separation. Because the separations are based on polarity, the n-alkanes are eluted from the hexane fraction, the DGFAs, sterols, and respiratory quinones from the chloroform fraction, glycolipids from the acetone 
fraction, and polar lipids (including phospholipids) from the methanol fraction. The PLFAs were recovered from the methanol fraction while the DGFAs were recovered from the chloroform fraction. The chloroform and methanol fractions were evaporated to dryness before trans methylation into fatty acid methyl esters (FAMEs) using methanolic potassium hydroxide for subsequent analysis with the gas chromatography-mass spectrometer (GC-MS; Kieft et al., 1994; White et al., 1979; Guckert et al., 1985; Ringelberg et al., 1997). Because additional lipids like betaine lipids (BLs) are characterized by an ether bond connecting the head group with diacylglycerol (DAG) backbone (Heinzelmann et al., 2014), we do not account for them in the separation. It is also important to understand that ether-linked polar lipids may be recovered in the methanol fraction, however, the extraction is not vigorous enough to sufficiently recover Archaeal lipids (Huguet et al., 2010). More so, ether lipids do not undergo methylation. Lipid extraction, silicic acid column separation, and methylation are generally performed at room temperature (not to exceed $37^{\circ} \mathrm{C}$ ) followed by storing the samples in the freeze after each procedure (White and Ringelberg 1998; Findlay, 2004). Mild alkaline methanolysis cleaves the fatty acids from the phospholipid glycerol backbone and replaces the glycerol bonds with methyl groups, creating FAMEs (White and Ringelberg 1998). Reagents for this procedure include chloroform, toluene, hexane, methanol, acids, and bases. The lipid extracts were redissolved in $1 \mathrm{~mL}$ toluene: methanol $(1: 1, \mathrm{v}: \mathrm{v})$ and $1 \mathrm{~mL} 0.2 \mathrm{M}$ methanolic $\mathrm{KOH}$ and the mixture vortexed for 5 minutes at temperatures no greater than $37^{\circ} \mathrm{C}$. After the samples cooled to room temperature, $2 \mathrm{~mL}$ of hexane:chloroform $(4: 1 \mathrm{v} ; \mathrm{v})$ was added and the sample vortexed prior to being neutralized $(\mathrm{pH}$ 6-7) with approximately $200 \mu \mathrm{L}$ of $1 \mathrm{~N}$ acetic acid. After neutralization, $2 \mathrm{~mL}$ of nanopure distilled water was then added to break phase and the samples vortexed for at least 30 seconds. The phases (upper: organic containing the FAME, lower: aqueous) were separated by centrifugation (5 minutes, 
approximately $2000 \mathrm{rpm}$ ). The upper phase was transferred to a clean test tube and the lower phase re-extracted with $2 \mathrm{~mL}$ of hexane, centrifuged, and transferred as above, two more times. The solvent was then removed with the nitrogen gas blow-down and the FAMEs extracts stored in the freezer until separation and quantification.

\subsubsection{GC-MS Analysis, Quantification, and Lipid Identification}

The lipid samples were then dissolved in $200 \mu \mathrm{L}$ of hexane containing $50 \mathrm{pmol} / \mathrm{uL}$ of external injection standard (docosanoic acid methyl ester; Matreya, Inc) and transferred into GCMS vials containing $500 \mu \mathrm{L}$ glass inserts. The external standard was used to quantify the concentration of individual fatty acids in each profile. Aliquots of samples were then injected into an Agilent 6890 series gas chromatograph interfaced to an Agilent 5973 mass selective detector (MS) equipped with a non-polar cross-linked methyl silicone column (Restek RTX-1 column 60m, $0.25 \mathrm{~mm}$ I.D. $\times 0.25 \mu \mathrm{m}$ film thickness) to be further separated, identified, and quantified. The GC operating conditions were as follows: $60^{\circ} \mathrm{C}$ for 2 minutes then increased at a rate of $10^{\circ} \mathrm{C} /$ minute to $150^{\circ} \mathrm{C}$ and followed by a second ramp at $3^{\circ} \mathrm{C} /$ minute to $312^{\circ} \mathrm{C}$ for a total run time of 65 minutes (White and Ringelberg, 1998). The injector temperature was $230^{\circ} \mathrm{C}$; the detector temperature was $300^{\circ} \mathrm{C}$, and Helium was the carrier gas. The following methyl ester standards (Matreya LLC, State College, Pennsylvania, USA) were included in each sample run to calibrate retention times and assist with peak identification: Bacterial Acid Methyl Ester CP Mixture (BacFAME [1114]), Polyunsaturated FAME Mixture 2 (PUFA-2 [1081]), and Polyunsaturated FAME Mixture 3 (PUFA-3 [1177]). An internal standard curve (1 pmol, 5 pmol, 10 pmol, 20 pmol, 30 pmol, $40 \mathrm{pmol}$, and $50 \mathrm{pmol} / \mu \mathrm{L}$ ) was prepared and analyzed on the GC-MS to determine the detection limit and to establish the best sample dilution range. The standard curve and the regression analysis had a linear relationship (0.99). The external standard curve of 1 pmol standard 
peak represented a detection limit of $0.18 \mathrm{ng}$. Multiple replicates of core samples would be ideal for estimating uncertainty in PLFA or DGFA yield, however, we were restricted in the amount of uncontaminated core available. Because we expected low concentrations of lipids to be present (Wilkins et al., 2014), we prioritized detecting a diverse array of lipids by maintaining the standard protocol for lipid extraction input mass instead of opting for extracting less starting material with multiple replicates. Indeed, further studies would benefit by increased starting core material and additional replicates. Although ionization efficiency can vary between FAMEs, we assume equimolar ionization response for standard FAMEs as described in previous studies (Dobbs and Guckert, 1988; Reichardt et al., 1997; White and Ringelberg, 1998). Nevertheless, we calculated an average standard deviation based on the BacFAME methyl ester standard (Matreya, Inc.) analyzed in duplicates at the time of sample analysis. The standard contains 26 FAMEs ranging from 11-20 carbons in length and has representative saturates, terminally branched saturates, monounsatruates (including cyclopropyl FAMEs), and polyunsaturates. We examined the results for differences in MS detection of the FAMEs in the Bac FAME standard which showed similar peak area detection across the FAMEs. The average standard deviation by GC-MS analysis was $0.07 \%$, which implies that variance in GC-MS had a minimal influence on the variability of the DGFA results.

In some lipid samples, the external standard peak co-eluted with phthalate isomers and was corrected before the lipid concentration was calculated as described in Akondi et al. (2017). Identified peaks were confirmed across all samples and validated independently via GC-MS spectra using the Agilent MSD ChemStation Data Analysis Software F.01.00 along with the NIST11 compound library. Lipid identities were as described in Ringelberg et al. (1988). A singleion monitoring program was also used to scan the base peaks for lipids to validate all identified 
peaks. The SIM program was based on $\mathrm{m} / \mathrm{z}(43,55,74$, and 87$)$ common among FAMEs ions. Once peaks were identified, the PLFAs and DGFAs were quantified by integration of the TIC peak areas. This was done by calculating the area of the corresponding peaks in the chromatograms and quantifying them with respect to the peak area and known concentration of the external standard (C22:0). The following calculation was used to obtain the molar or weight amounts per sample and normalized to per gram by using appropriate dilution factors and mass measurements as shown below.

$\mathrm{C}_{\mathrm{x}}=\left(\mathrm{A}_{\mathrm{x}} / \mathrm{A}_{\mathrm{ISTD}}\right) * \mathrm{C}_{\mathrm{ISTD}} * \mathrm{D}$ where:

$\mathrm{C}_{\mathrm{X}}$ is the calculated concentration of compound $\mathrm{X}$ (moles or weight per unit volume), $\mathrm{A}_{\mathrm{x}}$ is the GC area of compound $\mathrm{X}$ (unitless),

AISTD is the GC area of the external injected standard

$\mathrm{c}_{\text {ISTD }}$ is the concentration of the external injection standard, and

$\mathrm{D}$ is the appropriate dilution factor

\subsubsection{Statistical Analyses}

Non-metric multidimensional scaling (NMDS) analysis was used to evaluate variations in the lipid profiles between the formations and the drilling mud samples. NMDS analysis was performed in the R statistical software version 3.2.4 using the 'stats' (version 2.15.3) and 'vegan' (version 2.3-5) packages (Oksanen et al., 2016). Bray-Curtis distances were calculated from absolute lipid (DGFA) concentrations (pmol) and the resulting distance matrices were used in the NMDS. A dendrogram was designed from the Bray-Curtis distances and used to sort samples for heat map analysis. Differences in drilling muds, core washes, and core samples were analyzed using one-way Analysis of Variance (ANOVA) tests. 


\subsection{Results}

Individual DGFA concentrations in $\mathrm{pmol} / \mathrm{g}$ and relative abundance in mol\%, as well as functional group lipid biomarkers, are shown in Tables 1 and 2. Samples from the Mahantango (258 pmol/g) had a higher total concentration of DGFA than the Marcellus Shale Top (162 pmol/g) and Upper Marcellus Shale (183 pmol/g) zones (Figure 2).

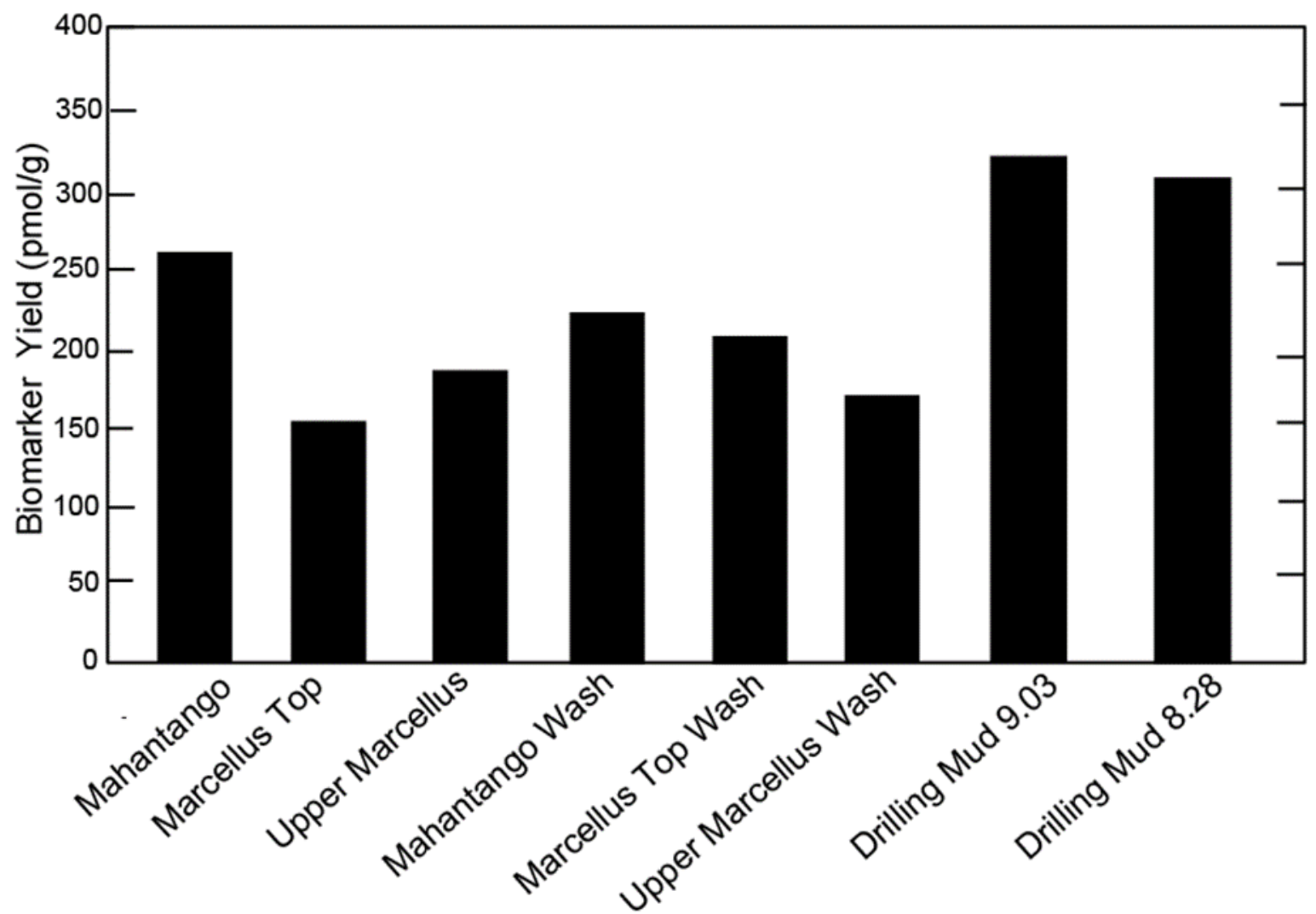

Figure 2. DGFA yields (detection limit $<0.18 \mathrm{ng}$ ) in the Mahantango, Marcellus Shale Top, Upper Marcellus Shale, Mahantango Wash, Marcellus Top Wash, Upper Marcellus Wash, Drilling Mud 9-03 (2015) and Drilling Mud 8-28 (2015) samples.

In the drilling mud samples, total DGFA concentrations ranged from $305 \mathrm{pmol} / \mathrm{g}$ to 318 $\mathrm{pmol} / \mathrm{g}$. Overall, the drilling mud samples had significantly higher $(\mathrm{p}=0.01)$ lipid biomarker concentrations compared to the core samples. The DGFA concentration ranged from $222 \mathrm{pmol} / \mathrm{g}$, $210 \mathrm{pmol} / \mathrm{g}$ and $157 \mathrm{pmol} / \mathrm{g}$ for the Mahantango Wash, Marcellus Top Wash, and Upper Marcellus 
Shale Wash respectively (Figure 2). Even though the biomarker yield in drilling mud samples was higher, the biomarker profiles detected in the cores and drilling muds were compositionally different (Figure 3), suggesting that individual lipid profiles associated with the cores were derived from the subsurface and not from the drilling muds. We used procedural blanks in each extraction treatment to monitor laboratory contamination. With the exception of the internal and external standard peaks, the blanks did not have any fatty acid peaks (detection limit $<0.18 \mathrm{ng}$ ), indicating that no fatty acids were introduced during the extraction process. In addition, the absence of fluorescent beads on decontaminated cores was another indication that there was minimal influence of drilling mud contaminants in these samples.

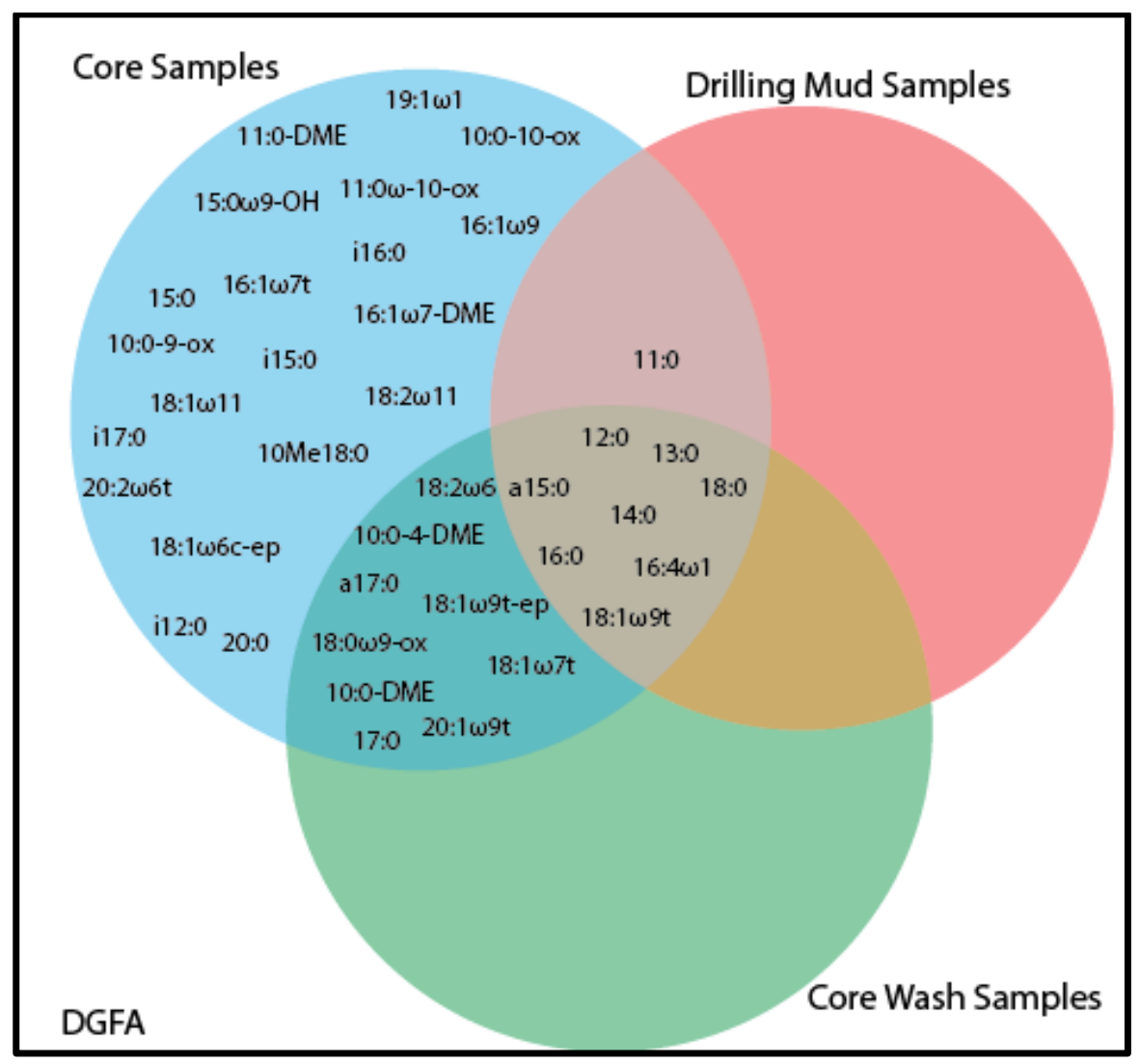

Figure 3. Venn diagram illustrating the distribution of the individual lipid biomarkers for the DGFA within the core samples, core washes, and drilling mud samples. The figure shows the lipid fatty acids detected only in the cores, and those shared across the drilling muds and core samples. 


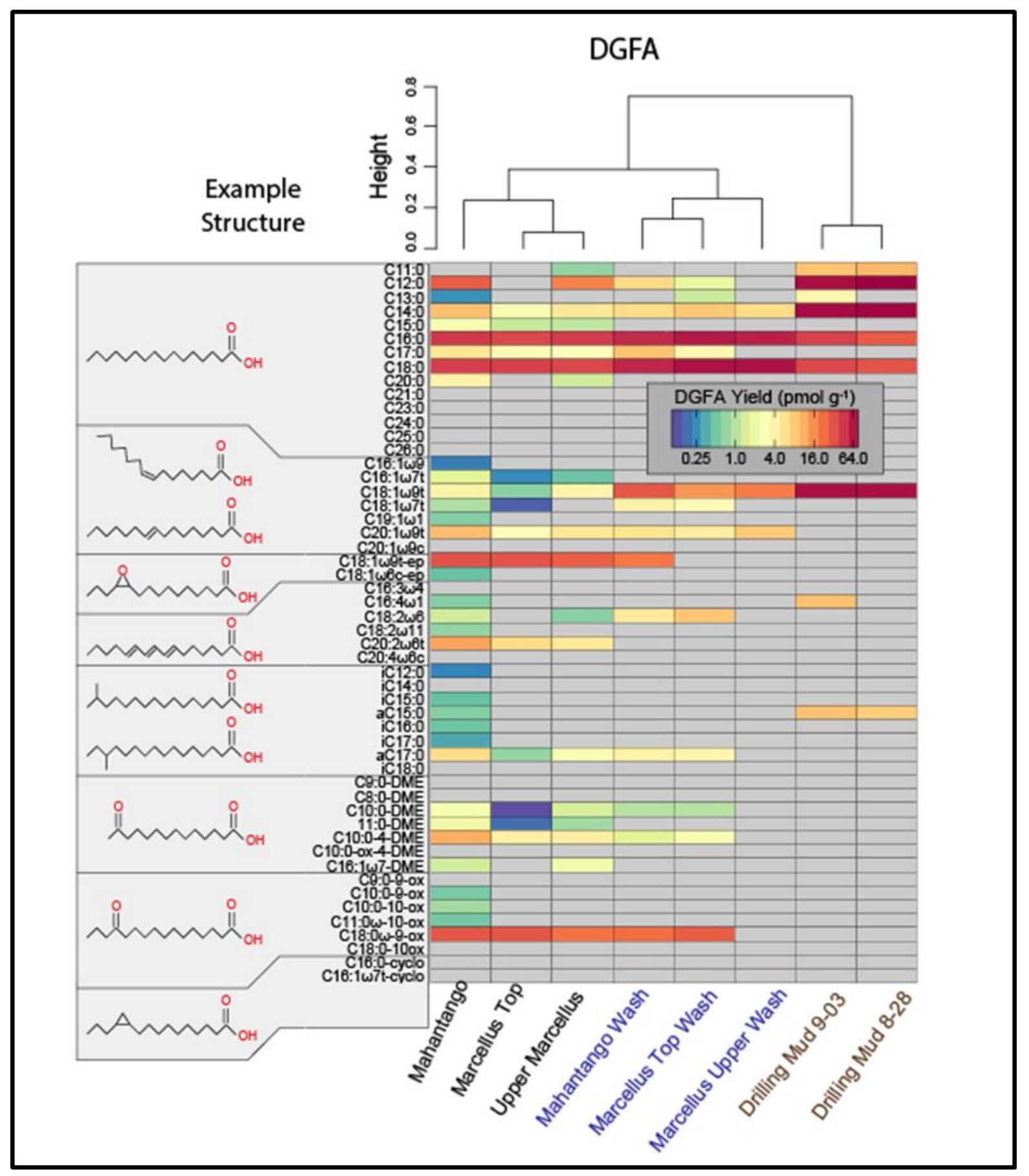

Figure 4. Dendrogram and heat map distribution of individual DGFA biomarkers in the Mahantango, Marcellus Shale Top, Upper Marcellus Shale, Mahantango Wash, Marcellus Top wash, Upper Marcellus Wash, Drilling Mud 8-28 (2015), and Drilling Mud 9-03 (2015) samples together with common lipid structures. Samples are sorted based on dendrogram groupings calculated from Bray-Curtis dissimilarities. 


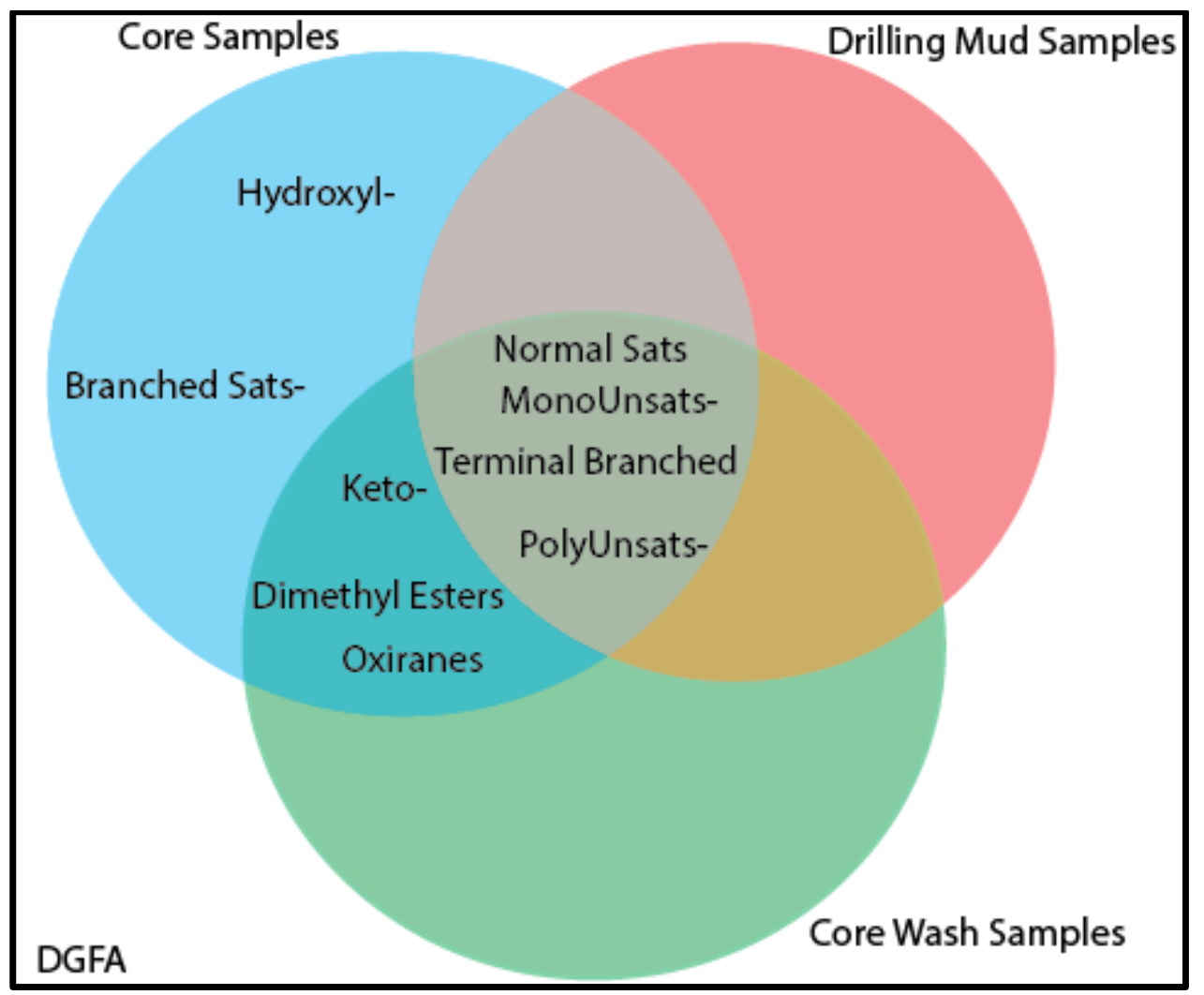

Figure 5. Venn diagram illustrating the distribution of the functional group lipid biomarkers for the DGFA within the core samples, core washes, and drilling mud samples. The figure shows the lipid fatty acids detected only in the cores, and those shared across the drilling muds and core samples.

Of the 38 DGFAs detected in the dataset, 29 (76.31\%) were detected solely in the core samples and $9(23.68 \%)$ were shared across all samples (Figures 3, 4). DGFA profiles like keto-, oxiranes, hydroxyl, branched saturates, and dimethyl lipid fatty acids were present only in the core samples while lipid biomarkers such as normal saturates, monounsaturates, terminally branched, and polyunsaturates were shared across all the samples (Figure 5, 6). The individual DGFA biomarkers of the functional groups were not shared across all the samples (Figure 3) and the profiles of core wash samples were considerably more similar to the cores than the drilling muds (Figure 4). The high abundance lipid fatty acids ( $>10 \%$ relative abundance) such as normal saturates and monounsauturates were only consistent within the drilling mud samples while other 
high abundance lipid fatty acids like the keto- and oxiranes were solely present in the core samples (Figure 5).

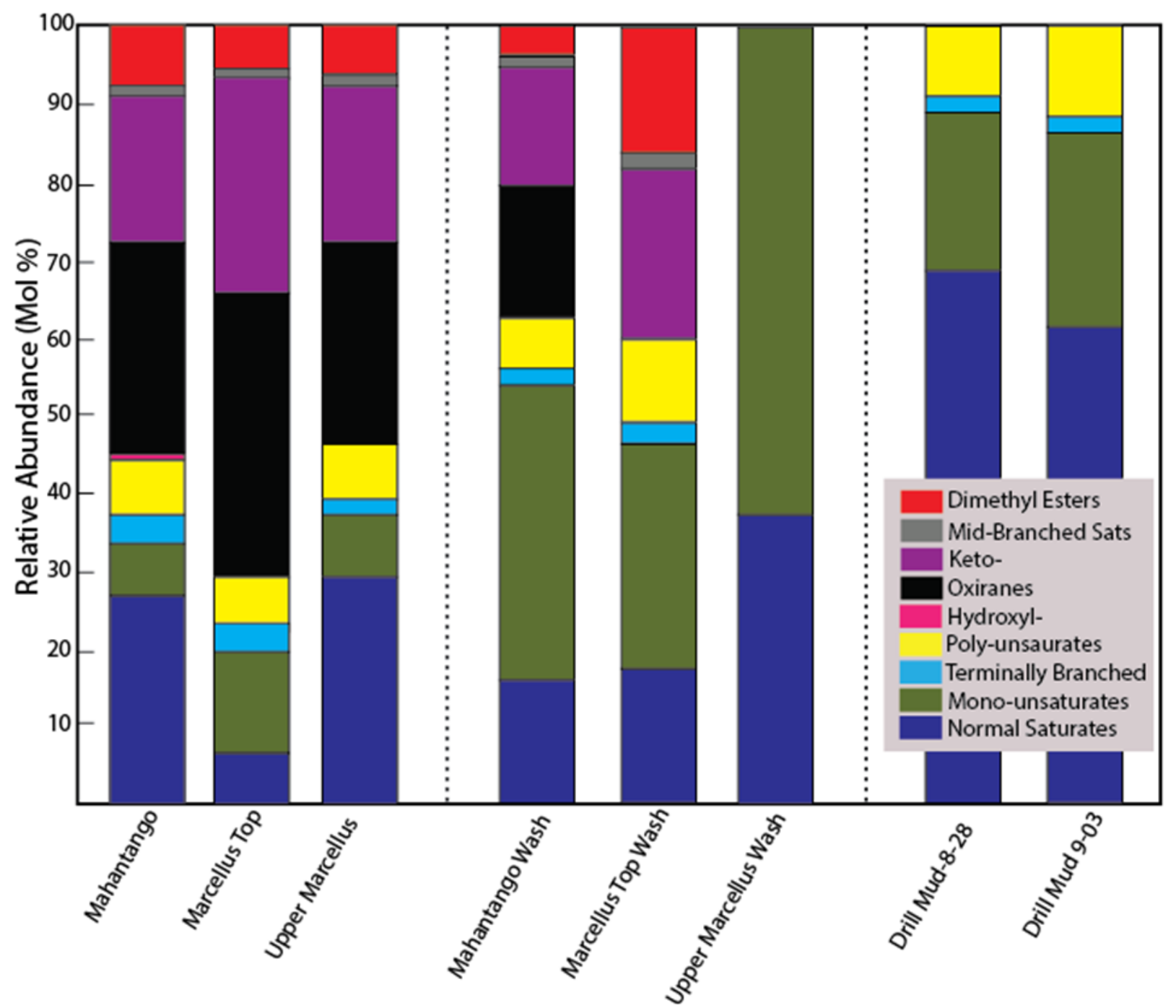

Figure 6. Relative abundance and distribution of and DGFA biomarker functional groups for the Mahantango, Marcellus Shale Top, Upper Marcellus Shale zones, Mahantango Wash, Marcellus Top Wash, Upper Marcellus Wash, Drilling Mud 8-28 (2015) and Drill Mud 9-03 (2015) samples.

As can be seen in figure 7, the distribution of the functional group lipid profiles was also different in the cores and drilling mud samples. The NMDS analysis showed differences in the distribution of DGFA functional group patterns across two dimensions (Figure 7). The 
polyunsaturated and monounsaturated DGFAs were significantly correlated to drilling muds while core samples were predominantly driven by oxiranes, keto-, and terminally branched DGFAs (Figure 7). We also estimated variations in ratios of signature lipid biomarkers like the Gram (+): Gram (-) and the saturated:monounsaturated lipid fatty acids between the cores and drilling muds. The ratio of Gram (+): Gram (-) lipid biomarkers were higher in the core samples relative to the drilling mud samples (Figure 8). The core samples also showed higher saturated:monounsaturated ratios compared to the drilling mud samples (Figure 8).

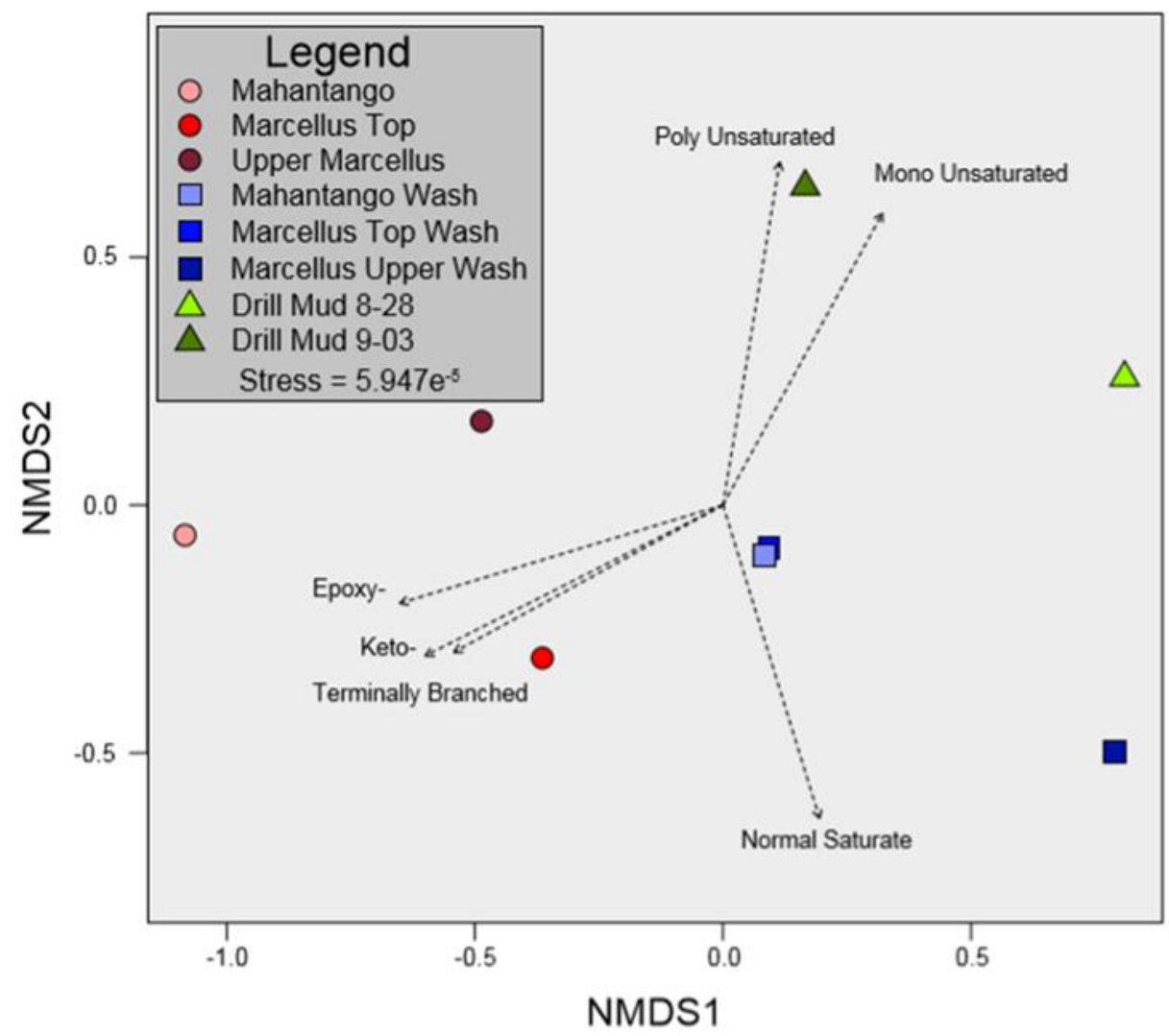

Figure 7. Nonmetric multidimensional scaling (NMDS) plot showing DGFA functional groups of core samples (circles), drilling muds (triangles), and core washes (squares). NMDS is performed based on Bray-Curtis dissimilarities of the DGFA relative abundances. The vectors which correspond to DGFA classes and significantly correlate $(\mathrm{p}<0.05)$ with the samples were plotted from the origin. 

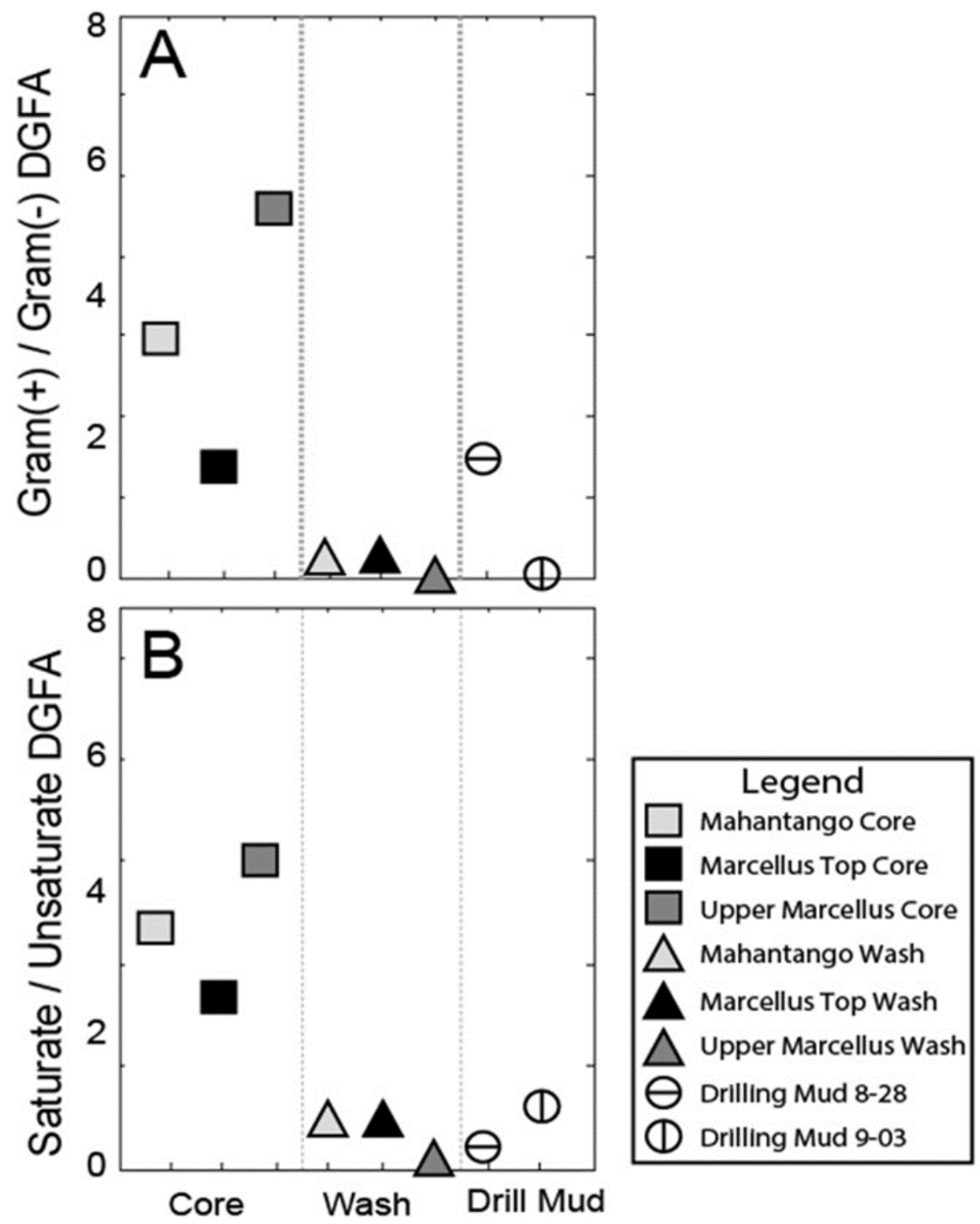

Figure 8. Biomass yields showing ratio of $\operatorname{Gram}(+) / \operatorname{Gram}(-)$ lipid biomarkers and ratio of saturated/unsaturated lipid biomarkers for the PLFA (A and C), DGFA (B and D), in the Mahantango, Marcellus Shale Top, Upper Marcellus Shale, Mahantango Wash, Marcellus Top wash, Upper Marcellus Wash, Drilling Mud 8-28 (2015), and Drilling Mud 9-03 (2015) samples. 


\subsection{Discussion}

\subsubsection{Lipid Biomarkers Recovered in Drilling Muds and Core Samples}

In accordance with appropriate sampling protocols (Phelps et al., 1989; Colwell et al., 1992; Lehman et al., 1995; Wilkins et al., 2014), and to rule out any microbial contamination during sample collection and processing, we compared the yield and diversity of lipids (estimated as the number of individual lipids in each sample) detected in the cores to the drilling muds and core washes. We found considerably higher concentrations of DGFA in the drilling mud samples relative to the cores samples (Figure 2). Despite the high lipid concentration in drilling muds, the diversity of DGFA profiles in the drilling muds and core samples were substantially different (Figures 3, 4, and 5), a strong indication that the biomarkers were probably sourced from indigenous subsurface microbial community. Based on the average standard deviation $(0.07 \%)$ calculated from the BacFAME methyl ester standard, the variance in GC detection had minimal influence on the variability between DGFA results. Our data further revealed that the polyunsaturates which are indicators of microeukaryotes (Baird and White, 1985; Rajendran et al., 1993; Madigan et al., 1997; Olsson, 1999), were prominent in drilling mud samples but were not detected in the core samples (Figures 3,5 ). The absence of polyunsaturates in the core samples highlights the fact that the drilling mud components had limited influence on the integrity of the lipid profiles of the core samples. If the drilling muds were major contributors to the core lipid profiles one would not expect the remarkable differences in the diversity of the profiles between the cores and drilling mud samples. Most of the lipid biomarkers detected in the cores were representatives of Gram (-), Gram (+), as well as stress indicative biomarkers. The iso-, anteiso-, terminally branched, and mid-branched lipid fatty acids have been associated with Gram(+) bacteria (Dowling et al., 1986; Kohring et al., 1994) while the monounsaturates have been 
associated with Gram(-) bacteria (Haack et al., 1994; Pfiffner et al., 2006). The presence of Gram(+) and Gram(-) microbial communities in the drilling muds is consistent with 16S rRNA gene biomarker analysis from Marcellus shale wells (Cluff et al 2014; Daly et al 2016) as well as studies conducted on drill mud samples collected from boreholes in the Barnett Shale (Struchtemeyer et al., 2011). Similar to Struchtemeyer et al. (2011), we suggest that the lipid profiles in the drilling mud samples could potentially represent a mix of drilling mud and native subsurface microbial signatures.

\subsubsection{Lipid Biomarker Distribution and Implications of Subsurface Microbial Life}

Lipid biomarkers have been used as essential proxies to monitor the microbial ecology of natural subsurface environment where most bacterial species are uncultured (Hinrichs et al., 1999; Schubotz et al., 2009; Kellermann et al., 2012; Lincoln et al., 2013). Membrane lipid biomarkers do not, however, possess the taxonomic specificity of other -omic-based techniques like DNA analysis. Instead of using the membrane lipid fatty acids as chemotaxonomic tools, we have used the concentration and diversity of the individual profiles to understand microbial membrane distribution along the different lithologic gradients. The diversity and yield of the lipid profile were higher in the Mahantango zone compared to both Marcellus Shale top and upper Marcellus Shale zones (Figure 2). The organic carbon concentrations in all our core samples exceeded 3.5\% (Figure 1D), and though the lability can vary widely between different shale formations (Schlegel et al., 2011; Wuchter et al., 2013; Buchwalter et al., 2015), this abundant organic matter may have served as carbon substrate for deposited microorganisms and influenced microbial dynamics before and during diagenesis. The permeability of the Mahantango Formation estimated to be 6 millidarcy (mD), higher than the $2.5 \mathrm{mD}$ in Marcellus Shale Top and the Upper Marcellus Shale (Paronish, 2017), could also have influenced microbial presence and activity. Previous microbial 
and geochemical investigations in shale/sand interfaces have also demonstrated higher subsurface microbial activity and biomass in the shale/sand contact (McMahon and Chapelle, 1991), fractured zones (Colwell et al., 1997), organic-filled matrix voids (Buchwalter et al., 2015; Mouser et al., 2016) and zones of higher permeability (McMahon and Chapelle, 1991; Murphy et al., 1992; Fredrickson et al., 1997) due to increased nutrient diffusion across interfaces.

The DGFA concentration, however, did not coincide with high organic matter content because the Mahantango formation had less organic matter content compared to the Marcellus Shale formations (Figure 1). Interestingly, PLFA analysis from these same cores showed higher concentrations of biomarkers in the Marcellus Top (Trexler, 2017, Master's Thesis, The Ohio State University). We did not expect a similar distribution for DGFA biomarkers as other factors like diagenesis, redox conditions, salinity could affect the distribution of the DGFA (by affecting the rate of cell death or rate of PLFA to DGFA conversion; Fredrickson et al., 1997; Ringelberg et al., 1997; Onstott et al., 1998; Schlegel et al., 2011; Wuchter et al., 2013; Buchwalter et al., 2015; Mouser et al., 2016). PLFA and DGFA therefore represent different microbial communities with DGFAs being more stable and less polar as compared with PLFAs (Kieft et al., 1994; Haldeman et al., 1995; White and Ringelberg, 1998; Fredrickson et al., 1997; Ringelberg et al., 1997; Pfiffner et al., 2006). Although PLFAs are generally known to be fragile, the rate of PLFA to DGFA conversion in subsurface shales has not been characterized. Onstott et al. (1998), argued that severe water-limited environments could impede dephosphorylation of PLFA, raising uncertainties about PLFA hydrolysis in such geological settings. Because PLFA dephosphorylation requires water, the rate of PLFA to DGFA conversion in deep shale may be considerably lower than shallow terrestrial systems with a higher degree of saturation. Furthermore, under conditions of low permeability and limited nutrient supply, microbes are known to adopt various states of dormancy 
which can leave the lipid signature from subsurface microbial communities unchanged for several million years (Phelps et al., 1994; Fredrickson et al., 1995b; 1997; Machel and Foght, 2000; Javadpour F. 2009; Sondergeld et al., 2010).

Long-term preservation of DGFAs may also derive from their interactions with the shale (Salmon et al. 2000; Stroes-Gascoyne et al. 2005; Mauclaire et al. 2007). Black shales are made up of complex organic matter matrices and clay mineralogy, capable of interacting with lipid fatty acids (Rapuano and Carmona-Ribeiro, 2000; Sahai, 2002; Wiegart et al., 2005; Wicklein et al., 2010; Shaw and Weaver, 1965), thereby hindering microbial and chemical degradation (Franchi et al. 2003, Gallori et al. 1994, Garet and Moriarty 1996). In addition to preservation, higher DGFA concentrations in subsurface samples could also be related to biological inactivity, long-term sequestration, or nutrient deprivation associated with the deep subsurface (Stroes-Gascoyne et al. 2005; 2007; Kieft et al., 1997), although this study did not directly assess these environmental conditions.

\subsubsection{Lipid Biomarkers as Indicators of Environmental Conditions}

Microbes are able to adjust their cell membranes to adapt for survival under stressful conditions or environmental disturbance associated with natural environments (Hazel and Williams, 1990; Hedrick et al., 1991; White et al., 1991; Amy and Morita., 1983; Amy et al., 1993; Kieft et al., 1994; Stoeck and Kronke, 2001). For instance, microbes are known to synthesize the more stable trans-monoenoic fatty acids, alter the cis-fatty acids to their cyclopropyl derivatives or increase levels of unsaturation during starvation (Guckert et al., 1985, 1986, 1987; Nichols et al., 1986, Rajendran et al., 1992; Kieft et al., 1994). The trans-configured monounsaturates in the core samples (Figures 3,4) suggest environmentally stressful conditions such as physiological 
stress or nutrient deprivation (Kieft et al., 1994; Stoeck and Kronke, 2001). When compared with the PLFA results, the trans-membrane lipid fatty acids in the cores had the highest concentration and diversity for the DGFA profiles (Figures 3, 4, and 5). A possible explanation for the relatively higher concentration and diversity of the trans-lipid biomarkers in the DGFA than the PLFA profiles can be attributed to the fact that the DGFA biomarkers represent non-living microbial signatures, and as such could have experienced more stressful environmental conditions compared to the PLFA biomarkers which represent relatively recent microbial communities. An alternative explanation is that the microbial community responded to environmental stress through cell death resulting in a higher concentration of DGFA stress biomarkers and modifications to cellular membranes.

The DGFA profiles of the core samples also contained the oxiranes, keto-, and dimethyl lipid fatty acids which were not present in the drilling mud samples (Figures 3, 4, and 5). The NMDS analyses (Figure 7), further illustrates the functional group differences between the core samples and drill mud samples. The presence of oxiranes has been associated with both salt stress and nutrient limitation (Smith et al., 2000; Lin et al., 2006). Oxiranes are produced from the oxidation of unsaturated fatty acids under stress in the presence of radical oxygen species (ROS) or from lipid monooxygenases (Smith et al., 2000). The presence of oxiranes have previously been reported in a deep subsurface gold mine in Witwatersrand Basin in South Africa (Onstott et al., 2003; Pfiffner et al., 2006). Notably, both the Witwatersrand Basin and the Marcellus Formation are chemically reducing environments with little or no molecular oxygen necessary for the monooxygenase mechanism. However, Pfiffner et al. (2006), suggested that the decay of naturally occurring radioactive material (NORM) could generate ROS needed for the formation of oxiranes. The high NORM levels in the Marcellus Shale samples (Figure 1D; Hill et al., 2004; EPA, 2008; 
Kargbo et al., 2010) support the possibility of a similar mechanism for the generation of oxiranes. Lin et al. (2006), also argued that microbes in deep subsurface systems could utilize nonradioactive $\mathrm{H}_{2}$ generated by the radiolysis of water to sustain microbial activities. Like the oxiranes, keto-lipids can also be formed by free radicals and ROS (Barbosa et al., 2016). Their occurrence in the core samples could, therefore, be indicative of microbial response to stress and their mechanism of formation can be explained in a similar mechanism as the oxiranes. Similar to the trans-configured lipid fatty acids, the concentration and diversity of oxiranes and keto-lipids were higher in the DGFA biomarkers, further supporting the notion that the dead microbial community represented by the DGFAs experienced relatively more stressful environmental conditions compared to the recent microbial community represented by the PLFA.

Dimethyl lipid features in microbial membranes of thermophiles (Carballeira et al., 1997; Jung et al., 1994) and acidophiles (Damste et al., 2011) have also been reported. Given the current projected Marcellus Formation temperature of $\sim 70^{\circ} \mathrm{C}$ (Carr et al., 2016), microbes must adapt to survive such extreme conditions. It is suggested that dimethyl lipid fatty acids can covalently link polar membrane glycerol groups (Clarke et al., 1980), spanning across cell membranes (Jung et al., 1994) thereby reducing membrane permeability and enhancing membrane resistance to heat and acid. Additionally, membrane lipid fatty acids can incorporate an additional methyl group into their structures to congest the hydrophobic region of their bilayers (membrane bulking), thereby limiting ion leakage across the membrane under heat stress, which in turn conserves energy (Haines, 2001, Valentine et al. 2007 ; Sollich et al., 2017). The rationale is that by reducing the permeability, the microbes are able to restrain the diffusion of ions thus conserving energy under elevated temperatures (van de Vossenberg et al., 1995 Poger et al., 2014). These observations in 
combination with our results suggest that the dimethyl lipid fatty acids in core samples may be related to physiological adaptation to increasing temperatures, acidity, and perhaps salinity.

The higher ratio of Gram (+) to Gram (-) biomarkers in the core samples compared to the drilling mud samples (Figure 8A, B), could also be related to the stressful environmental conditions. Gram (+) bacteria have thicker peptidoglycan layer in their cell wall which could aid survival under environmental stress and pressure (Holtje, 1998; Delcour et al., 1999). Many sporeforming bacteria are Gram (+) and are known for their extraordinary ability to persist and survive environmental stresses such as heat, UV radiation, gamma radiation, lack of nutrients, and desiccation. As a result, the high abundance of Gram (+) lipid biomarkers in our samples may be attributed to membrane adaptation to environmental stress. Other physiological adaptations to persist under extreme environmental conditions include the ability for microbes to decrease unsaturation levels in response to elevated temperatures and lack of nutrients (Guckert et al., 1985; Reizer et al., 1985; Gennis, R.B, 1989; Russell et al., 1989; Ringelberg et al., 1997; Valentine and Valentine, 2004; Sollich et al., 2017). In addition, there is experimental evidence suggesting that the ratio of saturated:unsaturated lipid fatty acids increase with increasing levels of nutrient deprivation in bacteria (Kieft et al., 1994). By increasing levels of saturation, the lipid membranes are rendered less mobile and less fluidized, thereby hindering unnecessary ion cycling, and thus conserving energy (Valentine and Valentine, 2004). It is, therefore, possible that the relatively high ratios of saturated: unsaturated lipid biomarkers in our samples (Figure 7C, D), is related to physiological adaptations for limited energy and/or nutrient resources.

\subsection{Summary}


Irrespective of whether microbial lipid signatures in our samples represent dead, dormant, or active microbial communities, any given microbial cell (ancient or modern) must adjust its cell membranes to the in situ subsurface conditions. Even though studies have suggested that DGFA biomarkers in the deep subsurface shale cores could be associated with sediments at the time of deposition and early diagenesis (Lehman et al., 1995; Colwell et al., 1997; Fredrickson et al., 1997; Onstott et al., 1998), we are unable to say with certainty if the lipid profiles in these cores were associated with the sediments during deposition or were re-colonized. These indications of indigenous microbial life in deep shale like the Marcellus Shale accords enormous opportunities for the improvement of biocides in the shale energy industry, understanding subsurface microbial colonization, and engineering efforts for enhanced gas recovery.

\subsection{Acknowledgements}

Samples for this research were provided by the Marcellus Shale Energy and Environment Laboratory (MSEEL) funded by the Department of Energy's National Energy Technology Laboratory (DOE-NETL) grant DE\# FE0024297. This research was also supported by the NSF grants to SS (NSF EAR \# 1205596; NSF-DEB \# 1342732) and PJM (NSFDEB\#1342701/1830742). We thank the participating teams from the WVU and the OSU for assistance with sample collection and preparation for analysis. Laboratory assistance from Dr. Warrier, other members of WVU isotope laboratory and members of the OSU Microbiology research team is greatly appreciated. Mr. Venter in the Department of Forensic and Investigative Sciences at WVU is also acknowledged for providing assistance with the GC/MS during methods development for this work. 


\subsection{References}

Akondi, R. N., Trexler, R. V., Pfiffner, S. M., Mouser, P. J., Sharma, S. (2017). Modified lipid extraction methods for deep subsurface shale. Frontiers in Microbiology, 8, 2141.

Amy, P. S., Morita, R. Y. (1983). Starvation-survival patterns of sixteen freshly isolated openocean bacteria. Applied and Environmental Microbiology, 45(3), 1109-1115.

Amy, P. S., Durham, C., Hall, D., Haldeman, D. L., 1993. Starvation-survival of deep subsurface isolates. Current Microbiology, 26(6), 345-352.

Arthur, M. A., Sageman, B. B. (2005). Sea-level control on source-rock development: perspectives from the Holocene Black Sea, the mid-Cretaceous Western Interior Basin of North America, and the Late Devonian Appalachian Basin.

Baird, B. H., Nivens, D. E., Parker, J. H., White, D. C., 1985. The biomass, community structure, and spatial distribution of the sedimentary microbiota from a high-energy area of the deep sea. Deep Sea Research Part A. Oceanographic Research Papers, 32(9), 1089-1099.

Barbosa, M., Valentão, P., Andrade, P. B. (2016). Biologically active oxylipins from enzymatic and nonenzymatic routes in macroalgae. Marine drugs, 14(1), 23.

Bateman, H. G., \& Jenkins, T. C. (1997). Method for extraction and separation by solid phase extraction of neutral lipid, free fatty acids, and polar lipid from mixed microbial cultures. Journal of agricultural and food chemistry, 45(1), 132-134.

Bastin, E. S., Greer, F. E., Merritt, C. A., Moulton, G., 1926. The presence of sulphate reducing bacteria in oil field waters. Science (New York, NY), 63(1618), 21-24.

Beeman, R. E., Suflita, J. M. (1989). Evaluation of deep subsurface sampling procedures using serendipitous microbial contaminants as tracer organisms. Geomicrobiology Journal, 7(4), 223-233.

Biddle, J. F., House, C. H., \& Brenchley, J. E. (2005). Microbial stratification in deeply buried marine sediment reflects changes in sulfate/methane profiles. Geobiology, 3(4), 287-295.

Biddle, J. F., Lipp, J. S., Lever, M. A., Lloyd, K. G., Sørensen, K. B., Anderson, R., ... \& Sogin, M. L. (2006). Heterotrophic Archaea dominate sedimentary subsurface ecosystems off Peru. Proceedings of the National Academy of Sciences of the United States of America, 103(10), 3846-3851.

Bjornstad, B. N., Gullett, C. D., Long, P. E. (1997). Geohydrologic and Geochemical Characterization. Microbiology of the Terrestrial Deep Subsurface, 4, 7.

Bligh, E.G., and Dyer, W.J. (1959). A sapid method of total lipid extraction and purification. Canadian Journal of Biochemistry and Physiology 37, 911-917.

Bobbie, R. J., White, D. C., 1980. Characterization of benthic microbial community structure by high-resolution gas chromatography of fatty acid methyl esters. Applied and Environmental Microbiology, 39(6), 1212-1222.

Boles, J.R., and Franks, S.G. (1979). Clay diagenesis in wilcox sandstones of southwest Texas Implications of smectite diagenesis on sandstone cementation. Journal of Sedimentary Petrology 49, 55-70.

Boyce, M. L., Yanni, A. E., \& Carr, T. R. (2010). Depositional control of organic content in the Middle Devonian Marcellus interval of West Virginia and Western Pennsylvania. In AAPG Hedberg Research Conference, Austin, Texas, USA (pp. 5-10).

Brassell, S. C., Eglinton, G. (1986). Molecular geochemical indicators in sediments.

Brassell, S. C. (1993). Applications of biomarkers for delineating marine paleoclimatic fluctuations during the Pleistocene. In Organic Geochemistry (pp. 699-738). Springer US. 
Brockman, F. J., Kieft, T. L., Fredrickson, J. K., Bjornstad, B. N., Shu-mei, W. L., Spangenburg, W., Long, P. E. (1992). Microbiology of vadose zone paleosols in south-central Washington state. Microbial ecology, 23(3), 279-301.

Buchwalter, E., Swift, A., Sheets, J., Cole1, D., Prisk, T., Anovitz, L., Ilavsky, J., Rivers, M., Welch, S., and Chipera, S. (2015). "Mapping of Microbial Habitats in Organic-Rich Shale", in: Unconventional Resources Technology Conference. (San Antonio, TX: American Association of Petroleum Geologists).

Carballeira, N.M., Reyes, M., Sostre, A., Huang, H., Verhagen, M.F., and Adams, M.W. (1997). Unusual fatty acid compositions of the hyperthermophilic archaeon Pyrococcus furiosus and the bacterium Thermotoga maritima. J Bacteriol 179, 2766-2768.

Carr, T. R., Wilson, T. H., Kavousi, P., Amini, S., Sharma, S., Hewitt, J., ... \& MacPhail, K. (2017, September). Insights from the Marcellus Shale Energy and Environment Laboratory (MSEEL). In Unconventional Resources Technology Conference, Austin, Texas, 24-26 July 2017 (pp. 1130-1142). Society of Exploration Geophysicists, American Association of Petroleum Geologists, Society of Petroleum Engineers.

Chen, R., Sharma, S., Bank, T., Soeder, D., \& Eastman, H. (2015). Comparison of isotopic and geochemical characteristics of sediments from a gas-and liquids-prone wells in Marcellus shale from Appalachian Basin, West Virginia. Applied Geochemistry, 60, 59-71.

Chen, R., \& Sharma, S. (2016). Role of alternating redox conditions in the formation of organicrich interval in the Middle Devonian Marcellus Shale, Appalachian Basin, USA. Palaeogeography, Palaeoclimatology, Palaeoecology, 446, 85-97.

Chermak, J. A., and Schreiber, M. E. (2014). Mineralogy and trace element geochemistry of gas shales in the United States: environmental implications. Int. J. Coal Geol. 126, 32-44. doi: 10.1016/j.coal.2013.12.005

Clarke, N.G., Hazlewood, G.P., and Dawson, R.M. (1980). Structure of diabolic acidcontaining phospholipids isolated from Butyrivibrio sp. Biochem J 191, 561-569.

Cluff, M. A., Hartsock, A., MacRae, J. D., Carter, K., Mouser, P. J. (2014). Temporal changes in microbial ecology and geochemistry in produced water from hydraulically fractured Marcellus Shale gas wells. Environmental science \& technology, 48(11), 6508-6517.

Colwell, F., Stormberg, G., Phelps, T., Birnbaum, S., McKinley, J., Rawson, S., Veverka, C., Goodwin, S., Long, P., Russell, B., Garland, T., Thompson, D., Skinner, P. and Grover, S., 1992. Innovative techniques for collection of saturated and unsaturated subsurface basalts and sediments for microbiological characterization. J. Microbiol. Methods 15, 279-292.

Colwell, F.S., Onstott, T.C., Delwiche, M.E., Chandler, D., Fredrickson, J.K., Yao, Q.J., McKinley, J.P., Boone, D.R., Griffiths, R., Phelps, T.J., Ringelberg, D., White, D.C., LaFreniere, L., Balkwill, D., Lehman, R.M., Konisky, J., and Long, P.E. (1997). Microorganisms from deep, high temperature sandstones: Constraints on microbial colonization. Fems Microbiology Reviews 20, 425-435. doi: Doi 10.1016/S0168-

Colwell, F. S., D'Hondt, S. (2013). Nature and extent of the deep biosphere. Reviews in Mineralogy and Geochemistry, 75(1), 547-574.

Daly, R. A., Borton, M. A., Wilkins, M. J., Hoyt, D. W., Kountz, D. J., Wolfe, R. A., ... \& Krzycki, J. A. (2016). Microbial metabolisms in a $2.5-\mathrm{km}$-deep ecosystem created by hydraulic fracturing in shales. Nature microbiology, 1, 16146.

Damste, J.S., Rijpstra, W.I., Hopmans, E.C., Weijers, J.W., Foesel, B.U., Overmann, J., and Dedysh, S.N. (2011). 13,16-Dimethyl octacosanedioic acid (iso-diabolic acid), a common 
membrane-spanning lipid of Acidobacteria subdivisions 1 and 3.Appl Environ Microbiol 77, 4147-4154. doi: 10.1128/AEM.00466-11.

D'hondt, S., Jørgensen, B. B., Miller, D. J., Batzke, A., Blake, R., Cragg, B. A., ... Holm, N. G. (2004). Distributions of microbial activities in deep subseafloor sediments. Science, 306(5705), 2216-2221.

Davis, E.N., Wallen, L.L., Goodwin, J.C., Rohwedder, W.K., and Rhodes, R.A. (1969). Microbial hydration of cis-9-alkenoic acids. Lipids 4, 356-362.

Delcour, J., Ferain, T., Deghorain, M., Palumbo, E., and Hols, P. (1999). The biosynthesis and functionality of the cell-wall of lactic acid bacteria. Antonie Van Leeuwenhoek 76, 159184

Denich, T. J., Beaudette, L. A., Lee, H., \& Trevors, J. T. (2003). Effect of selected environmental and physico-chemical factors on bacterial cytoplasmic membranes. Journal of microbiological methods, 52(2), 149-182.

Dennison, J. M., \& Hasson, K. O. (1976). Stratigraphic Cross Section of Hamilton Group (Devonian) and Adjacent Strata along South Border of Pennsylvania: GEOLOGIC NOTES. AAPG Bulletin, 60(2), 278-287.

Dobbs, F., \& Guckert, J. (1988). Microbial food resources of the macrofaunal-deposit feeder Ptychodera bahamensis (Hemichordata: Enteropneusta). Marine Ecology Progress Series,45(1/2), 127-136. Retrieved from http://www.jstor.org/stable/24827701

Dowling, N. J., Widdel, F., White, D. C., 1986. Phospholipid ester-linked fatty acid biomarkers of acetate-oxidizing sulphate-reducers and other sulphide-forming bacteria. Journal of General Microbiology, 132(7), 1815-1825.

Edlund, T., Walker, M. D., Barr, P. J., \& Rutter, W. J. (1985). Cell-specific expression of the rat insulin gene: evidence for role of two distinct 5'flanking elements. Science, 230(4728), 912-916.

Edwards, K. J., Becker, K., \& Colwell, F. (2012). The deep, dark energy biosphere: intraterrestrial life on earth. Annual Review of Earth and Planetary Sciences, 40, 551-568.

Ettensohn, F. R. (1985). The Catskill delta complex and the Acadian orogeny: A model. Geological Society of America Special Papers, 201, 39-50.

Ettensohn, F. R., Zhang, C., Gao, L., \& Lierman, R. T. (2011). Soft-sediment deformation in epicontinental carbonates as evidence of paleoseismicity with evidence for a possible new seismogenic indicator: Accordion folds. Sedimentary Geology, 235(3), 222-233.

Ferrer, I., \& Thurman, E. M. (2015). Analysis of hydraulic fracturing additives by LC/Q-TOFMS. Analytical and bioanalytical chemistry, 407(21), 6417-6428.

Fichtel, K., Logemann, J., Fichtel, J., Rullkötter, J., Cypionka, H., \& Engelen, B. (2015). Temperature and pressure adaptation of a sulfate reducer from the deep subsurface. Frontiers in microbiology, 6, 1078.

Findlay, R. H. (1996). The use of phospholipid fatty acids to determine microbial community structure. In Molecular Microbial Ecology Manual (pp. 77-93). Springer Netherlands.

Fisk, M. R., Giovannoni, S. J., \& Thorseth, I. H. (1998). Alteration of oceanic volcanic glass: textural evidence of microbial activity. Science, 281(5379), 978-980.

Fredrickson, J. K., Garland, T. R., Hicks, R. J., Thomas, J. M., Li, S. W., \& McFadden, K. M. (1989). Lithotrophic and heterotrophic bacteria in deep subsurface sediments and their relation to sediment properties. Geomicrobiology Journal, 7(1-2), 53-66.

Fredrickson, J. K., Balkwill, D. L., Zachara, J. M., Li, S. M. W., Brockman, F. J., \& Simmons, M. A. (1991). Physiological diversity and distributions of heterotrophic bacteria in deep 
cretaceous sediments of the Atlantic coastal plain. Applied and Environmental Microbiology, 57(2), 402-411.

Fredrickson, J. K., Balkwill, D. L., Drake, G. R., Romine, M. F., Ringelberg, D. B., White, D. C. (1995a). Aromatic-degrading Sphingomonas isolates from the deep subsurface. Applied and environmental microbiology, 61(5), 1917-1922.

Fredrickson, J.K., Mckinley, J.P., Nierzwickibauer, S.A., White, D.C., Ringelberg, D.B., Rawson, S.A., Li, S.M., Brockman, F.J., and Bjornstad, B.N. (1995b). Microbial community structure and biogeochemistry of Miocene subsurface sediments - Implications for longterm microbial survival. Molecular Ecology 4, 619-626. doi: Doi 10.1111/J.1365294x.1995.Tb00262.X.

Fredrickson, J.K., McKinley, J.P., Bjornstad, B.N., Long, P.E., Ringelberg, D.B., White, D.C., Krumholz, L.R., Suflita, J.M., Colwell, F.S., and Lehman, R.M. (1997). Pore-size constraints on the activity and survival of subsurface bacteria in a late cretaceous shalesandstone sequence, northwestern New Mexico. Geomicrobiology Journal 14, 183-202.

Fredricks, H. F., and Hinrichs, K.-U. (2007). Data report: intact membrane lipids as indicators of subsurface life in cretaceous and paleogene sediments from sites 1257 and 1258, in Proceedings of ODP, Scientific Results, Vol. 207 (College Station, TX: Ocean Drilling Program), 1-11.

Gaspar, J., Mathieu, J., Yang, Y., Tomson, R., Leyris, J. D., Gregory, K. B., et al. (2014). Microbial dynamics and control in shale gas production. Environ. Sci. Technol. Lett. 1, 465-473. doi: $10.1021 /$ ez5003242

Gennis, R. B. (1989). Interactions of small molecules with membranes: partitioning, permeability, and electrical effects. In Biomembranes (pp. 235-269). Springer, New York, NY.

Ghiorse, W. C., \& Wilson, J. T. (1988). Microbial ecology of the terrestrial subsurface. Advances in applied microbiology, 33, 107-172.

Gomez-Brandon, M., Lores, M., and Dominguez, J. (2008). Comparison of extraction and derivatization methods for fatty acid analysis in solid environmental matrixes. Analytical and Bioanalytical Chemistry 392, 505-514. doi: 10.1007/s00216-008-2274-7.

Guckert, J.B., Antworth, C.P., Nichols, P.D., and White, D.C. (1985). Phospholipid, Ester-Linked Fatty-Acid Profiles as Reproducible Assays for Changes in Prokaryotic Community Structure of Estuarine Sediments. Fems Microbiology Ecology 31, 147-158. doi: Doi 10.1111/J.1574-6968.1985.Tb01143.X.

Guckert, J. B., Hood, M. A., \& White, D. C. (1986). Phospholipid ester-linked fatty acid profile changes during nutrient deprivation of Vibrio cholerae: increases in the trans/cis ratio and proportions of cyclopropyl fatty acids. Applied and environmental microbiology, 52(4), 794-801.

Ruiz-Gutiérrez, V., \& Pérez-Camino, M. D. C. (2000). Update on solid-phase extraction for the analysis of lipid classes and related compounds. Journal of Chromatography A, 885(1-2), 321-341.

Haack, S. K., Garchow, H., Odelson, D. A., Forney, L. J., \& Klug, M. J. (1994). Accuracy, reproducibility, and interpretation of fatty acid methyl ester profiles of model bacterial communities. Applied and Environmental Microbiology, 60(7), 2483-2493.

Haines, T. H. (2001). Do sterols reduce proton and sodium leaks through lipid bilayers? Prog. Lipid Res. 40, 299-324. doi: 10.1016/S0163-7827(01)00009-1 
Halverson, L. J., \& Firestone, M. K. (2000). Differential Effects of Permeating and Nonpermeating Solutes on the Fatty Acid Composition ofPseudomonas putida. Applied and environmental microbiology, 66(6), 2414-2421.

Haldeman, D. L., Amy, P. S., Ringelberg, D., White, D. C., 1993. Characterization of the microbiology within a $21 \mathrm{~m} 3$ section of rock from the deep subsurface. Microbial ecology, 26(2), 145-159.

Hazel, J. R., \& Williams, E. E. (1990). The role of alterations in membrane lipid composition in enabling physiological adaptation of organisms to their physical environment. Progress in lipid research, 29(3), 167-227.

Hedrick, D. B., Richards, B., Jewell, W., Guckert, J. B., White, D. C. (1991). Disturbance, starvation, and overfeeding stresses detected by microbial lipid biomarkers in high-solids high-yield methanogenic reactors. Journal of Industrial Microbiology \& Biotechnology, 8(2), 91-98.

Heinzelmann, S. M., Bale, N. J., Hopmans, E. C., Damsté, J. S. S., Schouten, S., \& van der Meer, M. T. (2014). Critical assessment of glyco-and phospholipid separation by using silica chromatography. Appl. Environ. Microbiol., 80(1), 360-365.

Heipieper, H. J., Loffeld, B., Keweloh, H., \& de Bont, J. A. (1995). The cis/trans isomerisation of unsaturated fatty acids in Pseudomonas putida S12: an indicator for environmental stress due to organic compounds. Chemosphere, 30(6), 1041-1051.

Hinrichs, K. U., Inagaki, F. (2012). Downsizing the deep biosphere. Science, 338(6104), 204-205.

Holtje, J.V. (1998). Growth of the stress-bearing and shape-maintaining murein sacculus of Escherichia coli. Microbiol Mol Biol Rev 62, 181-203.

Huguet, C., Martens-Habbena, W., Urakawa, H., Stahl, D. A., \& Ingalls, A. E. (2010). Comparison of extraction methods for quantitative analysis of core and intact polar glycerol dialkyl glycerol tetraethers (GDGTs) in environmental samples. Limnology and Oceanography: Methods, 8(4), 127-145.

Hupp, B., (2017). Provenance of the Hamilton Group: A study of source-to-sink relationships within the Middle Devonian central Appalachian Basin. Masters Thesis. West Virginia University.

Inagaki, F., Hinrichs, K.-U., Kubo, Y., and the IODP Expedition 337 Scientists (2016): IODP Expedition 337: Deep Coalbed Biosphere off Shimokita - Microbial processes and hydrocarbon system associated with deeply buried coalbed in the ocean, Sci. Dril., 21, 1728, doi:10.5194/sd-21-17-2016.

Jenneman, G. E., McInerney, M. J., \& Knapp, R. M. (1985). Microbial penetration through nutrient-saturated Berea sandstone. Applied and Environmental Microbiology, 50(2), 383391.

Jenkins, T.C., Abughazaleh, A.A., Freeman, S., and Thies, E.J. (2006). The production of 10hydroxystearic and 10-ketostearic acids is an alternative route of oleic acid transformation by the ruminal microbiota in cattle. J Nutr 136, 926-931.

Ji, Y., Mao, G., Wang, Y., and Bartlam, M. (2013). Structural insights into diversity and n-alkane biodegradation mechanisms of alkane hydroxylases. Frontiers in Microbiology 4. doi: 10.3389/fmicb.2013.00058.

Jung, S., Zeikus, J.G., and Hollingsworth, R.I. (1994). A new family of very long chain alpha,omega-dicarboxylic acids is a major structural fatty acyl component of the membrane lipids of Thermoanaerobacter ethanolicus 39E. J Lipid Res 35, 10571065. 
Kates M (1986) Techniques of Lipidology, 2nd ed. Elsevier Science Publishing Co., Inc., New York.

Kellermann, V., Overgaard, J., Hoffmann, A. A., Fløjgaard, C., Svenning, J. C., \& Loeschcke, V. (2012). Upper thermal limits of Drosophila are linked to species distributions and strongly constrained phylogenetically. Proceedings of the National Academy of Sciences, 201207553.

Kennedy, M. J., Reader, S. L., \& Swierczynski, L. M. (1994). Preservation records of microorganisms: evidence of the tenacity of life. Microbiology, 140(10), 2513-2529.

Kester, A.S., and Foster, J.W. (1963). Diterminal Oxidation of Long-Chain Alkanes by Bacteria. J Bacteriol 85, 859-869.

Kieft, T.L., Ringelberg, D.B., and White, D.C. (1994). Changes in ester-linked phospholipid fattyacid profiles of subsurface bacteria during starvation and desiccation in a porous-medium. Applied and Environmental Microbiology 60, 3292-3299.

Kieft, T. L., Fredrickson, J. K., McKinley, J. P., Bjornstad, B. N., Rawson, S. A., Phelps, T. J., ... Pfiffner, S. M. (1995). Microbiological comparisons within and across contiguous lacustrine, paleosol, and fluvial subsurface sediments. Applied and environmental microbiology, 61(2), 749-757.

Kieft, T.L., W.P.Kovacik, D.B. Ringelberg, D.C. White, D.L. Haldeman, P.S.Amy and L.E. Hersman. 1997. Factors limiting microbial growth and activity at a proposed high-level nuclear repository, Yucca Mountain, Nevada. Appl. Environ. Microbiol. 63, 3128-3133.

Kishino, S., Takeuchi, M., Park, S.B., Hirata, A., Kitamura, N., Kunisawa, J., Kiyono, H., Iwamoto, R., Isobe, Y., Arita, M., Arai, H., Ueda, K., Shima, J., Takahashi, S., Yokozeki, K., Shimizu, S., and Ogawa, J. (2013). Polyunsaturated fatty acid saturation by gut lactic acid bacteria affecting host lipid composition. Proc Natl Acad Sci U S A 110, 17808-17813. doi: 10.1073/pnas.1312937110.

Kohring, L. L., Ringelberg, D. B., Devereux, R., Stahl, D. A., Mittelman, M. W., White, D. C. 1994. Comparison of phylogenetic relationships based on phospholipid fatty acid profiles and ribosomal RNA sequence similarities among dissimilatory sulfate-reducing bacteria. FEMS Microbiology Letters, 119(3), 303-308.

Krumholz, L.R., McKinley, J.P., Ulrich, G.A., and Suflita, J.M. (1997). Confined subsurface microbial communities in Cretaceous rock. Nature 386, 64-66.

Lehman, R.M., Colwell, F.S., Ringelberg, D.B., and White, D.C. (1995). Combined microbial community-level analyses for quality assurance of terrestrial subsurface cores. Journal of Microbiological Methods 22, 263-281. doi: Doi 10.1016/0167-7012(95)00012-A.

Lester, Y., Ferrer, I., Thurman, E. M., Sitterley, K. A., Korak, J. A., Aiken, G., \& Linden, K. G. (2015). Characterization of hydraulic fracturing flowback water in Colorado: Implications for water treatment. Science of the Total Environment, 512, 637-644.

Lipus, D., Vikram, A., Ross, D., Bain, D., Gulliver, D., Hammack, R., \& Bibby, K. (2017). Predominance and metabolic potential of Halanaerobium in produced water from hydraulically fractured Marcellus Shale wells. Applied and environmental microbiology, AEM-02659.

Lin, L.H., Wang, P.L., Rumble, D., Lippmann-Pipke, J., Boice, E., Pratt, L.M., Sherwood Lollar, B., Brodie, E.L., Hazen, T.C., Andersen, G.L., DeSantis, T.Z., Moser, D.P., Kershaw, D., and Onstott, T.C. (2006). Long-term sustainability of a highenergy, low-diversity crustal biome. Science 314, 479-482. doi:10.1126/science.1127376. 
Lincoln, S. A., Bradley, A. S., Newman, S. A., \& Summons, R. E. (2013). Archaeal and bacterial glycerol dialkyl glycerol tetraether lipids in chimneys of the Lost City Hydrothermal Field. Organic geochemistry, 60, 45-53.

Madigan, M. T., Martinko, J. M., \& Parker, J. (1997). Brock biology of microorganisms (Vol. 11). Upper Saddle River, NJ: Prentice hall.

Machel, H. G., Foght, J. (2000). Products and depth limits of microbial activity in petroliferous subsurface settings. In Microbial Sediments (pp. 105-120). Springer Berlin Heidelberg.

Martini, A. M., Walter, L. M., Ku, T. C., Budai, J. M., McIntosh, J. C., Schoell, M., 2003. Microbial production and modification of gases in sedimentary basins: A geochemical case study from a Devonian shale gas play, Michigan basin. AAPG bulletin, 87, 1355-1375.

McMahon, P. B., \& Chapelle, F. H. (1991). Microbial production of organic acids in aquitard sediments and its role in aquifer geochemistry. Nature, 349(6306), 233-235.

McMahon, S., Parnell, J. (2014). Weighing the deep continental biosphere. FEMS microbiology ecology, 87(1), 113-120.

McMahon, S., \& Parnell, J. (2014). Weighing the deep continental biosphere. FEMS Microbiology Ecology, 87(1), 113-120.

Morgan, J., \& Winstanley, C. R. A. I. G. (1997). Microbial biomarkers. Modern Soil Microbiology. Marcel Dekker, Inc., New York, 331-352.

Mohan, A. M., Hartsock, A., Hammack, R. W., Vidic, R. D., \& Gregory, K. B. (2013). Microbial communities in flowback water impoundments from hydraulic fracturing for recovery of shale gas. FEMS microbiology ecology, 86(3), 567-580.

Mouser, P. J., Borton, M., Darrah, T. H., Hartsock, A., Wrighton, K. C. (2016). Hydraulic fracturing offers view of microbial life in the deep terrestrial subsurface. FEMS microbiology ecology, 92(11).

Murphy, E. M., Schramke, J. A., Fredrickson, J. K., Bledsoe, H. W., Francis, A. J., Sklarew, D. S., Linehan, J. C. (1992). The influence of microbial activity and sedimentary organic carbon on the isotope geochemistry of the Middendorf aquifer. Water Resources Research, 28(3), 723-740.

Nichols, P., Stulp, B. K., Jones, J. G., \& White, D. C. (1986). Comparison of fatty acid content and DNA homology of the filamentous gliding bacteriaVitreoscilla, Flexibacter, Filibacter. Archives of Microbiology, 146(1), 1-6.

Olsson, P. A. (1999). Signature fatty acids provide tools for determination of the distribution and interactions of mycorrhizal fungi in soil. FEMS Microbiology Ecology, 29(4), 303-310.

Onstott, T.C., Phelps, T.J., Colwell, F.S., Ringelberg, D., White, D.C., Boone, D.R., McKinley, J.P., Stevens, T.O., Long, P.E., and Balkwill, D.L. (1998). Observations pertaining to the origin and ecology of microorganisms recovered from the deep subsurface of Taylorsville Basin, Virginia. Geomicrobiology Journal 15, 353-385.

Onstott, T. C., Phelps, T. J., Kieft, T., Colwell, F. S., Balkwill, D. L., Fredrickson, J. K., \& Brockman, F. J. (1999). A global perspective on the microbial abundance and activity in the deep subsurface. In Enigmatic microorganisms and life in extreme environments (pp. 487-500). Springer Netherlands.

Onstott, T. C., Moser, D. P., Pfiffner, S. M., Fredrickson, J. K., Brockman, F. J., Phelps, T. J., ... \& Krumholz, L. R. (2003). Indigenous and contaminant microbes in ultradeep mines. Environmental Microbiology, 5(11), 1168-1191.

Oksanen F. J., Guillaume Blanchet, Roeland Kindt, Pierre Legendre Peter R. Minchin, R. B. O'Hara Gavin L. Simpson Peter Solymos M. Henry H. Stevens Helene Wagner vegan: 
Community Ecology Package. R package version 2.3-5 Year: 2016 URL: https://CRAN.Rproject.org/package $=$ vegan

Paronsih, T., (2017) Meso- and macro-scale facies and chemostratigraphic analysis of middle Devonian Marcellus Shale in northern West Virginia, USA. Masters Thesis, West Virginia University.

Pedersen, T. F., \& Calvert, S. E. (1990). Anoxia vs. productivity: what controls the formation of organic-carbon-rich sediments and sedimentary Rocks?(1). Aapg Bulletin, 74(4), 454-466.

Peters, K. E., Walters, C. C., Moldowan, J. M. (2005). The biomarker guide (Vol. 1). Cambridge University Press.

Petsch, S. T., Edwards, K. J., Eglinton, T. I., 2003. Abundance, distribution and $\delta 13 \mathrm{C}$ analysis of microbial phospholipid-derived fatty acids in a black shale weathering profile. Organic Geochemistry, 34(6), 731-743.

Pfiffner, S. M., Cantu, J. M., Smithgall, A., Peacock, A. D., White, D. C., Moser, D. P., ... van Heerden, E. (2006). Deep subsurface microbial biomass and community structure in Witwatersrand Basin mines. Geomicrobiology Journal, 23(6), 431-442.

Phelps, T. J, Fliermans C.B, Garland T. R, Pfiffner S. M, White D.C., 1989. Methods for recovery of deep terrestrial subsurface sediments for microbiological studies. J Microbiol Methods 9:267-279

Phelps, T. J., Murphy, E. M., Pfiffner, S. M.,White, D. C. (1994). Comparison between geochemical and biological estimates of subsurface microbial activities. Microbial Ecology, 28(3), 335-349.

Piotrowska-Seget, Z., Mrozik, A. (2003). Signature lipid biomarker (SLB) analysis in determining changes in community structure of soil microorganisms. Polish Journal of Environmental Studies, 12(6).

Poger, D., Caron, B., and Mark, A. E. (2014). Effect of methyl-branched fatty acids on the structure of lipid bilayers. J. Phys. Chem. B 118, 13838-13848. doi: 10.1021/jp503910r

Rajendran, N., Matsuda, O., Imamura, N., \& Urushigawa, Y. (1992). Variation in microbial biomass and community structure in sediments of eutrophic bays as determined by phospholipid ester-linked fatty acids. Applied and Environmental Microbiology, 58(2), $562-571$.

Ramos, J. L., Gallegos, M. T., Marqués, S., Ramos-González, M. I., Espinosa-Urgel, M., \& Segura, A. (2001). Responses of Gram-negative bacteria to certain environmental stressors. Current opinion in microbiology, 4(2), 166-171.

Reichardt, W., Mascarina, G., Padre, B., \& Doll, J. (1997). Microbial communities of continuously cropped, irrigated rice fields. Applied and environmental microbiology, 63(1), 233-238.

Ringelberg, D. B., Davis, J. D., Smith, G. A., Pfiffner, S. M., Nichols, P. D., Nickels, J. S., ... \& Read, H. W. (1989). Validation of signature polarlipid fatty acid biomarkers for alkaneutilizing bacteria in soils and subsurface aquifer materials. FEMS microbiology letters, 62(1), 39-50.

Ringelberg, D.B., Sutton, S., and White, D.C. (1997). Biomass, bioactivity and biodiversity: microbial ecology of the deep subsurface: analysis of ester-linked phospholipid fatty acids. FEMS Microbiology Reviews 20, 371-377. doi: Doi 10.1016/S0168-6445(97)00019-3.

Russell, N. J. (1989). Functions of lipids: structural roles and membrane functions. Microbial lipids, 2, 279-365.

Sageman, B. B., Murphy, A. E., Werne, J. P., Ver Straeten, C. A., Hollander, D. J., \& Lyons, T. W. (2003). A tale of shales: the relative roles of production, decomposition, and dilution 
in the accumulation of organic-rich strata, Middle-Upper Devonian, Appalachian basin. Chemical Geology, 195(1), 229-273.

Šajbidor, J. (1997). Effect of some environmental factors on the content and composition of microbial membrane lipids. Critical reviews in biotechnology, 17(2), 87-103.

Schubotz, F., Wakeham, S. G., Lipp, J. S., Fredricks, H. F., \& Hinrichs, K. U. (2009). Detection of microbial biomass by intact polar membrane lipid analysis in the water column and surface sediments of the Black Sea. Environmental Microbiology, 11(10), 2720-2734.

Schlegel, M.E., McIntosh, J.C., Bates, B.L., Kirk, M.F., and Martini, A.M. (2011).Comparison of fluid geochemistry and microbiology of multiple organic-rich reservoirs in the Illinois Basin, USA: Evidence for controls on methanogenesis and microbial transport. Geochimica et Cosmochimica Acta 19, 75, doi:http://dx.doi.org/10.1016/j.gca.2011.01.016.

Sharma, S., Mulder, M. L., Sack, A., Schroeder, K., Hammack, R., 2013. Isotope approach to assess hydrologic connections during Marcellus Shale drilling. Groundwater, 52(3), 424433.

Shaw, D.B., and Weaver, C.E., 1965. The Mineralogical Composition of Shale. Journal of Sedimentary Petrology 35, 213-222.

Smith, C. A., Phiefer, C. B., Macnaughton, S. J., Peacock, A., Burkhalter, R. S., Kirkegaard, R., \& White, D. C. (2000). Quantitative lipid biomarker detection of unculturable microbes and chlorine exposure in water distribution system biofilms. Water Research, 34(10), 2683-2688.

Soeder, D. J., Sharma, S., Pekney, N., Hopkinson, L., Dilmore, R., Kutchko, B., ... \& Capo, R. (2014). An approach for assessing engineering risk from shale gas wells in the United States. International Journal of Coal Geology, 126, 4-19.

Sollich, M., Yoshinaga, M. Y., Häusler, S., Price, R. E., Hinrichs, K. U., \& Bühring, S. I. (2017). Heat stress dictates microbial lipid composition along a thermal gradient in marine sediments. Frontiers in microbiology, 8, 1550.

Sondergeld, C. H., Ambrose, R. J., Rai, C. S., Moncrieff, J. 2010. Micro-structural studies of gas shales. In SPE Unconventional Gas Conference. Society of Petroleum Engineers.

Song, Y., Deng, S. P., Acosta-Martínez, V., \& Katsalirou, E. (2008). Characterization of redoxrelated soil microbial communities along a river floodplain continuum by fatty acid methyl ester (FAME) and 16S rRNA genes. applied soil ecology, 40(3), 499-509.

Stoeck, T., \& Kröncke, I. (2001). Influence of particle mixing on vertical profiles of chlorophyll a and bacterial biomass in sediments of the German Bight, Oyster Ground and Dogger Bank (North Sea). Estuarine, Coastal and Shelf Science, 52(6), 783-795.

Stroes-Gascoyne, S., Garisto, F., \& Betteridge, J. S. (2005). The effects of alpha-radiolysis on UO2 dissolution determined from batch experiments with $238 \mathrm{Pu}$-doped UO2. Journal of nuclear materials, 346(1), 5-15.

Stroes-Gascoyne, S., Schippers, A., Schwyn, B., Poulain, S., Sergeant, C., Simonoff, M., ... \& McKenzie, J. (2007). Microbial community analysis of Opalinus clay drill core samples from the Mont Terri underground research laboratory, Switzerland. Geomicrobiology Journal, 24(1), 1-17.

Struchtemeyer, C. G., Davis, J. P., Elshahed, M. S. (2011). Influence of the drilling mud formulation process on the bacterial communities in thermogenic natural gas wells of the Barnett Shale. Applied and environmental microbiology, 77(14), 4744-4753. 
Trexler, (2017). Lipid Analysis and Microbial Community Characterization of Subsurface Shale. Master's Thesis, The Ohio State University.

Tucker, Y. T., Kotcon, J., \& Mroz, T. (2015). Methanogenic Archaea in Marcellus Shale: a possible mechanism for enhanced gas recovery in unconventional shale resources. Environmental science \& technology, 49(11), 7048-7055.

Valentine, D. L. (2007). Adaptations to energy stress dictate the ecology and evolution of the Archaea. Nat. Rev. Microbiol. 5, 316-323. doi: 10.1038/nrmicro1619

Valentine, R. C., and Valentine, D. L. (2004). Omega-3 fatty acids in cellular membranes: a unified concept. Prog. Lipid Res. 43, 383-402. doi: 10.1016/j.plipres.2004.05.004

van de Vossenberg, J. L. C. M., Ubbink-Kok, T., Elferink, M. G. L., Driessen, A. J. M., and Konings, W. N. (1995). Ion permeability of the cytoplasmic membrane limits the maximum growth temperature of bacteria and archaea. Mol. Microbiol.18, 925-932. doi: 10.1111/j.1365-2958.1995.18050925.x

Vikram, A., Lipus, D., \& Bibby, K. (2014). Produced water exposure alters bacterial response to biocides. Environmental science \& technology, 48(21), 13001-13009.

Wang, G., \& Carr, T. R. (2013). Organic-rich Marcellus Shale lithofacies modeling and distribution pattern analysis in the Appalachian Basin. AAPG bulletin, 97(12), 2173-2205.

Wang, G., Carr, T. R., Ju, Y., \& Li, C. (2014). Identifying organic-rich Marcellus Shale lithofacies by support vector machine classifier in the Appalachian basin. Computers \& Geosciences, 64, 52-60.

White, D.C., Davis, W.M., Nickels, J.S., King, J.D., and Bobbie, R.J. (1979). Determination of the Sedimentary Microbial Biomass by Extractable Lipid Phosphate. Oecologia 40, 51-62. doi: Doi 10.1007/Bf00388810.

White, D. C., 1988. Validation of quantitative analysis for microbial biomass, community structure, and metabolic activity. Adv. Limnol, 31(1).

White, D. C., Pinkart, H. C., \& Ringelberg, D. B. (1997). Biomass measurements: biochemical approaches. Manual of environmental microbiology. ASM Press, Washington, DC, 91-101.

White, D. C., \& Ringelberg, D. B. (1998). Signature lipid biomarker analysis(Vol. 255, p. 272). Oxford University Press: New York.

Whitman, W. B., Coleman, D. C., \& Wiebe, W. J. (1998). Prokaryotes: the unseen majority. Proceedings of the National Academy of Sciences, 95(12), 6578-6583.

Wilkins, M.J., Daly, R.A., Mouser, P.J., Trexler, R., Sharma, S., Cole, D.R., Wrighton, K.C., Biddle, J.F., Denis, E.H., Fredrickson, J.K., Kieft, T.L., Onstott, T.C., Peterson, L., Pfiffner, S.M., Phelps, T.J., and Schrenk, M.O. (2014). Trends and future challenges in sampling the deep terrestrial biosphere. Front Microbiol 5, 481. doi: 10.3389/fmicb.2014.00481.

Wuchter, C., Banning, E., Mincer, T.J., Drenzek, N.J., and Coolen, M.J. (2013). Microbial diversity and methanogenic activity of Antrim Shale formation waters 102 from recently fractured wells. Front microbiol 4, 367. doi:10.3389/fmicb.2013.00367.

Yanni, A. (2010). Subsurface stratigraphy and petrophysical analysis of the Middle Devonian interval, including the Marcellus shale, of the central Appalachian basin; northwestern Pennsylvania. West Virginia University. 


\section{CHAPTER 3}

\section{Effects of Sampling and Long Term Storage on Microbial Lipid Biomarker Distribution in Deep Subsurface Marcellus Shale Cores}

\subsection{Abstract}

During unconventional hydrocarbon exploitation, a subset of subsurface-derived microorganisms is inadvertently brought to the surface via drill cuttings, retrieved well cores, and produced water which is a mix of formation water and hydraulic fracturing fluids injected in shale reservoir during drilling. In accordance with the recent increase in natural gas recovery from black shales, it has become apparent to understand the extent of surface adaptive response of these subsurface shale microbiota due to changes in pressure, temperature, and oxygen. This study thus uses membrane ester-linked phospholipid (PLFA) and diglyceride fatty acid (DGFA) analyses to examine the effects of sampling and surface storage conditions on the microbial community structure and composition of deep subsurface black shale cores. Core samples were collected from lithologic units of same depth in two Marcellus Shale wells (WV 6 and MSEEL) in Monongalia County, West Virginia. The WV 6 core samples were collected using routine coring methods and stored under room temperature conditions for several years. On the other hand, the MSEEL core samples were collected using pertinent microbial sampling protocols and stored at $-80^{\circ} \mathrm{C}$ until analysis. The PLFAs and DGFAs were extracted, trans-esterified, and analyzed as fatty acid methyl esters (FAMEs) using the gas chromatography-mass spectrometry (GC-MS). The average lipid biomarker concentration and diversity were higher in the MSEEL core samples compared to the WV 6 core samples. Stress indicative biomarkers like oxiranes, keto, and dimethyl lipid fatty acids were only present in the MSEEL core samples. Gram (+) microbial lipid biomarkers were also more dominant in the MSEEL compared to WV 6 core samples. Other lipid classes such as normal saturates and monounsaturates, were shared across the WV 6 and MSEEL core samples. 
The absence of some stress biomarkers after storage could suggest the transformation of the subsurface adapted biomarkers to relatively more stable structures in response to low temperatures and pressures in the surface. This study highlights the adaptive ability of subsurface shale microbes and emphasizes the necessity of efficient sample storage for deep subsurface ecological studies.

\subsection{Introduction}

Geologic, hydrologic, and anthropogenic processes operating on a variety of time-scales transport microbes to the subsurface, within the subsurface, and in many cases to the surface ecosystem (Stevens, 1997). For instance, deep subsurface shales host diverse microbial communities (e.g., Colwell et al., 1997; Fredrickson et al., 1997; Krumholz et al., 1997; Onstott et al., 1998; Edwards et al., 2012; Hinrichs and Inagaki, 2012; Colwell and D’Hondt, 2013; Mohan et al., 2013; Cluff et al., 2014; Gaspar et al., 2014), some of which are inadvertently brought to the surface during hydrocarbon exploitation through drill cuttings, retrieved cores, and produced fluid. With the increased interest in natural gas production from subsurface shales (U.S.E.I., 2016), it is important to understand the extent to which subsurface shale microbiota can adapt and survive prolonged exposure to ambient surface environmental conditions. Within the subsurface, selective environmental parameters like oxygen concentration, pressure, $\mathrm{pH}$, salinity, temperature, and nutrient quality determine the microbial species that can adapt for survival. When the microbes are eventually brought to the surface, surface environmental parameters like moisture content, permeability, sample perturbation, redox potential, temperature and pressure are the essential factors that determine microbial response to changing environmental conditions and shifts in community structure (Brockman et al., 1992; Haldeman et al., 1994, 1995b). Introducing subsurface microbial life to the surface ecosystem could therefore result in successional changes in microbial communities thus affecting important surface geochemical and microbial phenomena. 
This notion of potentially altering microbial community structure/composition when exposed to surface environmental conditions has been supported by the rigorous sampling and storage techniques required to preserve the integrity of in-situ subsurface microbial, geochemical, and mineralogical composition (Phelps et al., 1989; Kinkel et al., 1992; Colwell et al., 1992; Yayanos, 1995; Fredrickson and Phelps, 1996; Wilkins et al., 2014).

Microbes regulate membrane lipid structures (e.g., length of lipid fatty acid, amount of double bonds, methyl branching etc), in accordance with living habits (Annous et al., 1997; Klein et al., 1999) and in response to changing environmental parameters (temperature, salinity, and $\mathrm{pH}$ ) (e.g.; Fredrickson et al., 1991; Brockman et al., 1992; Haldeman et al, 1993; Kieft et al., 1994; Sollich et al., 2017). Common microbial community changes recorded after surface storage of subsurface samples include: increase in microbial activity, increase in culturable counts, and decrease in culturable diversity (Amy et al., 1992; Brockman et al., 1992; Fredrickson et al., 1995; Haldeman et al., 1994). Researchers have reported changes in microbial community composition in subsurface sediments as a result of changing environmental conditions in situ (Roszak and Colwell, 1987; Hirsch and Rades-Rohkohl, 1988; Haldeman et al., 1993, 1994, 1995; Thorn and Ventullo., 1988; Kieft et al., 1994; Frederickson et al., 1995). Similarly, studies have measured considerable shifts in the microbial community in produced water compared to hydraulic fracturing fluids that are injected in the shale reservoir due to adaptations to the changing environmental conditions (Mohan et al., 2013; Cluff et al., 2014; Akob et al., 2015; Mouser et al., 2016; Daly et al., 2016). Even though several researchers have studied microbial adaptation to environmental conditions, there are still questions to be answered about how subsurface shale microbial communities adapt to ambient surface conditions. For example we are still trying to understand, (1) the taxonomical relationship (phylogenetical and physiological) between the 
isolated deep subsurface shale microbial species and their surface counterparts and (2) the metabolic status and physiological response of subsurface microbial cells exposed to surface environmental conditions.

Phospholipid fatty acids (PLFAs) provide evidence of living microbes while diglyceride fatty acids (DGFAs) that are the breakdown products of the phospholipids are indicators of nonviable microbial communities (White et al., 1979; Baird and White, 1985; White, 1988; Haldeman et al., 1995; White and Ringelberg, 1996; Ringelberg et al., 1997; Petsch et al., 2003). Cellular membranes, which are largely composed of PLFAs, play an essential role in controlling how microbes adapt to changing environmental conditions. The chemical structures of these membrane-derived PLFAs therefore serve as excellent proxies for environmental conditions (Cronan and Gelmann, 1975; Guckert et al., 1986; Harwood and Russell, 1984). Here we report and compare PLFA and DGFA concentrations in subsurface shale samples that were collected following pertinent microbial sampling protocols and storage at $-80^{\circ} \mathrm{C}$ (MSEEL), and samples that were collected and stored at room temperature conditions for about 40 years (WV 6). The major goals of the study are to investigate the influence of storage on the presence, abundance, distribution, and diversity of deep subsurface microbial biomarkers. The knowledge of adaptations or colonization of subsurface shale microbiota provides an important reference point for conceptualizing the influence of physiologies, metabolic rates, permeability, and reaction mechanisms on subsurface shale microbial communities upon exposure to surface environmental conditions.

\subsection{Methods:}

\subsubsection{Site Description, Drilling, and Sample Collection Procedures}


The samples for this study were collected from lithological units of the same depth; Mahantango (MSEEL-1 and WV 6-1), Marcellus Shale Top (MSEEL-2 and WV 6-2), and Upper Marcellus Shale (MSEEL-3 and WV 6-3) within two Marcellus Shale wells (WV 6 and MSEEL) in Monongahela County, West Virginia (Figure 1). The WV 6 samples were collected from vertical core obtained during the development of a production well and stored at the West Virginia Geological and Economic Survey at room temperature for several years. The samples therefore lack control on any microbial contamination that might have occurred during drilling, core handling, and core storage. In contrast, the MSEEL cores were collected aseptically during drilling of a DOE funded MSEEL scientific well and stored at $-80^{\circ} \mathrm{C}$ (Wilkins et al., 2014). Sample collection, decontamination, and processing are described in detail in Akondi et al. (2019). To remove contamination that could have resulted from drilling, sample collection and/or handling, core samples were placed in a sterile saline bath $(1.5 \mathrm{M} \mathrm{NaCl})$ and the outer portion abraded with autoclaved steel wool (Wilkins et al., 2014). The cores were then sequentially placed in saline baths for decontamination. After cleaning the cores, the outer portion was flame sterilized. The cores were then crushed with a Plattner mortar and pestle (Humboldt Mfg. Co., Elgin, IL) and then ground in a ceramic mortar and pestle using sterile technique. The older WV 6 core samples were broken, scraped, and subsampled in the radial-center portion to remove any likely contamination. Lipid distribution of MSEEL core samples have been published in Akondi et al. (2019).

\subsubsection{Laboratory methods}

Both core samples were crushed with a sterile mortar and pestle (Humboldt Mfg. Co., Elgin, IL) and ground using sterile techniques. The ground core samples were sieved with mesh sizes of $2000 \mu \mathrm{m}, 1000 \mu \mathrm{m}$, and $500 \mu \mathrm{m}$ (Dual Manufacturing Co., Inc., Franklin Park, IL), and reground until all the samples could pass through a sterile $500 \mu \mathrm{m}$ sieve. All glassware was cleaned in a $10 \%$ 
(v/v) micro cleaner solution (International Products Corporation, Burlington, NJ), soaked in tap water overnight and rinsed with distilled water and 10 times with Millipore water.

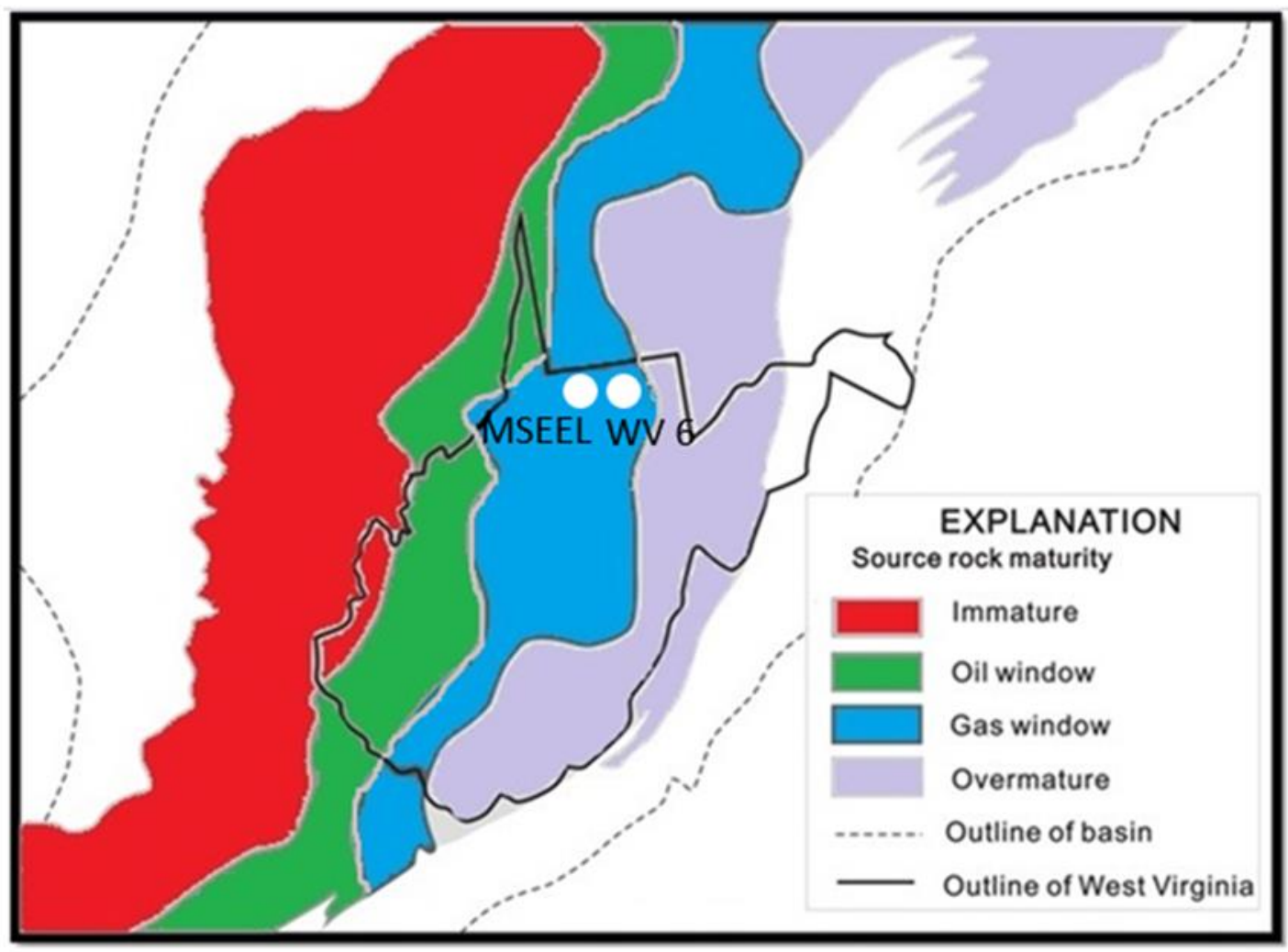

Figure 1. Map showing the approximate location of the WV 6 and MSEEL wells in Monongalia County in West Virginia, USA

The glassware was then allowed to dry, wrapped in aluminum foil and heated at $450^{\circ} \mathrm{C}$ in a muffled furnace for at least 8 hours. The aluminum foil was also combusted at $450^{\circ} \mathrm{C}$ for a minimum of 8 hours. Metal lab wares (forceps, mortar, pestle, and spatulas) were cleaned with tap water and then with distilled water and finally with a solution of 1:1 chloroform: methanol. Teflonlined caps were cleaned in the same manner as glassware and then solvent rinsed with acetone. All organic solvents used were of purest grade (Fisher Optima). Fisher Optima organic-free nano-pure water used in the analytic experimental process were extracted using approximately $50 \mathrm{~mL}$ of 
chloroform per $1 \mathrm{~L}$ of distilled water (ratio chloroform: water, 1:2) to remove any lipids or other extractable organics.

\subsubsection{Lipid analyses}

The pared, crushed, and homogenized powdered samples were extracted ultrasonically following the modified Bligh and Dyer method (Bligh and Dyer, 1959; White et al. 1979), with an intact polar lipid (Phosphate Buffer + phosphatidylcholine; POPC) amendment (Akondi et al., 2019). The equivalent concentration of the amended POPC was subtracted from the total lipid concentration prior to interpretation. Procedural blanks were used to monitor any laboratory contamination. Lipid extraction and analysis for both MSEEL and WV 6 samples were performed in the Pfiffner lab at the Center for Environmental Biotechnology at the University of Tennessee (Knoxville, TN, USA). The lipid extractions were carried out from $37.5 \mathrm{~g}$ of sediment and transferred to a $250 \mathrm{~mL}$ glass centrifuge bottle, which was then suspended in $30 \mathrm{ml}$ of chloroform extracted 50mM PO 4 buffer $\left(\mathrm{CHCl}_{3}: \mathrm{K}_{2} \mathrm{HPO}_{4}, 1: 2\right)$ (made by dissolving $8.7 \mathrm{~g}$ of $\mathrm{K}_{2} \mathrm{HPO}_{4}$ in $1 \mathrm{~L}$ nanopure distilled water and neutralized with $1 \mathrm{~N} \mathrm{HCL}$ to $\mathrm{pH}$ of 7.4), $75 \mathrm{ml}$ of methanol and 37.5 $\mathrm{ml}$ of chloroform (v/v ratio $0.8: 1: 2) .50 \mathrm{uL}$ of $50 \mathrm{pmol}$ of internal standard (19:0, nonadecanoic acid methyl ester; Matreya) was added and the suspension was shaken and sonicated two times in an ultrasonicator for 30 to 45 seconds (with 30 seconds interval). The samples were then allowed in the dark at room temperature to extract for about 8 hours. More chloroform $(37.5 \mathrm{~mL})$ and water $(37.5 \mathrm{~mL})$ were added to the suspension and the centrifuge bottles were shaken and kept for an hour to split phase, after which the bottles were centrifuged at 2000 RPM for 30 minutes. The supernatant was then transferred into a $250 \mathrm{~mL}$ separatory funnel, shaken vigorously and kept to split phase (upper: aqueous, lower: organic containing the lipids). The organic phase was collected in a glass tube through a stopcock on the separatory funnel. The volume ratio of reagents for the 
second phase separation was 1:1:0.9. The extract was concentrated with a $\mathrm{N}_{2}$ blowdown evaporator and the dried total lipids were transferred into test tubes using $3 \times 2 \mathrm{~mL}$ of chloroform, after which the solvent was evaporated, and the total lipid at $-20^{\circ} \mathrm{C}$.

The lipid extracts were sequentially fractionated on a silicic acid column, 100-200 mesh powder (dried at $110^{\circ} \mathrm{C}$ for 1 hour; Clarkson Chromatography Products, Inc), into fractions of different polarity using hexane, chloroform, acetone, and methanol. Hydrocarbons were eluted with $5 \mathrm{ml}$ hexane, neutral lipids (including DGFAs) with $5 \mathrm{ml}$ chloroform, and glycolipids with 5 $\mathrm{ml}$ acetone and phospholipids with $10 \mathrm{ml}$ methanol (Tunlid et al., 1989). The chloroform (DGFA) and methanol (PLFA) fractions were evaporated to dryness before transmethylation into fatty acid methyl esters (FAMEs) using methanolic potassium hydroxide for subsequent analysis with the gas chromatography-mass spectrometer (GC-MS; Kieft et al., 1994; White et al., 1979; Guckert et al., 1985; Ringelberg et al., 1997).

\subsubsection{GC-MS Analysis, Quantification, and Lipid Identification}

Lipid samples were then dissolved in hexane containing $50 \mathrm{pmol} / \mu \mathrm{L}$ of external injection standard (docosanoic acid methyl ester; Matreya, Inc). Aliquots of $1 \mu 1$ were injected into a GCMS equipped with a Restek RTx-1 column $(60 \mathrm{~m}, 0.25 \mathrm{~mm} \times 0.25 \mu \mathrm{m})$ to be further separated, identified, and quantified. The column operating conditions were as follows: $\left(60^{\circ} \mathrm{C}\right.$ for 2 minutes, ramped $10^{\circ} \mathrm{C} /$ minutes to $150^{\circ} \mathrm{C}$, ramped $3^{\circ} \mathrm{C} /$ minutes to $312^{\circ} \mathrm{C}$ for 5 minutes, Injector temperature $=$ $230^{\circ} \mathrm{C}$, detector temperature $=300^{\circ} \mathrm{C}$ and total run time of 65 minutes) with He as a carrier gas. The quantitation was done by mass spectra using external standard (docosanoic acid methyl ester; Matreya, Inc) while the identification and response factors of the different FAME compounds were based on the retention times of the FAME standards (PUFA-3, and Bacterial fatty methyl esters; 
Matreya, Inc). A single-ion monitoring (SIM) program was also used to scan the base peaks for FAMEs. The SIM program was based on $\mathrm{m} / \mathrm{z}(43,55,74$, and 87$)$ common among FAMEs ions. The individual PLFA and DGFA values were then transformed to mol \%. Once peaks were identified, lipid concentration was calculated from peak area in proportion to the area of external standard. An internal standard curve (1 pmol, 5 pmol, 10 pmol, 20 pmol, 30 pmol, 40 pmol, and $50 \mathrm{pmol} / \mu \mathrm{L}$ ) was prepared and analyzed on the GC-MS to determine the detection limit and to establish the best sample dilution range. The standard curve and the regression analysis had a linear relationship (0.99). Values below $1 \mathrm{pmol} / \mathrm{uL}$ were considered to be outside analytical quantitation limits. The external standard curve of 1 pmol standard peak represented a detection limit of 0.18 ng. Although ionization efficiency can vary between FAMEs, we assume equimolar ionization response for standard FAMEs as described in previous studies (Dobbs and Guckert, 1988; Reichardt et al., 1997; White and Ringelberg, 1998). Nevertheless, we calculated an average standard deviation based on the BacFAME methyl ester standard (Matreya, Inc.) analyzed in duplicates at the time of sample analysis. The standard contains 26 FAMEs ranging from 11-20 carbons in length and has representative saturates, terminally branched saturates, monounsatruates (including cyclopropyl FAMEs), and polyunsaturates. We examined the results for differences in MS detection of the FAMEs in the Bac FAME standard which showed similar peak area detection across the FAMEs. The average standard deviation by GC detection was $0.07 \%$, which implies that variance in GC detection had a minimal influence on the variability of PLFA and DGFA results. In some MSEEL lipid samples, however, the external standard peak co-eluted with phthalate isomers and was corrected before the lipid concentration was calculated as described in Akondi et al. (2017). 


\subsection{Results:}

The individual PLFA and DGFA distribution in pmol/g and mol\% for the MSEEL and WV 6 core samples are presented in Tables 1 and 2.
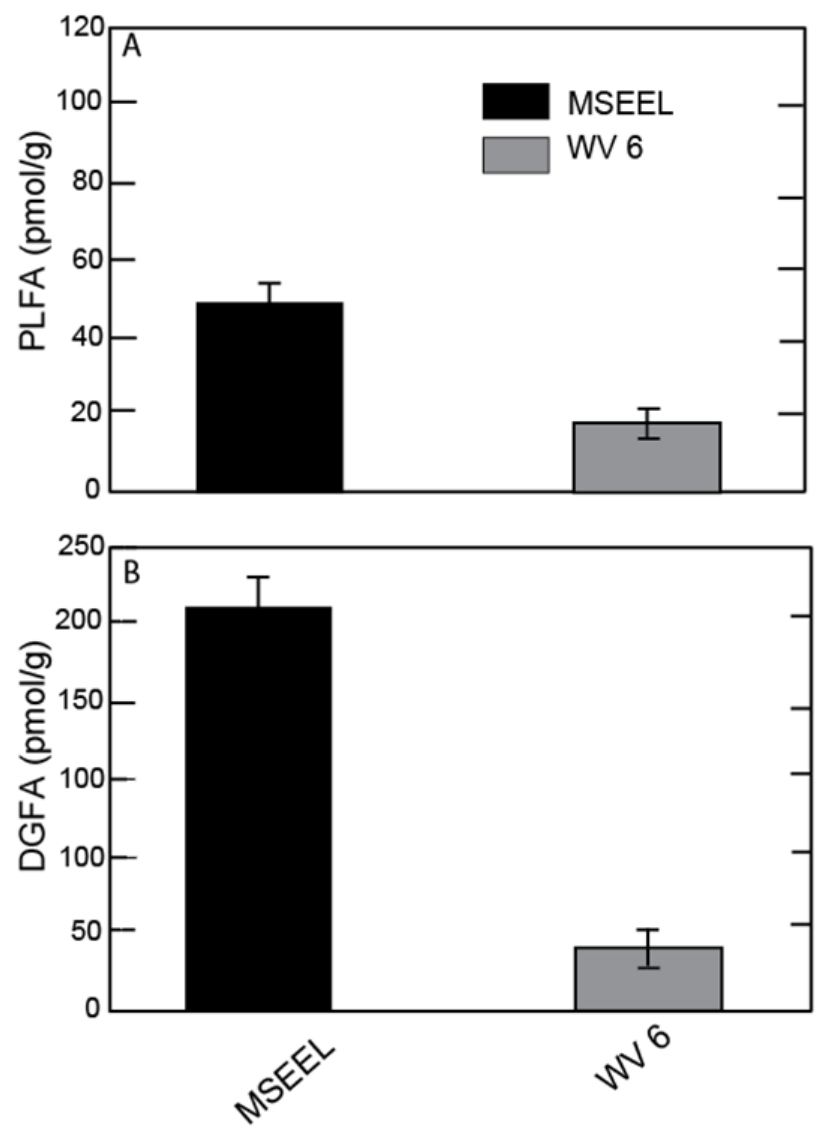

Figure 2. Average PLFA (A) and DGFA (B) yields in the WV 6 and corresponding MSEEL core samples. The bars indicate the standard deviation between samples from same well.

Total microbial lipid concentrations were higher in the MSEEL core samples compared to the corresponding WV 6 core samples for both the PLFA and DGFA (Figure 2A, B).

Differences between core samples were analyzed using one-way Analysis of Variance (ANOVA) tests. The variety of the individual lipid biomarkers were also higher in the MSEEL core samples than the WV 6 core samples for both the PLFA and DGFA (Figure 3A, B). 


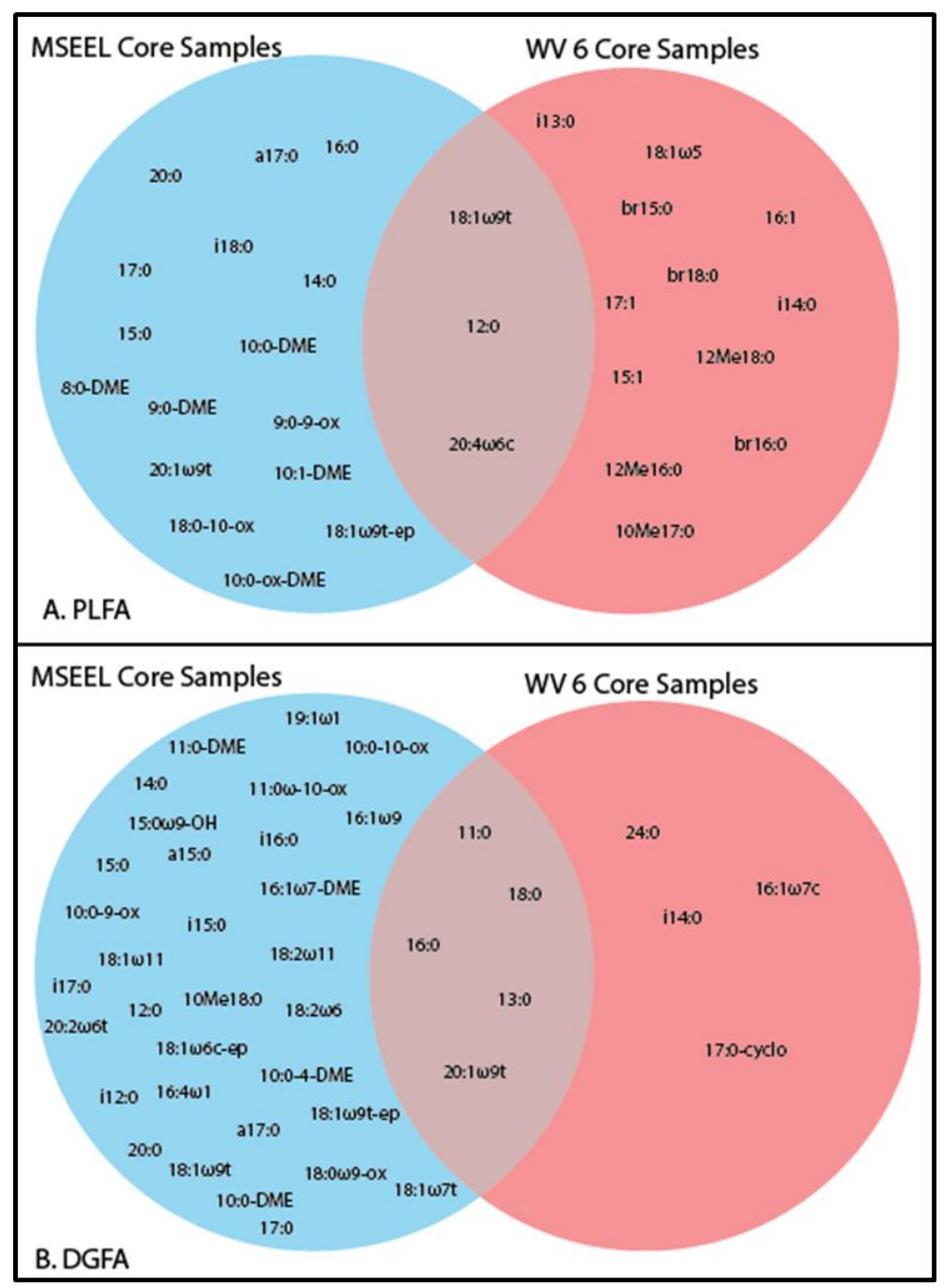

Figure 3. Venn diagram illustrating the distribution of the individual lipid biomarkers for the PLFA (A) and DGFA (B) within the MSEEL and WV 6 core samples. The figure shows the lipid fatty acids detected within each core sample and those shared between the MSEEL and WV 6 cores.

Like the individual lipid profiles, the variety of lipid functional groups were also higher in the MSEEL than the WV 6 samples for both PLFA and DGFA (Figure 4A, B). Of the 31 PLFAs detected in the dataset, $16(51.61 \%)$ were detected solely in the MSEEL core samples, $12(38.71 \%)$ were only found in the WV 6 core samples, and $3(9.67 \%)$ were present in both samples (Figure 3A). The PLFA functional groups, normal saturates, polyunsaturates, and monounsaturates were present in both WV 6 and MSEEL core samples. The dimethyl, oxiranes, and keto- lipid biomarkers were only present in the MSEEL core samples while the branch saturates, and 
cyclopropyl lipid biomarkers were only present in WV 6 samples (Figure 4A). Of the 41 DGFAs present in the dataset, 32 (78.04\%) were detected solely in the MSEEL core samples, 4 (9.75\%) were present in the WV 6 core samples and 5 (12.19\%) were present in both samples (Figure 3B). DGFA functional groups like normal saturates and monounsaturates were present in both WV 6 and MSEEL core samples (Figure 4B). The dimethyl, keto, oxiranes, hydroxyl, and polyunsaturates were present only in the MSEEL core samples while the cyclopropyl were only present in WV 6 core samples.
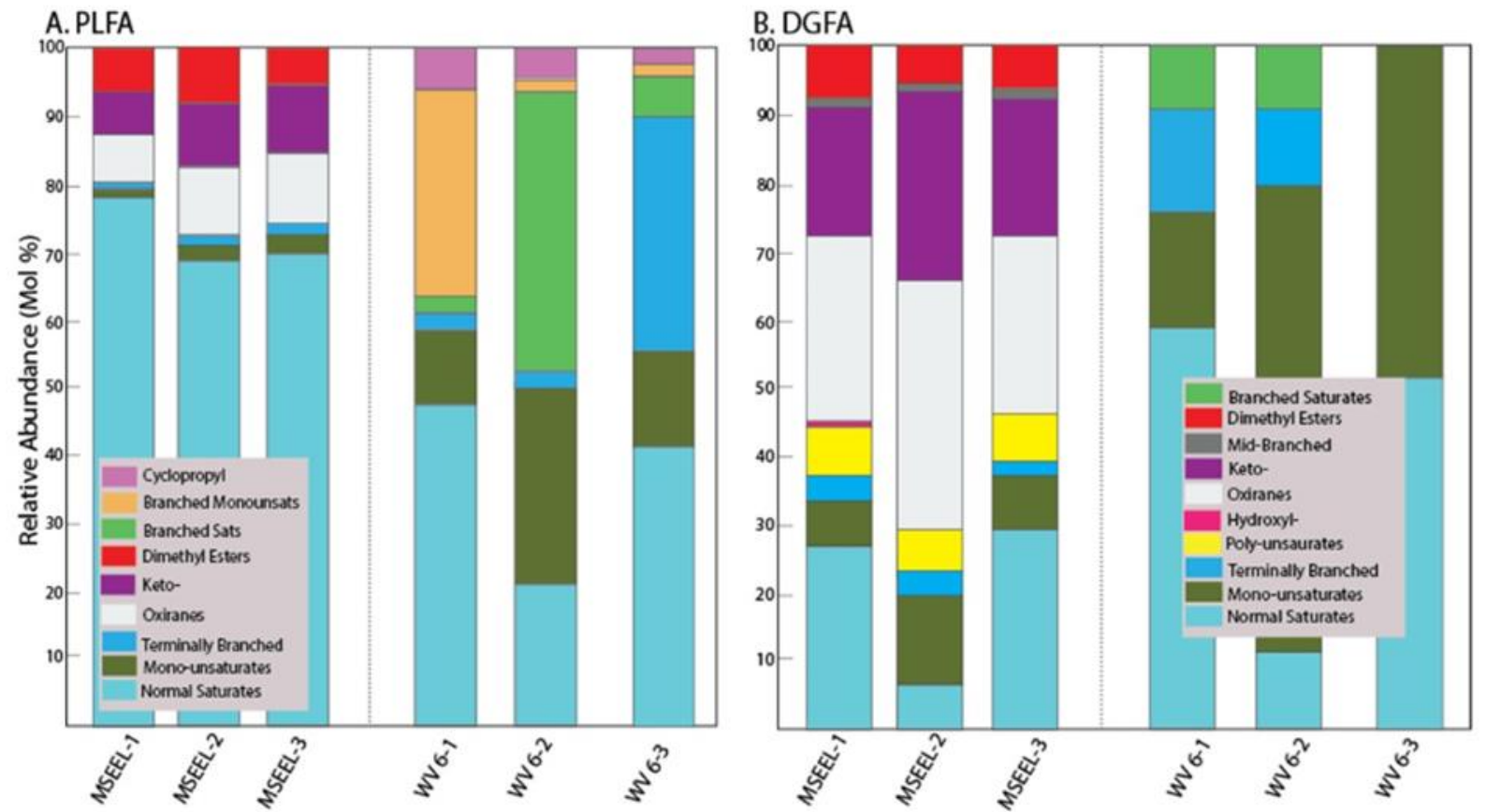

Figure 4. Relative abundance and distribution of PLFA (A) and DGFA (B) biomarker functional groups for the MSEEL and WV 6 core samples. MSEEL-1 and WV 6-1=Mahantango, MSEEL-2 and WV 6-2=Marcellus Top, MSEEL-3 and WV 6-3=Upper Marcellus Shale zones. The cores from the same well had similar distribution of lipid communities.

As speculated, there is a clear difference in the relative abundance of the PLFA and DGFA biomarkers between the MSEEL and WV 6 core samples (Figure 4A, B). The distribution of the 
high abundance PLFA (i.e. PLFAs with $>10 \%$ relative abundance) such as normal saturates were similar between the MSEEL and WV 6 samples (Figure 4A). The proportion of other lipid functional groups like branched saturates and terminally branched were of high abundance (>10\% relative abundance) in some of WV 6 samples but not in the MSEEL samples (Figure 4A). The proportion of DGFA normal saturates were of higher relative abundance $(>10 \%$ relative abundance) in the WV 6 and MSEEL core samples (Figure 4B).

On the other hand, the monounsaturates and terminal branched were of high abundance (>10\% relative abundance) in all WV 6 samples while the keto and oxiranes were of high relative abundance in the MSEEL samples (Figure 4B). Lipid biomarkers were similar within core samples from the same well i.e. WV 6 (WV 6-1, WV 6-2, and WV 6-3) and the MSEEL (MSEEL-1, MSEEL-2, and MSEEL-3), suggesting that the respective cores contained similar microbial communities and were probably exposed to similar environmental conditions. The MSEEL core samples had higher Gram (+)/Gram (-) ratios compared to WV 6 core samples (Figure 5A, B). There was, however, no considerable difference in the ratio of saturates/unsaturates between the MSEEL and WV 6 core samples (Figure 5C, D). The trans/cis ratios were higher in the DGFA for the MSEEL samples compared to the WV 6 samples (Figure 5F). 

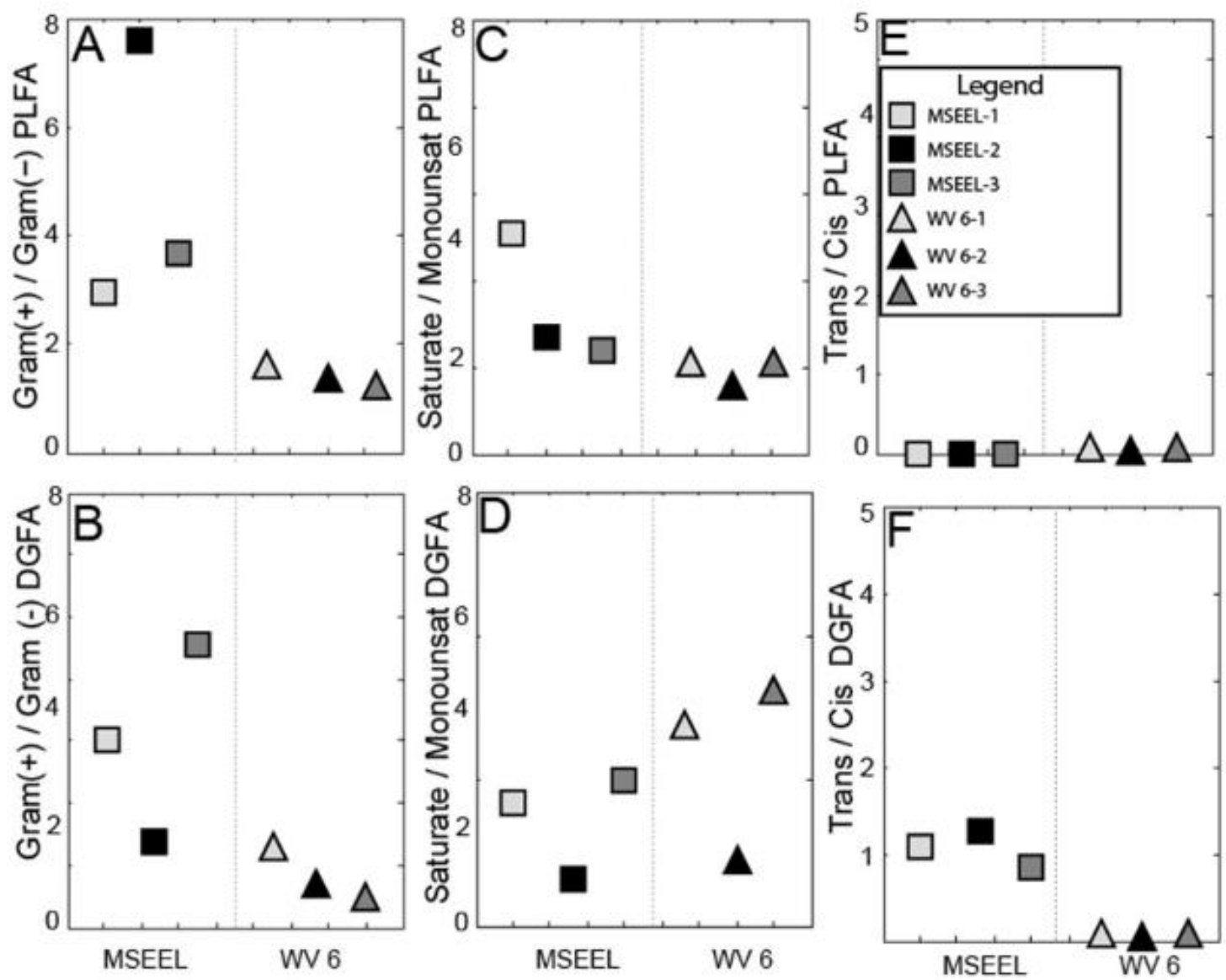

Figure 5. Biomass yields showing ratio of Gram $(+) / \operatorname{Gram}(-)(A, B)$, ratio of saturated/unsaturated $(\mathrm{C}, \mathrm{D})$, and trans/cis lipid biomarkers $(\mathrm{E}, \mathrm{F})$ for the PLFA and DGFA in the MSEEL and WV 6 core samples.

\subsection{Discussion}

\subsubsection{Membrane Lipid Yield}

The microbial lipid concentrations in the MSEEL core samples were higher compared to the corresponding WV 6 core samples for both PLFA and DGFA (Figure 2A, B). The variety of the PLFA and DGFA biomarkers were also higher in the MSEEL core samples (Figures 3, 4), indicating that there was a loss in lipid variety after storage. Our observations were in contrast to 
previous researchers who have suggested that surface storage conditions provide stimuli necessary for growth and resuscitation of dormant subsurface microbes, thus increasing culturability of otherwise subsurface viable but non-culturable cells (VBNC; Hirsch and Rades-Rohkohl., 1988; Munro et al., 1989; Nilsson et al., 1991; Amy et al., 1993; Fredrickson et al., 1995; Halderman et al., 1994, 1995). In fact, Haldeman et al. (1995), reported increase in microbial biomass in samples stored at $4{ }^{\circ} \mathrm{C}$ compared to samples stored at $-20^{\circ} \mathrm{C}$. Our results were more in line with other researchers who suggested that while exposure to surface physical and chemical conditions could result in the stimulation of microbial growth, it could also lead to the loss of otherwise subsurfaceadapted microbes (Roszak and Colwell, 1987; Thorn and Ventullo., 1988; Kieft et al., 1994; Haldeman et al., 1993). Accordingly, studies have reported decrease in diversity of culturable microbial cells after storage due to the inability of some microbial species to adapt to changing environmental conditions (Roszak and Colwell, 1987; Thorn and Ventullo., 1988; Amy et al., 1993; Brockman et al., 1992; Haldeman et al., 1993; 1994; Kieft et al., 1994). This implies that during storage, the growth of some microbes could be occurring concurrently at the expense of the death of others. The decline in total biomass and lipid variety in WV 6 core samples after long term storage could therefore be a result of loss or degradation of other membrane lipids (Thomas and Batt, 1969) due to the inability of some of the subsurface adapted microbial species to adapt to surface environmental settings. The WV 6 microbial communities have been exposed to surface temperature, nutrient, and osmotic conditions very different from the subsurface for an extended amount of time. Because of the low permeability and small pore-throat sizes in shales (Fukunaga and Russell, 1990; Mills, 1997), it is possible that microbial cells may not be able to metabolize and stimulate growth despite conducive surface conditions or may do so at the expense of the loss 
of other microbial cell constituents. More so, efforts to recover cultivable microbes from these core samples have not yet been successful.

\subsubsection{Environmental Adaptations and Membrane Lipid Composition}

Microbes modify their membrane lipid structures (e.g., length of lipid fatty acid, double bonds, methyl branching etc.), depending on environmental parameters (temperature, salinity, and $\mathrm{pH}$ ), which in turn controls ion diffusion across the membrane, thus cell bioenergetics. The chemical structure of membrane biomarkers therefore provides important clues to interpret microbial environments (Harwood and Russell, 1984; Guckert et al., 1986). For example, biomarkers like the iso and anteiso-lipid fatty acids which are associated with Gram (+) bacteria (Edlund et al., 1985; Guckert et al., 1985; Dowling et al., 1986; Ringelberg et al., 1997; Pennanen et al., 1998; Zelles, 1999), were present in both WV 6 and MSEEL core samples. However, considerably higher amounts were detected in the MSEEL core samples (i15:0, a15:0, i16:0, i17:0, i18:0, a17:0) while only two (i13:0 and i14:0) were present in the WV 6 core samples (Figure 3A, B). Higher ratio of Gram (+)/Gram (-) lipid profiles were also observed in the MSEEL core samples compared to the WV 6 core samples (Figure 5A, B). This could be because many Gram (+) microbes are spore forming and are more resistant (Stevenson, 1978; Keynan, 1978; Kaneda, 1991), and hence better suited for survival in prolonged periods of high temperature and pressure conditions. More so, the Gram (+) bacteria have thick peptidoglycan layer in their cell membranes that provide a protective mechanism for the microbes under conditions of high salinity or pressure (Holtje, 1998; Ward et al., 1998; Delcour et al., 1999; Bansal-Mutalik and Nikaido, 2014). This dominance of Gram (+) microbial signatures in MSEEL core samples is thus reasonable since the thick peptidoglycan layers will serve as a robust protective barrier for the cells under subsurface conditions of high temperature and pressure stress. This notion has also been supported by 
researchers who observed the predominance of Gram (+) microbial cells as the residence time of flow back fluids in Marcellus Shale wells increased (Mohan et al., 2013; Cluff et al., 2014; Mohan et al., 2014; Daly et al., 2016; 2018). The researchers attributed the dominance of the Gram (+) microbial cells to the biochemical adaptive mechanism (osmoprotection) for microbial survival under subsurface conditions of temperature, pressure, and salinity.

The saturate:unsaturated ratios in both WV 6 and MSEEL cores were similar (Figure 5B, C), indicating that microbial communities in both cores maintained similar membrane packing. Microbes change degree of unsaturation in membrane lipids to balance membrane fluidity for proper functioning in response to changes in environmental conditions (Reizer et al., 1985; Suutari and Laakso, 1992; Hazel, 1995; Beranová et al., 2008; Sollich et al., 2017). Some researchers have associated increase saturated to unsaturated fatty acids ratios with response to limited nutrient availability (Amy and Morita., 1983; Oliver and Stringer., 1984; Guckert et al., 1986; Moyer and Morita., 1989; Amy et al., 1993; Kieft et al., 1994; Bossio and Scow, 1998). This is because as the amount of double bonds decrease, the membrane lipid structures become less mobile and less fluidized, thereby serving as a barrier to the inadvertent passage of ions across the membrane, thus conserving energy (Valentine, 2007; Valentine and Valentine, 2004). It is plausible therefore, that both MSEEL and WV 6 core samples responded to some form of nutrient limitation. Since we do not know the metabolic status, transformation pathways, and energy sources of the deep subsurface microbes, we cannot exclusively define the environmental stress factors responsible for the similar saturated:unsaturated lipid ratios. Microbes will, however, adjust membrane lipid structures to maintain fluidity, balance permeability to survive stress, irrespective of whether the stress is linked with subsurface or surface conditions. 
Another starvation-stress response strategy microbes adopt is by increasing amounts of trans- compared to cis-monoenoic unsaturated fatty acids (Amy and Morita., 1983; Oliver and Stringer., 1984; Guckert et al., 1986; Moyer and Morita., 1989; Amy et al., 1993; Kieft et al., 1994).

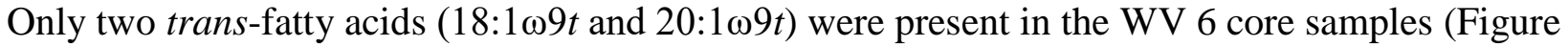

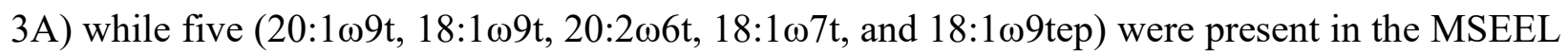
core samples (Figure 3A, B). Under conditions of high stress the enzyme cis-trans isomerase converts the cis double bond to a trans double bond (Figure 6). We therefore suggest that microbes in both WV 6 and MSEEL cores samples modified their membrane lipid fatty acids in response to some form of stress. However, the greater variety of trans lipid fatty acid profiles and higher trans to cis ratios in MSEEL core samples (Figure 6D), indicates that biomarkers in MSEEL cores experienced higher forms of nutrient-limited stress compared to the WV 6 core samples.

\subsubsection{Exclusive Subsurface Membrane Lipid Biomarkers}

Lipid biomarkers such as the oxiranes, keto-, and dimethyl lipid fatty acids were only present (high relative abundance $>10 \%$ ) in the MSEEL core samples (Figures 3, 4). Oxiranes are produced from the oxidation of unsaturated fatty acids under stress in the presence of radical oxygen species (ROS) or from lipid monooxygenases in response to environmental conditions like salt stress and nutrient limitation (Smith et al., 2000; Lin et al., 2006). The WV 6 core samples stored under surface conditions had higher oxygen availability in contrast to MSEEL core samples that were not exposed to oxygenating conditions. Despite the lack of molecular oxygen in the deep subsurface conditions, the MSEEL samples showed the presence of oxiranes. The decay of naturally occurring radioactive material (NORM) can produce ROS necessary for oxirane production (Pfiffner et al., 2006). Since both MSEEL and WV 6 core samples have high NORM levels (Hill et al., 2004; EPA, 2008; Kargbo et al., 2010; Akondi et al., 2019), we should expect to 
see presence of oxiranes in both cores. We hypothesize that the absence of the oxiranes in the WV 6 core samples could be a result of the transformation of oxiranes to relatively more stable structures in response to the low temperatures and pressures on the surface. This is important because oxiranes are oxidative intermediate stress-related biomarkers formed as a stationary-phase survival mechanism. More so, changes in environmental signals like temperatures and pressures trigger modulation of lipid synthesis, raising the possibility that these lipid structures are selectively tailor-made to survive under high temperature stressed environment. With increasing conditions of stress like nutrient limitation the trans-lipid fatty acids are converted to the oxirane. Like the oxiranes, the keto- and dimethyl esters are also metabolic intermediates in the transformative process of unsaturated and hydroxyl lipids. We thus attribute the absence of unique membrane lipid classes such as keto- and dimethyl lipid fatty acids in all WV 6 core samples to either the response of the microbial community to surface conditions or to the successive breakdown of their lipid structures and the consequent proliferation of the more stable lipid fatty acids. However, to understand the extent of subsurface microbial adaptation and whether the microbial community in WV 6 core samples are surface representatives of subsurface microbial species, more research needs to be done by isolating and culturing different microbial species. 


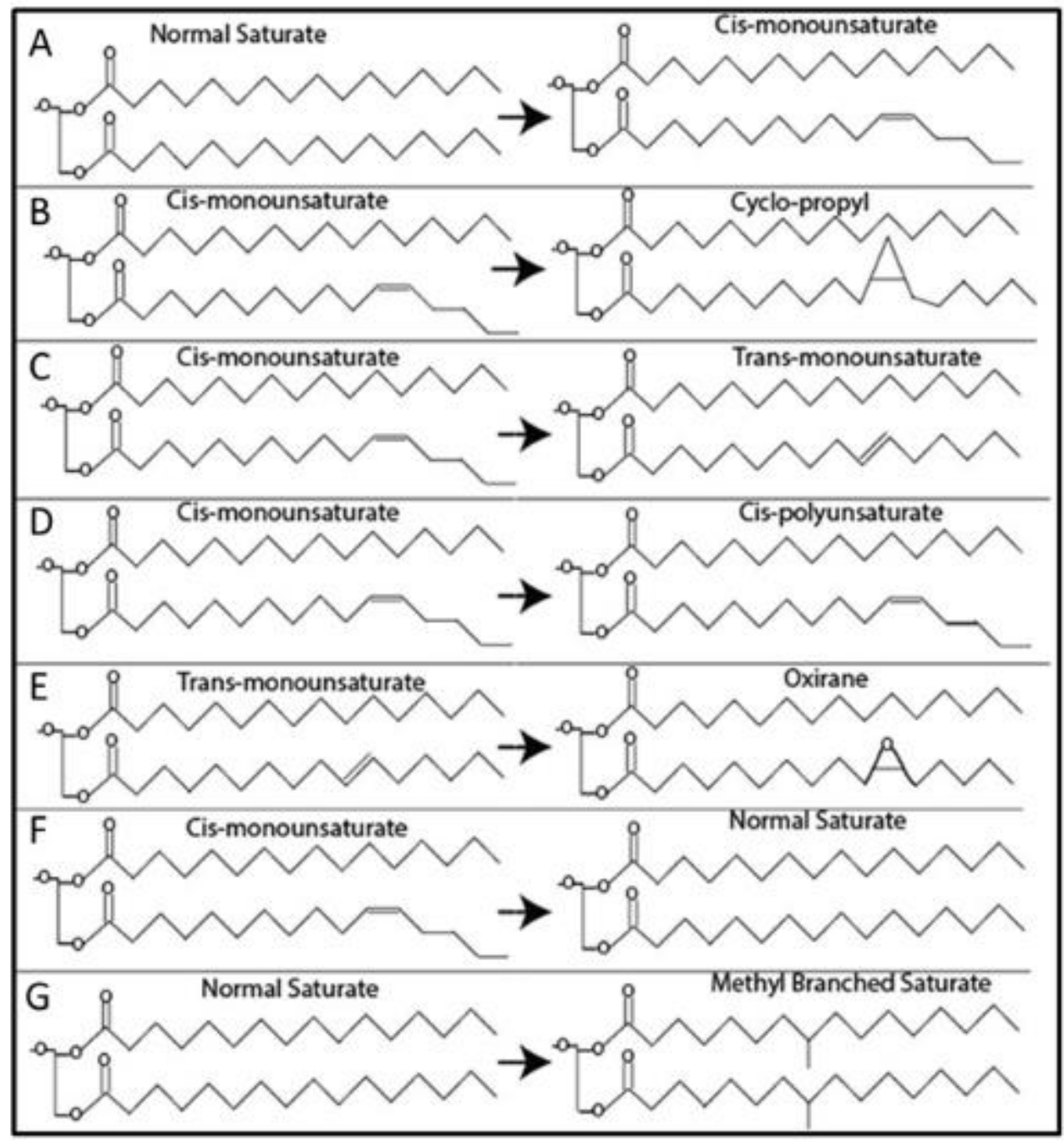

Figure 6. A conceptual representation of common lipid fatty acid modifications of biomarkers detected in this study. In response to changes in environmental rapidly to changes in environmental conditions by modify the structure of membrane phospholipids.

\subsubsection{Exclusive Surface Membrane Lipid Biomarkers}

Some lipid biomarkers of the branched saturates (br16:0, br18:0, br15:0) and cyclopropyl were only present in the WV 6 core samples (Figures 3, 4). It has been established that reduction in chain length and branching of methyl groups are some of the common response mechanisms which microbes employ to adapt to low temperature stress (Annous et al., 1996; Murata and Wada, 1995; Gombos et al., 1992; Los et al., 1997). Membrane modifications involving branched 
saturates are also associated with maintaining fluidity and balancing permeability. Klein et al. (1999), conducted experiments to measure microbial response to low temperature stress and reported that microbes were characterized by a high content of branched fatty acids irrespective of the growth medium. We suggest that exposure to low temperature stressed environments induced the formation of the branched saturated as a special set of membrane lipids to accommodate the surface environmental conditions.

Gram (-) bacteria form cyclopropyl fatty acids by modification of monounsaturated membrane lipids as a mechanism to survive under oligotrophic conditions or stationary phase of growth (Figure 6; Harwood and Russel, 1984; Guckert et al., 1985, 1986, 1987; Nichols et al., 1986, Rajendran et al., 1992; Kieft et al., 1994; Bossio and Scow, 1998). Because the $\mathrm{C}_{17}$ cyclopropyl and its precursor 16:1 $17 \mathrm{c}$ were only detected in the WV 6 sample (Figures 3 , 4), we hypothesize that some of the microbial community in WV 6 core samples could be surface transformed representatives of subsurface microbial communities. It is, however, unclear from this study whether the presence or absence of certain microbial signatures in the WV 6 samples constitute the obliteration or resuscitation of some microbial cells. The normal saturate is converted to cis-monounsaturated lipid fatty acid by the desaturase enzyme, thus increasing membrane fluidity (Figure 6). This is because the cis-unsaturated fatty acid takes up more molecular volume and thus makes the membrane less densely packed. With exposure to nutrient limited stress, the enzyme cyclopropane fatty acid synthase converts the cis-monounsaturated lipid fatty acid to cyclopropyl by introducing a cyclic ring in the double bond. The cyclopropyl lipids provide more stability and resistance from environmental stress. There is also a possibility that the microbial lipid signatures which were only detected in WV 6 samples could reflect exogenous or surface derived microbial signatures from drilling, storage and handling. The notion of 
contamination in the WV 6 cores is feasible since core samples with a large carbon pool and available oxygen would be a good place for microbes to grow. The absence of signature stress biomarkers like the oxiranes, dimethyl, and keto lipid fatty acids nonetheless indicates that in some ways, the WV 6 community structure represents surface transformative representatives of subsurface signatures. Such transformations could be a result of biotic or abiotic processes. It is also possible that the organisms themselves modulated their membrane structures or the community composition changed in response to some perturbation. Another plausibility is that the subsurface microbes within the core of WV 6 did not adapt but rather the core is being colonized by surface microbes. Small pore throat sizes might be the only limitation towards microbial surface colonization, but if there are small fractures in the core this could be a potential pathway for invasion.

\subsection{Conclusion}

The decline in total biomass and lipid variety in WV 6 core samples after long term storage could therefore be a result of degradation of other membrane lipids or a result of the inability to adapt to surface environmental settings. The absence of some stress related microbial biomarkers in WV 6 core samples suggest the transformation of the subsurface adapted biomarkers to relatively more stable structures in response to low temperatures and pressures in the surface. The similarity of some microbial biomarkers in MSEEL and WV 6 core samples after decades of storage indicates the potential persistence of subsurface microbial communities in surface environmental conditions for extended durations. Some of the WV 6 microbial community could therefore be surface-adapted representatives of the subsurface derived microbial community. It is also possible that microbial lipid biomarkers only present in the WV 6 samples could be exogenous signatures. This study thus emphasizes the necessity of efficient sample storage for deep 
subsurface ecological studies. However, as we do not know the metabolic status, transformation pathways, and energy sources of the deep subsurface microbes, we cannot exclusively define the environmental stress factors associated with subsurface and surface microbial cell membranes. As a result, we consider membrane adaptability as a survival mechanism for changing environmental conditions irrespective of the associated condition. To better understand the relationship between individual microbial communities in response to different environmental changes detailed studies involving DNA sequencing on pure subsurface microbial isolates are needed. Because, lipid analyses do not have the taxonomic specificity like DNA-based techniques, molecular analyses using DNA-based techniques are required to further analyze the microbial composition and to correlate the characteristic community component with changing environmental conditions.

\subsection{Acknowledgement}

This study was funded through NSF grants to Dr. Sharma (NSF EAR \# 1205596; NSFDEB \# 1342732). We thank the participating teams from the WVU and the OSU for assistance with sample collection and preparation for analysis. We would like to thank Dr. Paula J. Mouser for helpful suggestions. We also thank the West Virginia Geological and Economic Survey for

providing core samples for WV 6 well. Laboratory assistance from Dr. Warrier, other members of WVU isotope laboratory and members of the OSU Microbiology research team is greatly appreciated. 


\subsection{References}

Akob DM, Cozzarelli IM, Dunlap DS et al. Organic and inorganic composition and microbiology of produced waters from Pennsylvania shale gas wells. Appl Geochem 2015;60:116-25.

Akondi, R. N., Trexler, R. V., Pfiffner, S. M., Mouser, P. J., \& Sharma, S. (2018). Lipid Biomarkers Detected in Subsurface Shale (Environmental Science: Processes \& Impacts in review).

Amy, P. S., Haldeman, D. L., Ringelberg, D., Hall, D. H., Russell, C., 1992. Comparison of identification systems for classification of bacteria isolated from water and endolithic habitats within the deep subsurface. Applied and Environmental Microbiology, 58(10), 3367-3373.

Amy, P. S., Morita, R. Y., 1983. Starvation-survival patterns of sixteen freshly isolated open-ocean bacteria. Applied and Environmental Microbiology, 45(3), 1109-1115.

Amy, P. S., Durham, C., Hall, D., Haldeman, D. L., 1993. Starvation-survival of deep subsurface isolates. Current Microbiology, 26(6), 345-352.

Baird, B. H., White, D. C., 1985. Biomass and community structure of the abyssal microbiota determined from the ester-linked phospholipids recovered from Venezuela Basin and Puerto Rico Trench sediments. Marine Geology, 68(1), 217-231.

Bligh, E. G., Dyer, W. J., 1959. A rapid method of total lipid extraction and purification. Canadian journal of biochemistry and physiology, 37(8), 911-917.

Bossio, D. A., \& Scow, K. M. (1998). Impacts of carbon and flooding on soil microbial communities: phospholipid fatty acid profiles and substrate utilization patterns. Microbial ecology, 35(3-4), 265-278.

Brockman, F. J., Kieft, T. L., Fredrickson, J. K., Bjornstad, B. N., Shu-mei, W. L., Spangenburg, W., Long, P. E. (1992). Microbiology of vadose zone paleosols in south-central Washington state. Microbial ecology, 23(3), 279-301.

Colwell, F., Stormberg, G., Phelps, T., Birnbaum, S., McKinley, J., Rawson, S., Veverka, C., Goodwin, S., Long, P., Russell, B., Garland, T., Thompson, D., Skinner, P. and Grover, S., 1992. Innovative techniques for collection of saturated and unsaturated subsurface basalts and sediments for microbiological characterization. J. Microbiol. Methods 15, 279-292.

Colwell, F. S., Onstott, T. C., Delwiche, M. E., Chandler, D., Fredrickson, J. K., Yao, Q. J., Long, P. E., 1997. Microorganisms from deep, high temperature sandstones: constraints on microbial colonization. FEMS Microbiology Reviews, 20(3-4), 425-435.

Colwell, F. S., D'Hondt, S. (2013). Nature and extent of the deep biosphere. Reviews in Mineralogy and Geochemistry, 75(1), 547-574.

Cluff, M. A., Hartsock, A., MacRae, J. D., Carter, K., Mouser, P. J., 2014. Temporal changes in microbial ecology and geochemistry in produced water from hydraulically fractured Marcellus Shale gas wells. Environmental science \& technology, 48(11), 6508-6517.

Cronan Jr, J. E., Gelmann, E. P. (1975). Physical properties of membrane lipids: biological relevance and regulation. Bacteriological reviews, 39(3), 232.

Daly R, Borton M, Wilkins M et al. Microbial metabolisms in a new $2.5 \mathrm{~km}$ deep ecosystem created by hydraulic fracturing in shales. Nat Microbiol 2016.

Daly, R. A., Wrighton, K. C., \& Wilkins, M. J. (2018). Characterizing the Deep Terrestrial Subsurface Microbiome. In Microbiome Analysis (pp. 1-15). Humana Press, New York, NY. 
Delcour, J., Ferain, T., Deghorain, M., Palumbo, E., and Hols, P. (1999). The biosynthesis and functionality of the cell-wall of lactic acid bacteria. Antonie Van Leeuwenhoek 76, 159184

Dowling, N. J., Widdel, F., White, D. C., 1986. Phospholipid ester-linked fatty acid biomarkers of acetate-oxidizing sulphate-reducers and other sulphide-forming bacteria. Journal of General Microbiology, 132(7), 1815-1825.

Edlund, A., Nichols, P. D., Roffey, R., White, D. C., 1985. Extractable and lipopolysaccharide fatty acid and hydroxy acid profiles from Desulfovibrio species. Journal of Lipid Research, 26(8), 982-988.

EPA (2008). "Technologically Enhanced Naturally Occurring Radioactive MaterialsFrom Uranium Mining", (ed.) U.S. EPA/ORIA. (Washington, DC).

Edwards, K. J., Becker, K., Colwell, F. (2012). The deep, dark energy biosphere: intraterrestrial life on earth. Annual Review of Earth and Planetary Sciences, 40, 551-568.

Fredrickson, J. K., Balkwill, D. L., Zachara, J. M., Li, S. M. W., Brockman, F. J., \& Simmons, M. A. (1991). Physiological diversity and distributions of heterotrophic bacteria in deep cretaceous sediments of the Atlantic coastal plain. Applied and Environmental Microbiology, 57(2), 402-411.

Fredrickson, J. K., Onstott, T. C., 1996. Microbes deep inside the earth. Scientific American, 275(4), 68-73.

Fredrickson, J. K., McKinley, J. P., Nierzwicki-Bauer, S. A., White, D. C., Ringelberg, D. B., Rawson, S. A., Bjornstad, B. N., 1995. Microbial community structure and biogeochemistry of Miocene subsurface sediments: implications for long-term microbial survival. Molecular ecology, 4(5), 619-626.

Fredrickson, J.K., Phelps, T. J., 1996. Subsurface drilling and sampling. In: Knudsen G, Stetzenbach L, McInerney MM, Walter M (eds) Manual of environmental microbiology. ASM Press, Washington, DC, pp 526-540

Fredrickson, J. K., McKinley, J. P., Bjornstad, B. N., Long, P. E., Ringelberg, D. B., White, D. C., Phelps, T. J., 1997. Pore-size constraints on the activity and survival of subsurface bacteria in a late cretaceous shale-sandstone sequence, northwestern New Mexico. Geomicrobiology Journal, 14(3), 183-202.

Guckert, J. B., Antworth, C. P., Nichols, P. D., White, D. C., 1985. Phospholipid, ester-linked fatty acid profiles as reproducible assays for changes in prokaryotic community structure of estuarine sediments. FEMS Microbiology Ecology, 31(3), 147-158.

Guckert, J. B., Hood, M. A., White, D. C., 1986. Phospholipid ester-linked fatty acid profile changes during nutrient deprivation of Vibrio cholerae: increases in the trans/cis ratio and proportions of cyclopropyl fatty acids. Applied and environmental microbiology, 52(4), 794-801.

Guckert, J. B., Ringelberg, D. B., White, D. C., 1987. Biosynthesis of trans fatty acids from acetate in the bacterium Pseudomonas atlantica. Canadian journal of microbiology, 33(9), 748-754.

Haldeman, D. L., Amy, P. S., Ringelberg, D., White, D. C., 1993. Characterization of the microbiology within a $21 \mathrm{~m} 3$ section of rock from the deep subsurface. Microbial ecology, 26(2), 145-159.

Haldeman, D. L., Amy, P. S., White, D. C., Ringelberg, D. B., 1994. Changes in bacteria recoverable from subsurface volcanic rock samples during storage at $4 \mathrm{C}$. Applied and environmental microbiology, 60(8), 2697-2703. 
Haldeman, D. L., Amy, P. S., Ringelberg, D., White, D. C., Garen, R. E., Ghiorse, W. C., 1995. Microbial growth and resuscitation alter community structure after perturbation. FEMS Microbiology Ecology. 17 (1) 27-37; DOI: 10.

Hirsch, P., Rades-Rohkohl, E., 1988. Some special problems in the determination of viable counts of groundwater microorganisms. Microbial ecology, 16(1), 99-113.

Hill, D.G., Lombardi, T.E., and Martin, J.P. (2004). Fractured shale gas potential in New York. Northeastern Geol. Environ. Sci. 26.

Holtje, J.V. (1998). Growth of the stress-bearing and shape-maintaining murein sacculus of Escherichia coli. Microbiol Mol Biol Rev 62, 181-203.

Inagaki, F., Hinrichs, K. U., Kubo, Y., Bowles, M. W., Heuer, V. B., Hong, W. L., Kaneko, M., 2015. Exploring deep microbial life in coal-bearing sediment down to $2.5 \mathrm{~km}$ below the ocean floor. Science, 349(6246), 420-424.

Kargbo, D.M., Wilhelm, R.G., and Campbell, D.J. (2010). Natural gas plays in the Marcellus Shale: challenges and potential opportunities. Environ Sci Technol 44, 5679-5684. doi: 10.1021/es903811p.

Kieft, T. L., Ringelberg, D. B., White, D. C., 1994. Changes in ester-linked phospholipid fatty acid profiles of subsurface bacteria during starvation and desiccation in a porous medium. Applied and Environmental Microbiology, 60(9), 3292-3299.

Kinkel, L. L., Nordheim, E. V., \& Andrews, J. H. (1992). Microbial community analysis in incompletely or destructively sampled systems. Microbial ecology, 24(3), 227-242.

Krumholz, L. R., McKinley, J. P., Ulrich, G. A., Suflita, J. M., 1997. Confined subsurface microbial communities in Cretaceous rock.

Mohan AM, Hartsock A, Bibby KJ et al. Microbial community changes in hydraulic fracturing fluids and produced water from shale gas extraction. Environ Sci Technol 2013b;47:13141-50.

Mouser, P. J., Borton, M., Darrah, T. H., Hartsock, A., \& Wrighton, K. C. (2016). Hydraulic fracturing offers view of microbial life in the deep terrestrial subsurface. FEMS microbiology ecology, 92(11).

Munro, P. M., Gauthier, M. J., Breittmayer, V. A., \& Bongiovanni, J. (1989). Influence of osmoregulation processes on starvation survival of Escherichia coli in seawater. Applied and Environmental Microbiology, 55(8), 2017-2024.

Nichols, P.D., Guckert, J.B., White, D.C., 1986. Determination of monosaturated fatty acid double-bond position and geometry for microbial monocultures and complex consortia by capillary GC-MS of their dimethyl disulphide adducts Journal of Microbiological Methods, 5 (1), pp. 49-55.

Nilsson, L., Oliver, J. D., \& Kjelleberg, S. (1991). Resuscitation of Vibrio vulnificus from the viable but nonculturable state. Journal of bacteriology, 173(16), 5054-5059.

Oliver, J. D., Stringer, W. F., 1984. Lipid composition of a psychrophilic marine Vibrio sp. during starvation-induced morphogenesis. Applied and environmental microbiology, 47(3), 461466.

Onstott, T.C., Phelps, T.J., Colwell, F.S., Ringelberg, D., White, D.C., Boone, D.R., McKinley, J.P., Stevens, T.O., Long, P.E., and Balkwill, D.L. (1998). Observations pertaining to the origin and ecology of microorganisms recovered from the deep subsurface of Taylorsville Basin, Virginia. Geomicrobiology Journal 15, 353-385. 
Phelps, T. J, Fliermans C.B, Garland T. R, Pfiffner S. M, White D.C., 1989. Methods for recovery of deep terrestrial subsurface sediments for microbiological studies. J Microbiol Methods 9:267-279

Phelps, T. J, Pfiffner, S. M., Sargent, K, A., White, D.C., 1994. Factors influencing the abundance and metabolic capacities of microorganisms in eastern coastal plain sediments. Microbiol Ecol 28: 351-364.

Pennanen, T., Fritze, H., Vanhala, P., Kiikkilä, O., Neuvonen, S., \& Bååth, E. (1998). Structure of a microbial community in soil after prolonged addition of low levels of simulated acid rain. Applied and Environmental Microbiology, 64(6), 2173-2180.

Pfiffner, S. M., Cantu, J. M., Smithgall, A., Peacock, A. D., White, D. C., Moser, D. P., ... van Heerden, E. (2006). Deep subsurface microbial biomass and community structure in Witwatersrand Basin mines. Geomicrobiology Journal, 23(6), 431-442.

Rajendran, N., Matsuda, O., Imamura, N., Urushigawa, Y., 1992. Variation in microbial biomass and community structure in sediments of eutrophic bays as determined by phospholipid ester-linked fatty acids. Applied and Environmental Microbiology, 58(2), 562-571.

Rajendran, N., Suwa, Y., Urushigawa, Y., 1993. Distribution of phospholipid ester-linked fatty acid biomarkers for bacteria in the sediment of Ise Bay, Japan. Marine Chemistry, 42(1), 39-56.

Ringelberg, D. B., Davis, J. D., Smith, G. A., Pfiffner, S. M., Nichols, P. D., Nickels, J. S., Read, H. W., 1989. Validation of signature polarlipid fatty acid biomarkers for alkane-utilizing bacteria in soils and subsurface aquifer materials. FEMS Microbiology Ecology, 5(1), 3950.

Ringelberg, D. B., Sutton, S., White, D. C., 1997. Biomass, bioactivity and biodiversity: microbial ecology of the deep subsurface: analysis of ester-linked phospholipid fatty acids. FEMS Microbiology Reviews, 20(3-4), 371-377.

Roszak, D. B., Colwell, R. R., 1987. Survival strategies of bacteria in the natural environment. Microbiological reviews, 51(3), 365.

Russell, N.J., 1992. Physiology and molecular biology of psychrophilic microorganisms. In: R.A

Smith, C. A., Phiefer, C. B., Macnaughton, S. J., Peacock, A., Burkhalter, R. S., Kirkegaard, R., White, D. C., 2000. Quantitative lipid biomarker detection of unculturable microbes and chlorine exposure in water distribution system biofilms. Water Research, 34(10), 26832688.

Sollich, M., Yoshinaga, M. Y., Häusler, S., Price, R. E., Hinrichs, K. U., \& Bühring, S. I. (2017). Heat stress dictates microbial lipid composition along a thermal gradient in marine sediments. Frontiers in microbiology, 8, 1550.

Thorn, P. M., Ventullo, R. M., 1988. Measurement of bacterial growth rates in subsurface sediments using the incorporation of tritiated thymidine into DNA. Microbial ecology, 16(1), 3-16.

Tunlid, A., Ringelberg, D., Phelps, T. J., Low, C., White, D. C., 1989. Measurement of phospholipid fatty acids at picomolar concentrations in biofilms and deep subsurface sediments using gas chromatography and chemical ionization mass spectrometry. Journal of Microbiological Methods, 10(2), 139-153.

Volkman, J. K., 2000. Ecological and environmental factors affecting alkenone distributions in seawater and sediments. Geochemistry, Geophysics, Geosystems, 1(9).

White, D. C., Davis, W. M., Nickels, J. S., King, J. D., Bobbie, R. J., 1979. Determination of the sedimentary microbial biomass by extractible lipid phosphate. Oecologia, 40(1), 51-62. 
White, D. C., 1988. Validation of quantitative analysis for microbial biomass, community structure, and metabolic activity. Adv. Limnol, 31(1).

White, D. C., Ringelberg, D.B., Guckert, J.B., Phelps, J., 1991. Biochemical markers for insitu microbial community structure p.4-45-4-In C. B. Fliemans and T.C Hazen (ed), Proceedings of the Deep Subsurface, January 15-19, 1990. WSRC. Information Services, Aiken, S.C

White, D. C., Ringelberg, D. B., 1997. Utility of the signature lipid biomarker analysis in determining in situ viable biomass, community structure and nutritional/physiological status of deep subsurface

Wilkins, M. J., Daly, R., Mouser, P. J., Trexler, R., Wrighton, K. C., Sharma, S., \& Kieft, T. L. (2014). Trends and future challenges in sampling the deep terrestrial biosphere. Frontiers in microbiology, 5, 481.

Zelles L., 1999. Biol Fert Soils 29:111-129 
Tables

CHAPTER 1

Table 2. Molar percentages of DG-FAME yield in pmol/g, and number of detected DG-FAME biomarkers recovered from the different extraction treatment methods.

\begin{tabular}{|c|c|c|c|c|c|c|c|c|c|c|c|c|c|c|c|c|c|c|c|}
\hline Extraction Type & Phos & Phos & Cit & Cit & Cit & $\mathrm{Mg} 2+$ & $\mathrm{Mg} 2+$ & $\mathrm{Mg} 2+$ & POPC & POPC & POPC & Ecoli & Ecoli & Ecoli & Folc & Folc & MAE & MAE & MAE \\
\hline Sample ID & $\begin{array}{l}\mathrm{RTO}_{2} \\
\mathrm{DG}\end{array}$ & $\begin{array}{l}\text { RT01 } \\
\text { R_DG }\end{array}$ & $\begin{array}{l}\text { RT07 } \\
\text { _DG }\end{array}$ & $\begin{array}{l}\text { RTO8_ } \\
\text { DG }\end{array}$ & $\begin{array}{l}\text { RTO9_ } \\
\text { DG }\end{array}$ & $\begin{array}{l}\text { RT10D } \\
\text { G }\end{array}$ & $\begin{array}{l}\text { RT11_ } \\
\text { DG }\end{array}$ & $\begin{array}{l}\text { RT12_ } \\
\text { DG }\end{array}$ & $\begin{array}{l}\text { RT13_ } \\
\text { DG }\end{array}$ & $\begin{array}{l}\text { RT14_ } \\
\text { DG }\end{array}$ & $\begin{array}{l}\text { RT15_ } \\
\text { DG }\end{array}$ & $\begin{array}{l}\text { RT16 } \\
\text { DG }\end{array}$ & $\begin{array}{l}\text { RT17_ } \\
\text { DG }\end{array}$ & $\begin{array}{l}\text { RT18_ } \\
\text { DG }\end{array}$ & $\begin{array}{l}\text { RT19_ } \\
\text { DG }\end{array}$ & $\begin{array}{l}\text { RT21_- } \\
\text { DG }\end{array}$ & $\begin{array}{l}\text { RT2_D } \\
\text { G }\end{array}$ & $\begin{array}{l}\mathrm{RT} 2 \text { _D } \\
\mathrm{G}\end{array}$ & $\begin{array}{l}\mathrm{RT} 24 \\
\mathrm{DG}\end{array}$ \\
\hline C11:0 & 0.00 & 0.00 & 0.00 & 0.00 & 0.00 & 0.00 & 0.00 & 0.00 & 0.00 & 0.00 & 0.00 & 0.00 & 0.00 & 0.00 & 0.00 & 0.00 & 0.06 & 0.00 & 0.03 \\
\hline C12:0 & 0.17 & 0.00 & 0.15 & 0.00 & 0.00 & 0.00 & 0.12 & 0.47 & 0.29 & 0.12 & 0.11 & 0.07 & 0.00 & 0.00 & 0.12 & 0.00 & 0.50 & 0.08 & 0.36 \\
\hline C13:0 & 1.39 & 0.10 & 0.00 & 0.00 & 0.00 & 0.00 & 0.70 & 0.20 & 0.89 & 0.22 & 0.29 & 0.35 & 0.00 & 0.00 & 0.57 & 0.00 & 1.14 & 0.43 & 1.50 \\
\hline iso-C14:0 & 0.81 & 0.21 & 0.00 & 0.00 & 0.00 & 0.00 & 0.00 & 0.00 & 0.45 & 0.21 & 0.25 & 0.28 & 0.00 & 0.00 & 0.50 & 0.00 & 0.47 & 0.34 & 0.77 \\
\hline C14:0 & 3.85 & 3.76 & 1.51 & 4.39 & 2.42 & 3.12 & 3.43 & 4.84 & 3.30 & 2.16 & 2.50 & 2.63 & 0.56 & 0.61 & 2.94 & 1.56 & 3.74 & 3.64 & 4.57 \\
\hline C15:0 & 4.37 & 0.00 & 4.89 & 5.39 & 5.12 & 3.57 & 6.75 & 0.00 & 4.97 & 4.25 & 5.04 & 4.65 & 1.99 & 1.52 & 4.99 & 4.56 & 6.28 & 5.99 & 7.52 \\
\hline $\mathrm{C} 16: 1 \mathrm{w} 14 \mathrm{t}$ & 5.64 & 4.25 & 5.66 & 9.40 & 6.71 & 11.58 & 1.20 & 6.90 & 4.63 & 4.87 & 4.56 & 4.49 & 2.96 & 2.62 & 5.52 & 2.51 & 3.12 & 0.00 & 0.00 \\
\hline C16:0 & 25.19 & 26.98 & 13.86 & 19.44 & 18.53 & 21.49 & 29.20 & 24.98 & 20.57 & 19.46 & 21.02 & 25.03 & 29.44 & 29.94 & 21.22 & 40.56 & 29.92 & 25.72 & 22.42 \\
\hline anteiso-C17:0 & 7.54 & 6.76 & 7.19 & 14.15 & 10.08 & 0.00 & 0.00 & 0.00 & 5.06 & 5.71 & 6.36 & 4.57 & 3.24 & 3.33 & 4.69 & 4.52 & 5.40 & 5.82 & 5.15 \\
\hline C17:0 & 7.26 & 7.25 & 7.26 & 9.71 & 12.75 & 4.85 & 6.14 & 12.17 & 4.63 & 6.37 & 4.58 & 5.41 & 3.09 & 3.35 & 5.78 & 4.24 & 5.51 & 6.41 & 5.26 \\
\hline C18:2w6 & 3.61 & 6.31 & 0.00 & 0.00 & 0.00 & 0.00 & 0.00 & 0.00 & 3.30 & 3.53 & 3.39 & 2.72 & 2.22 & 2.46 & 0.00 & 0.00 & 0.00 & 0.00 & 0.00 \\
\hline C18:3w3 & 0.00 & 0.00 & 0.00 & 0.00 & 0.00 & 0.00 & 0.00 & 0.00 & 1.91 & 2.57 & 0.00 & 0.00 & 0.00 & 0.00 & 0.00 & 0.00 & 3.39 & 0.00 & 2.57 \\
\hline C18:1w9c & 0.00 & 18.25 & 12.56 & 15.45 & 13.70 & 21.84 & 22.74 & 17.07 & 18.09 & 19.12 & 19.00 & 20.37 & 28.53 & 27.23 & 22.07 & 0.00 & 4.19 & 0.00 & 18.52 \\
\hline C18:1w9t & 0.00 & 8.45 & 8.77 & 8.94 & 9.11 & 11.15 & 8.07 & 7.75 & 7.51 & 7.52 & 7.02 & 6.75 & 5.75 & 5.86 & 7.50 & 0.00 & 5.52 & 23.69 & 8.45 \\
\hline $4 \mathrm{OH}-18: 0$ & 0.00 & 0.00 & 0.00 & 0.00 & 0.00 & 0.00 & 0.00 & 0.00 & 1.69 & 2.22 & 4.31 & 0.00 & 0.00 & 0.00 & 0.00 & 0.00 & 1.38 & 0.00 & 0.00 \\
\hline C18:0 & 17.01 & 13.01 & 12.00 & 10.21 & 13.80 & 13.82 & 15.06 & 16.69 & 13.37 & 14.41 & 13.00 & 13.73 & 18.06 & 18.20 & 13.89 & 22.31 & 18.85 & 17.70 & 13.47 \\
\hline суC19:0 & 5.82 & 4.35 & 5.27 & 2.92 & 7.78 & 8.59 & 1.27 & 7.27 & 3.82 & 4.16 & 3.72 & 3.55 & 1.15 & 1.68 & 4.59 & 2.91 & 4.07 & 5.22 & 4.76 \\
\hline 6-epoxy-C18:1t & 4.46 & 0.00 & 4.48 & 0.00 & 0.00 & 0.00 & 4.84 & 0.00 & 2.59 & 2.72 & 4.48 & 2.23 & 1.56 & 1.76 & 3.08 & 2.86 & 3.38 & 4.17 & 3.55 \\
\hline 9-ероху-C18:1c & 6.79 & 0.00 & 0.00 & 0.00 & 0.00 & 0.00 & 0.00 & 1.66 & 0.00 & 0.00 & 0.00 & 0.00 & 0.00 & 0.00 & 0.00 & 1.79 & 2.14 & 0.00 & 0.00 \\
\hline
\end{tabular}




\begin{tabular}{|c|c|c|c|c|c|c|c|c|c|c|c|c|c|c|c|c|c|c|c|}
\hline C20:1w9t & 0.00 & 0.00 & 0.00 & 0.00 & 0.00 & 0.00 & 0.00 & 0.00 & 2.60 & 0.00 & 0.00 & 2.56 & 1.36 & 1.00 & 0.00 & 0.00 & 0.00 & 0.00 & 0.00 \\
\hline 12-cyclo-C18:1t & 1.84 & 0.00 & 0.00 & 0.00 & 0.00 & 0.00 & 0.00 & 0.00 & 0.00 & 0.00 & 0.00 & 0.00 & 0.00 & 0.00 & 0.76 & 2.08 & 0.00 & 0.00 & 0.00 \\
\hline $\begin{array}{l}\text { 9,10-chloro- } \\
\text { C18:0 }\end{array}$ & 3.00 & 0.00 & 0.00 & 0.00 & 0.00 & 0.00 & 0.00 & 0.00 & 0.00 & 0.00 & 0.00 & 0.20 & 0.00 & 0.00 & 0.59 & 9.28 & 0.00 & 0.00 & 0.00 \\
\hline C23:0 & 0.55 & 0.09 & 16.42 & 0.00 & 0.00 & 0.00 & 0.12 & 0.00 & 0.00 & 0.08 & 0.12 & 0.12 & 0.09 & 0.16 & 0.45 & 0.00 & 0.10 & 0.34 & 0.31 \\
\hline $\begin{array}{l}\text { DGFA Yield } \\
\text { (pmol/g) }\end{array}$ & 1356 & 1959 & 905 & 815 & 811 & 257 & 1418 & 389 & 3040 & 2479 & 3953 & 2528 & 752 & 1108 & 2921 & 258 & 2786 & 3155 & 3229 \\
\hline $\begin{array}{l}\text { Number of DG- } \\
\text { FAMEs }\end{array}$ & 18 & 14 & 12 & 10 & 10 & 9 & 14 & 11 & 20 & 19 & 18 & 19 & 14 & 15 & 18 & 13 & 20 & 14 & 17 \\
\hline $\begin{array}{l}\text { DGFA:PLFA } \\
\text { Ratio }\end{array}$ & 16 & 41 & 4 & 4 & 1 & 3 & 13 & 1 & 8 & 7 & 8 & 30 & 5 & 28 & 15 & 1 & 8 & 10 & 16 \\
\hline
\end{tabular}

\begin{tabular}{|c|c|c|c|c|c|c|c|c|c|c|c|c|c|c|c|c|c|c|c|}
\hline \multicolumn{20}{|c|}{ Functional Group Totals } \\
\hline N-Sats & 60.50 & 51.43 & 46.85 & 61.88 & 59.35 & 52.28 & 53.23 & 54.05 & 50.70 & 74.05 & 49.14 & 56.07 & 52.62 & 48.03 & 47.31 & 46.94 & 66.33 & 60.92 & 55.93 \\
\hline Mo-unsats & 5.64 & 30.94 & 44.57 & 32.01 & 31.72 & 34.16 & 38.61 & 36.72 & 35.09 & 2.51 & 33.79 & 27.00 & 29.52 & 32.83 & 31.51 & 30.58 & 12.83 & 23.69 & 26.97 \\
\hline Epoxy- & 11.24 & 0.00 & 0.00 & 4.84 & 1.66 & 2.23 & 1.56 & 1.76 & 3.08 & 4.66 & 0.00 & 4.48 & 0.00 & 2.59 & 2.72 & 4.48 & 5.52 & 4.17 & 3.55 \\
\hline Hydroxy- & 0.00 & 0.00 & 0.00 & 0.00 & 0.00 & 0.00 & 0.00 & 0.00 & 0.00 & 0.00 & 0.00 & 0.00 & 0.00 & 1.69 & 2.22 & 4.31 & 1.38 & 0.00 & 0.00 \\
\hline PolyUnsats & 3.61 & 6.31 & 0.00 & 0.00 & 0.00 & 2.72 & 2.22 & 2.46 & 0.00 & 0.00 & 0.00 & 0.00 & 0.00 & 5.20 & 6.10 & 3.39 & 3.39 & 0.00 & 2.57 \\
\hline Cyclopropy & 7.65 & 4.35 & 8.59 & 1.27 & 7.27 & 3.55 & 1.15 & 1.68 & 5.35 & 4.98 & 2.92 & 5.27 & 7.78 & 3.82 & 4.16 & 3.72 & 4.07 & 5.22 & 4.76 \\
\hline Chloro- & 3.00 & 0.00 & 0.00 & 0.00 & 0.00 & 0.20 & 0.00 & 0.00 & 0.59 & 9.28 & 0.00 & 0.00 & 0.00 & 0.00 & 0.00 & 0.00 & 0.00 & 0.00 & 0.00 \\
\hline
\end{tabular}

Abbreviations: $\mathrm{Phos}=\mathrm{mBD}+\mathrm{Phos}, \mathrm{Cit}=\mathrm{mBD}+\mathrm{Cit}, \mathrm{Mg} 2+=\mathrm{mBD}+\mathrm{Phos}+\mathrm{Mg} 2+, \mathrm{POPC}=\mathrm{mBD}+\mathrm{Phos}+\mathrm{POPC}, \mathrm{E}$ coli=mBD+Phos+E coli, Folch= Folch, $\mathrm{MAE}=\mathrm{Microwave}$ Assisted Extraction. $\mathrm{N}=$ Sats= normal saturates, Mo-unsats=monounsaturates, T-Branched=terminally branched, polyunsats=polyunsaturates,

DGFA/PLFA=Diglyceride fatty acid pmol/g to polar lipid fatty acid pmol/g ratio. 


\section{CHAPTER 2}

Table 1 Individual DGFA concentrations (DL<0.18 ng) and relative mole percentages in the Mahantango, Marcellus Shale top, Upper Marcellus Shale, Mahantango Wash, Marcellus Top Wash, Upper Marcellus Wash, Drilling Mud 9-03 (2015), and Drilling Mud 8-28 (2015) samples

\begin{tabular}{|c|c|c|c|c|c|c|c|c|c|c|c|c|c|c|c|c|}
\hline DGFA & $\begin{array}{l}\text { Maha } \\
\text { ntang } \\
\text { pmol/g }\end{array}$ & $\begin{array}{l}\text { Maha } \\
\text { ntang }\end{array}$ & $\begin{array}{l}\text { Marce } \\
\text { Top } \\
\text { pmol/g }\end{array}$ & $\begin{array}{l}\text { Marc } \\
\text { Top } \\
\text { mol \% }\end{array}$ & $\begin{array}{l}\text { Upper } \\
\text { Marce } \\
\text { pmol/g }\end{array}$ & $\begin{array}{l}\text { Upper } \\
\text { Marce }\end{array}$ & $\begin{array}{l}\text { Mahan } \\
\text { wash } \\
\text { pmol/g }\end{array}$ & $\begin{array}{l}\text { Mahan } \\
\text { wash } \\
\mathrm{mol} \%\end{array}$ & $\begin{array}{l}\text { MarTop } \\
\text { Wash }\end{array}$ & $\begin{array}{l}\begin{array}{l}\text { MarcTop } \\
\text { Wash }\end{array} \\
\mathrm{mol} \%\end{array}$ & $\begin{array}{l}\text { U Marce } \\
\text { Wash } \\
\mathrm{pmol} / \mathrm{g}\end{array}$ & $\begin{array}{c}\text { U Marce } \\
\mathrm{mol} \%\end{array}$ & $\begin{array}{l}\text { D Mud } \\
8: 28 \\
\mathrm{pmol} / \mathrm{g}\end{array}$ & $\begin{array}{l}\text { D Mud } \\
8: 28 \\
\mathrm{~mol} \%\end{array}$ & $\begin{array}{l}\text { D Mud } \\
9.03 \\
\mathrm{pmol} / \mathrm{g}\end{array}$ & $\begin{array}{l}\text { D Mud } \\
\frac{9.03}{\mathrm{~mol} \%}\end{array}$ \\
\hline c11:0 & N.D. & N.D. & N.D. & N.D. & 0.7 & 0.4 & N.D. & N.D. & N.D. & N.D. & N.D. & N.D. & 9.9 & 3.2 & 8.7 & 2.7 \\
\hline 19:1w1 & 0.6 & 0.2 & N.D. & N.D. & N.D. & N.D. & N.D. & N.D. & N.D. & N.D. & N.D. & N.D. & N.D. & N.D. & N.D. & N.D. \\
\hline 10:0-9-ox & 0.5 & 0.2 & N.D. & N.D. & N.D. & N.D. & N.D. & N.D. & N.D. & N.D. & N.D. & N.D. & N.D. & N.D. & N.D. & N.D. \\
\hline 10:0-10-ox & 0.8 & 0.3 & N.D. & N.D. & N.D. & N.D. & N.D. & N.D. & N.D. & N.D. & N.D. & N.D. & N.D. & N.D. & N.D. & N.D. \\
\hline c12:0 & 27.3 & 10.8 & N.D. & N.D. & 18.0 & 9.8 & 6.5 & 2.9 & 1.9 & 0.9 & N.D. & N.D. & 82.1 & 26.9 & 70.4 & 22.1 \\
\hline iC12:0 & 0.2 & 0.1 & N.D. & N.D. & N.D. & N.D. & N.D. & N.D. & N.D. & N.D. & N.D. & N.D. & N.D. & N.D. & N.D. & N.D. \\
\hline $\begin{array}{l}11: 0 \omega-10- \\
\text { ox }\end{array}$ & 0.5 & 0.2 & N.D. & N.D. & N.D. & N.D. & N.D. & N.D. & N.D. & N.D. & N.D. & N.D. & N.D. & N.D. & N.D. & N.D. \\
\hline c13:0 & 0.3 & 0.1 & N.D. & N.D. & N.D. & N.D. & N.D. & N.D. & 1.2 & 0.6 & N.D. & N.D. & N.D. & N.D. & 3.78 & 1.19 \\
\hline 10:0-DME & 2.4 & 1.1 & 0.1 & 0.1 & 1.4 & 0.8 & 1.0 & 0.4 & 1.0 & 0.5 & N.D. & N.D. & N.D. & N.D. & N.D. & N.D. \\
\hline c14:0 & 9.3 & 3.4 & 2.6 & 1.6 & 5.1 & 2.8 & 6.2 & 2.8 & 8.2 & 3.9 & 6.35 & 4.03 & 76.9 & 25.2 & 72.6 & 22.8 \\
\hline 11:0-DME & 2.1 & 0.7 & 0.2 & 0.1 & 0.8 & 0.4 & N.D. & N.D. & N.D. & N.D. & N.D. & N.D. & N.D. & N.D. & N.D. & N.D. \\
\hline 15:0w9-OH & 1.4 & 0.5 & N.D. & N.D. & N.D. & N.D. & N.D. & N.D. & N.D. & N.D. & N.D. & N.D. & N.D. & N.D. & N.D. & N.D. \\
\hline $16: 1 \omega 9$ & 0.2 & 0.1 & N.D. & N.D. & N.D. & N.D. & N.D. & N.D. & N.D. & N.D. & N.D. & N.D. & N.D. & N.D. & N.D. & N.D. \\
\hline i15:0 & 0.4 & 0.2 & N.D. & N.D. & N.D. & N.D. & N.D. & N.D. & N.D. & N.D. & N.D. & N.D. & N.D. & N.D. & N.D. & N.D. \\
\hline a15:0 & 0.6 & 0.2 & N.D. & N.D & N.D. & N.D. & N.D. & N.D. & N.D. & N.D. & N.D. & N.D. & 7.56 & 2.5 & 8.9 & 2.8 \\
\hline c15:0 & 2.5 & 0.8 & 1.2 & 0.7 & 1.07 & 0.6 & N.D. & N.D. & N.D. & N.D. & N.D. & N.D. & N.D. & N.D. & N.D. & N.D. \\
\hline C16:0 & 44.2 & 14.4 & 36.3 & 22.4 & 43.0 & 23.5 & 52.4 & 23.6 & 61.3 & 29.1 & 56.9 & 36.1 & 28.4 & 9.3 & 40.4 & 12.7 \\
\hline C18:0 & 41.6 & 13.5 & 41.6 & 25.6 & 36.9 & 20.1 & 54.4 & 24.5 & 68.5 & 32.6 & 67.4 & 42.8 & 31.3 & 10.2 & 36.7 & 11.5 \\
\hline $16: 4 \omega 1$ & 0.6 & 0.2 & N.D. & N.D. & N.D. & N.D. & N.D. & N.D. & N.D. & N.D. & N.D. & N.D. & N.D. & N.D. & 9.0 & 2.8 \\
\hline iC16:0 & 0.5 & 0.2 & N.D. & N.D. & N.D. & N.D. & N.D. & N.D. & N.D. & N.D. & N.D. & N.D. & N.D. & N.D. & N.D. & N.D. \\
\hline $16: 1 \omega 7 t$ & 1.6 & 0.5 & 0.2 & 0.15 & 0.5 & 0.26 & N.D. & N.D. & N.D. & N.D. & N.D. & N.D. & N.D. & N.D. & N.D. & N.D. \\
\hline 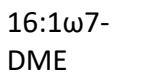 & 1.3 & 0.1 & N.D. & N.D. & 2.3 & 1.23 & N.D. & N.D. & N.D. & N.D. & N.D. & N.D. & N.D. & N.D. & N.D. & N.D. \\
\hline
\end{tabular}




\begin{tabular}{|c|c|c|c|c|c|c|c|c|c|c|c|c|c|c|c|c|}
\hline $\begin{array}{l}\text { 10:0-4- } \\
\text { DME }\end{array}$ & 11.4 & 3.7 & 4.2 & 2.6 & 4.4 & 2.42 & 1.60 & 0.72 & 2.54 & 1.21 & N.D. & N.D. & N.D. & N.D. & N.D. & N.D. \\
\hline iC17:0 & 0.3 & 0.1 & N.D. & N.D. & N.D. & N.D. & N.D. & N.D. & N.D. & N.D. & N.D. & N.D. & N.D. & N.D. & N.D. & N.D. \\
\hline aC17:0 & 6.2 & 2.0 & 0.7 & 0.4 & 2.7 & 1.5 & 4.1 & 1.9 & 3.9 & 1.8 & N.D. & N.D. & N.D. & N.D. & N.D. & N.D. \\
\hline C17:0 & 5.3 & 1.7 & 2.6 & 1.6 & 3.0 & 1.6 & 8.7 & 3.9 & 3.7 & 1.8 & N.D. & N.D. & N.D. & N.D. & N.D. & N.D. \\
\hline $18: 2 \omega 6$ & 1.3 & 0.4 & N.D. & N.D. & 0.6 & 0.3 & 4.9 & 2.2 & 8.4 & 4.0 & N.D. & N.D. & N.D. & N.D. & N.D. & N.D. \\
\hline $18: 1 \omega 9 t$ & 4.1 & 1.3 & 0.6 & 0.4 & 4.0 & 2.2 & 29.9 & 13.4 & 14.8 & 7.0 & 19.0 & 12.0 & 69.4 & 122.7 & 68.36 & 21.5 \\
\hline $18: 1 \omega 7 t$ & 0.9 & 0.3 & 0.2 & 0.1 & N.D. & N.D. & 4.1 & 1.9 & 3.6 & 1.7 & N.D. & N.D. & N.D. & N.D. & N.D. & N.D. \\
\hline $18: 2 \omega 11$ & 0.7 & 0.6 & N.D. & N.D. & N.D. & N.D. & N.D. & N.D. & N.D. & N.D. & N.D. & N.D. & N.D. & N.D. & N.D. & N.D. \\
\hline 10Me18:0 & 0.5 & 0.8 & N.D. & N.D. & N.D. & N.D. & N.D. & N.D. & N.D. & N.D. & N.D. & N.D. & N.D. & N.D. & N.D. & N.D. \\
\hline 18:1w9t-ep & 31.7 & 0.2 & 31.5 & 19.4 & 26.6 & 14.5 & 20.1 & 9.1 & N.D. & N.D. & N.D. & N.D. & N.D. & N.D. & N.D. & N.D. \\
\hline 18:1w6c-ep & 0.5 & 20.0 & N.D. & N.D. & 0 & N.D. & N.D. & N.D. & N.D. & N.D. & N.D. & N.D. & N.D. & N.D. & N.D. & N.D. \\
\hline 18:0w9-ox & 30.0 & 13.0 & 30.6 & 18.9 & 20.9 & 11.4 & 22.4 & 10.1 & 27.0 & 12.8 & N.D. & N.D. & N.D. & N.D. & N.D. & N.D. \\
\hline $20: 2 \omega 6 t$ & 12.6 & 4.1 & 6.2 & 3.8 & 4.0 & 2.7 & N.D. & N.D. & N.D. & N.D. & N.D. & N.D. & N.D. & N.D. & N.D. & N.D. \\
\hline $20: 1 \omega 9 t$ & 9.4 & 3.1 & 3.5 & 2.1 & 5.1 & 2.8 & 5.5 & 2.5 & 4.6 & 2.2 & 8.0 & 5.1 & N.D. & N.D. & N.D. & N.D. \\
\hline c20:0 & 4.0 & 1.3 & N.D. & N.D. & 1.3 & 0.7 & N.D. & N.D. & N.D. & N.D. & N.D. & N.D. & N.D. & N.D. & N.D. & N.D. \\
\hline Sum & 258.0 & 100.0 & 162.2 & 100.0 & 183.2 & 100.0 & 221.9 & 100.0 & 210.5 & 100.0 & 157.5 & 100.0 & 305.5 & 100.0 & 318.6 & 100.0 \\
\hline
\end{tabular}

Table 2 Distribution of DGFA functional group biomarker in the Mahantango, Marcellus Shale top, upper Marcellus Shale, Mahantango Wash, Marcellus Top Wash, Upper Marcellus Wash, Drilling Mud 9-03 (2015), and Drilling Mud 8-28 (2015) samples.

\begin{tabular}{|c|c|c|c|c|c|c|c|c|}
\hline Functional Group & Mah & Mar Top & U Mar & Mahan Wash & Ma To Wash & U Mar Wash & D Mud 8:28 & D Mud 9.03 \\
\hline normal sats & 46.0 & 52.0 & 59.5 & 57.8 & 68.8 & 83.0 & 79.2 & 69.8 \\
\hline mono-unsats & 5.5 & 2.8 & 5.2 & 17.8 & 10.9 & 17.1 & 17.5 & 24.0 \\
\hline term branched & 2.7 & 0.4 & 1.5 & 1.9 & 1.8 & N.D. & 3.4 & 2.2 \\
\hline Poly unsats & 5.3 & 3.8 & 3.1 & 2.2 & 4.0 & N.D. & N.D. & 4.0 \\
\hline hydroxy & 0.5 & N.D. & N.D. & N.D. & N.D. & N.D. & N.D. & N.D. \\
\hline Oxiranes & 20.2 & 19.4 & 14.5 & 9.1 & N.D. & N.D. & N.D. & N.D. \\
\hline Keto & 13.6 & 18.9 & 11.4 & 10.1 & 12.8 & N.D. & N.D. & N.D. \\
\hline Branched Sats & 0.8 & N.D. & N.D. & N.D. & N.D. & N.D. & N.D. & N.D. \\
\hline Dimethyl Esters & 5.6 & 2.8 & 4.9 & 1.2 & 1.7 & N.D. & N.D. & N.D. \\
\hline
\end{tabular}


Abbreviations: D.L = Detection Limit, Mah=Mahantango, Mar Top= Marcellus Shale Top, U Mar= Upper Marcellus Shale, Mahan Wash=Mahantango Wash, Ma Top Wash=Marcellus Top Wash, U Mar Wash=Upper Marcellus Wash, D Mud 8.28= Drilling Mud 8-28 (2015), D Mud 9-03= Drilling Mud 9-03 (2015) samples. Normal Sats= Normal Saturated, MonoUnsats= Monounsaturated, PolyUnsats= Polyunsaturated, TermBr= Terminally Branched, DME=Dimethylester, $\mathrm{Cyclo=}$ Cyclopropane, Branched Sats= Branched Saturated, and hydroxyl= hydroxyl lipid fatty acids. 
CHAPTER 3

Table 1. PLFA concentration, relative mole percentages, and number of PLFA profiles detected in the MSEEL-1, MSEEL-2, MSEEL-3, WV 6-1, WV 6-2, and WV 6-3 samples.

\begin{tabular}{|c|c|c|c|c|c|c|c|c|c|c|c|c|}
\hline & \multicolumn{2}{|c|}{ MSEEL-1 } & \multicolumn{2}{|c|}{ MSEEL-2 } & \multicolumn{2}{|c|}{ MSEEL-3 } & \multicolumn{2}{|c|}{ WV 6-1 } & \multicolumn{2}{|c|}{ WV 6-2 } & \multicolumn{2}{|c|}{ WV 6-3 } \\
\hline & Area & Mol \% & Area & Mol \% & Area & Mol \% & Area & Mol \% & Area & Mol \% & Area & Mol \% \\
\hline cyclo $16: 0$ & N.D. & N.D. & N.D. & N.D. & N.D. & N.D. & N.D. & N.D. & N.D. & N.D. & N.D. & N.D. \\
\hline cyclo 16:1w7t & N.D. & N.D. & N.D. & N.D. & N.D. & N.D. & N.D. & N.D. & N.D. & N.D. & N.D. & N.D. \\
\hline C10:0-DME & 0.16 & 0.68 & 0.32 & 0.39 & N.D. & N.D. & N.D. & N.D. & N.D. & N.D. & N.D. & N.D. \\
\hline C9:0-DME & 1.39 & 5.93 & 4.01 & 4.83 & 1.58 & 2.86 & N.D. & N.D. & N.D. & N.D. & N.D. & N.D. \\
\hline C10:0-DME & N.D. & N.D. & 0.38 & 0.46 & 0.20 & 0.36 & N.D. & N.D. & N.D. & N.D. & N.D. & N.D. \\
\hline C10:0-ox-4-DME & 0.13 & 0.55 & 1.66 & 2.00 & 1.12 & 2.02 & N.D. & N.D. & N.D. & N.D. & N.D. & N.D. \\
\hline C18:1w9t-ep & 1.41 & 6.02 & 8.38 & 10.09 & 6.08 & 10.99 & N.D. & N.D. & N.D. & N.D. & N.D. & N.D. \\
\hline C9:0-9ox & 0.40 & 1.71 & 1.98 & 2.38 & 1.50 & 2.71 & 0.05 & 0.29 & 0.56 & 1.46 & 2.14 & 11.09 \\
\hline C18:0-10ox & 1.15 & 4.91 & 6.32 & 7.61 & 3.98 & 7.19 & N.D. & N.D. & N.D. & N.D. & N.D. & N.D. \\
\hline C16:1w9c & N.D. & N.D. & N.D. & N.D. & N.D. & N.D. & N.D. & N.D. & N.D. & N.D. & N.D. & N.D. \\
\hline C16:1w7t & N.D. & N.D. & N.D. & N.D. & N.D. & N.D. & 1.39 & 7.58 & 9.84 & 25.64 & 0.06 & 0.32 \\
\hline C18:1w9t & 0.05 & 0.21 & 0.14 & 0.17 & 0.21 & 0.38 & 8.36 & 45.49 & 0.74 & 1.94 & 0.44 & 2.28 \\
\hline 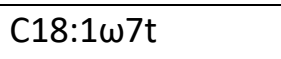 & N.D. & N.D. & N.D. & N.D. & N.D. & N.D. & N.D. & N.D. & N.D. & N.D. & N.D. & N.D. \\
\hline C20:1w9c & N.D. & N.D. & N.D. & N.D. & N.D. & N.D. & 0.13 & 0.68 & 0.45 & 1.18 & 0.00 & 0.01 \\
\hline$C 20: 4 \omega 6 c$ & 0.22 & 0.94 & 1.47 & 1.77 & 0.98 & 1.77 & 0.76 & 4.16 & 1.18 & 3.09 & 0.03 & 0.16 \\
\hline C12:0 & 2.05 & 8.75 & 3.48 & 4.19 & 0.82 & 1.48 & N.D. & N.D. & N.D. & N.D. & N.D. & N.D. \\
\hline C14:0 & 0.33 & 1.41 & 1.43 & 1.72 & 0.92 & 1.66 & 0.87 & 4.73 & 1.11 & 2.89 & 1.13 & 5.86 \\
\hline C15:0 & N.D. & N.D. & 0.19 & 0.23 & 0.12 & 0.22 & 0.91 & 4.95 & 3.89 & 10.15 & 2.53 & 13.10 \\
\hline C16:0 & 7.06 & 30.13 & 25.11 & 30.22 & 17.82 & 32.20 & 1.58 & 8.61 & 0.48 & 1.25 & 3.37 & 17.43 \\
\hline C17:0 & 0.14 & 0.60 & 0.67 & 0.81 & 0.54 & 0.98 & 0.07 & 0.40 & 0.52 & 1.35 & 0.28 & 1.44 \\
\hline C18:0 & 8.64 & 36.88 & 25.46 & 30.65 & 17.94 & 32.42 & N.D. & N.D. & N.D. & N.D. & N.D. & N.D. \\
\hline C20:0 & 0.15 & 0.64 & 1.03 & 1.24 & 0.76 & 1.37 & N.D. & N.D. & N.D. & N.D. & N.D. & N.D. \\
\hline
\end{tabular}




\begin{tabular}{|c|c|c|c|c|c|c|c|c|c|c|c|c|}
\hline C21:0 & N.D. & N.D. & N.D. & N.D. & N.D. & N.D. & N.D. & N.D. & N.D. & N.D. & N.D. & N.D. \\
\hline C23:0 & N.D. & N.D. & N.D. & N.D. & N.D. & N.D. & N.D. & N.D. & N.D. & N.D. & N.D. & N.D. \\
\hline C24:0 & N.D. & N.D. & N.D. & N.D. & N.D. & N.D. & N.D. & N.D. & N.D. & N.D. & N.D. & N.D. \\
\hline C25:0 & N.D. & N.D. & N.D. & N.D. & N.D. & N.D. & N.D. & N.D. & N.D. & N.D. & N.D. & N.D. \\
\hline C26:0 & N.D. & N.D. & N.D. & N.D. & N.D. & N.D. & N.D. & N.D. & N.D. & N.D. & N.D. & N.D. \\
\hline$C 16: 3 \omega 4$ & N.D. & N.D. & N.D. & N.D. & N.D. & N.D. & N.D. & N.D. & N.D. & N.D. & N.D. & N.D. \\
\hline 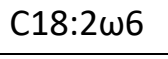 & N.D. & N.D. & N.D. & N.D. & N.D. & N.D. & N.D. & N.D. & N.D. & N.D. & N.D. & N.D. \\
\hline$C 20: 2 \omega 6 t$ & N.D. & N.D. & N.D. & N.D. & N.D. & N.D. & N.D. & N.D. & N.D. & N.D. & N.D. & N.D. \\
\hline iC14:0 & N.D. & N.D. & N.D. & N.D. & N.D. & N.D. & 0.79 & 4.31 & 0.88 & 2.29 & 6.95 & 36.02 \\
\hline iC15:0 & N.D. & N.D. & N.D. & N.D. & N.D. & N.D. & 0.23 & 1.25 & 14.69 & 38.26 & 0.01 & 0.06 \\
\hline aC15:0 & N.D. & N.D. & N.D. & N.D. & N.D. & N.D. & 1.10 & 5.98 & 0.77 & 1.99 & 0.06 & 0.30 \\
\hline iC17:0 & N.D. & N.D. & N.D. & N.D. & N.D. & N.D. & 0.28 & 1.53 & 0.35 & 0.90 & 0.28 & 1.44 \\
\hline aC17:0 & 0.15 & 0.64 & 0.79 & 0.95 & 0.59 & 1.07 & 0.26 & 1.43 & 0.35 & 0.90 & 1.31 & 6.76 \\
\hline iC18:0 & N.D. & N.D. & 0.26 & 0.31 & 0.18 & 0.33 & 1.58 & 8.61 & 2.58 & 6.73 & 0.72 & 3.73 \\
\hline SUM & 23.43 & 100.00 & 83.08 & 100.02 & 55.34 & 100.01 & 18.38 & 100.00 & 38.39 & 100.00 & 19.31 & 100.00 \\
\hline
\end{tabular}


Table 2. PLFA functional group biomarker distribution in the MSEEL-1, MSEEL-2, MSEEL-3, WV 6-1, WV 6-2, and WV 6-3 samples.

\begin{tabular}{|l|l|l|l|l|l|l|}
\hline & MSEEL 1 & MSEEL -2 & MSEEL-3 & WV 6-1 & WV 6-2 & WV 6-3 \\
& & & & & & \\
\hline Normal Sats & 78.40 & 69.05 & 70.33 & 47.43 & 21.42 & 39.38 \\
\hline MonoUnsats & 0.21 & 0.17 & 0.38 & 11.33 & 33.18 & 14.80 \\
\hline PolyUnsats & 0.94 & 1.77 & 1.77 & N.D. & N.D. & N.D. \\
\hline Keto & 7.17 & 11.99 & 11.93 & N.D. & N.D. & N.D. \\
\hline Epoxy & 6.02 & 10.09 & 10.99 & N.D. & N.D. & N.D. \\
\hline TermBr & 0.64 & 1.26 & 1.39 & 2.96 & 2.24 & 35.22 \\
\hline DME & 6.62 & 5.67 & 3.22 & N.D. & N.D. & N.D. \\
\hline Cyclo & N.D. & N.D. & N.D. & 5.16 & 2.84 & 1.70 \\
\hline Branched mono & N.D. & N.D. & N.D. & 31.27 & 1.90 & 2.23 \\
\hline Br Sats & N.D. & N.D. & N.D. & 1.84 & 38.41 & 6.67 \\
\hline
\end{tabular}


Table 3. DGFA concentration, relative mole percentages, detected in the MSEEL-1, MSEEL-2, MSEEL-3, WV 6-1, WV 6-2, and WV 6-3

\begin{tabular}{|c|c|c|c|c|c|c|c|c|c|c|c|c|}
\hline & \multicolumn{2}{|c|}{ MSEEL-1 } & \multicolumn{2}{|c|}{ MSEEL-2 } & \multicolumn{2}{|c|}{ MSEEL-3 } & \multicolumn{2}{|c|}{ WV 6-1 } & \multicolumn{2}{|c|}{ WV 6-2 } & \multicolumn{2}{|c|}{ WV 6-3 } \\
\hline & Area & Mol \% & Area & Mol \% & Area & Mol \% & Area & Mol \% & Area & Mol \% & Area & Mol \% \\
\hline $\mathrm{c} 11: 0$ & N.D. & N.D. & N.D. & N.D. & 0.68 & 0.37 & N.D. & N.D. & 0.90 & 8.56 & N.D. & N.D. \\
\hline 19:1w1 & 0.59 & 0.19 & N.D. & N.D. & N.D. & N.D. & N.D. & N.D. & N.D. & N.D. & N.D. & N.D. \\
\hline 10:0-9-ox & 0.53 & 0.17 & N.D. & N.D. & N.D. & N.D. & N.D. & N.D. & N.D. & N.D. & N.D. & N.D. \\
\hline 10:0-10-ox & 0.79 & 0.26 & N.D. & N.D. & N.D. & N.D. & N.D. & N.D. & N.D. & N.D. & N.D. & N.D. \\
\hline $\mathrm{c} 12: 0$ & 27.32 & 10.82 & N.D. & N.D. & N.D. & N.D. & N.D. & N.D. & N.D. & N.D. & N.D. & N.D. \\
\hline iC12:0 & 0.23 & 0.07 & N.D. & N.D. & N.D. & N.D. & N.D. & N.D. & N.D. & N.D. & N.D. & N.D. \\
\hline 11:0w-10-ox & 0.51 & 0.17 & N.D. & N.D. & N.D. & N.D. & N.D. & N.D. & N.D. & N.D. & N.D. & N.D. \\
\hline c13:0 & 0.26 & 0.08 & N.D. & N.D. & N.D. & N.D. & N.D. & N.D. & 1.54 & 5.00 & N.D. & N.D. \\
\hline 10:0-DME & 2.43 & 1.11 & 0.12 & 0.07 & 1.39 & 0.76 & N.D. & N.D. & N.D. & N.D. & N.D. & N.D. \\
\hline c14:0 & 9.30 & 3.35 & 2.56 & 1.58 & 5.11 & 2.79 & 0.91 & 2.68 & 0.00 & 9.15 & N.D. & N.D. \\
\hline 11:0-DME & 2.19 & 0.65 & 0.17 & 0.10 & 0.79 & 0.43 & N.D. & N.D. & N.D. & N.D. & N.D. & N.D. \\
\hline 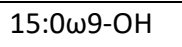 & 1.44 & 0.47 & N.D. & N.D. & N.D. & N.D. & N.D. & N.D. & N.D. & N.D. & N.D. & N.D. \\
\hline $16: 1 \omega 9$ & 0.21 & 0.07 & N.D. & N.D. & N.D. & N.D. & N.D. & N.D. & N.D. & N.D. & N.D. & N.D. \\
\hline i15:0 & 0.45 & 0.15 & N.D. & N.D. & N.D. & N.D. & N.D. & N.D. & N.D. & N.D. & N.D. & N.D. \\
\hline a15:0 & 0.60 & 0.19 & N.D. & N.D. & N.D. & N.D. & N.D. & N.D. & 2.64 & N.D. & N.D. & N.D. \\
\hline$c 15: 0$ & 2.46 & 0.80 & 1.17 & 0.72 & 1.07 & 0.58 & N.D. & N.D. & N.D. & N.D. & N.D. & N.D. \\
\hline C16:0 & 44.24 & 14.37 & 36.32 & 22.39 & 42.98 & 23.46 & 27.96 & 82.25 & 0.00 & 36.71 & N.D. & N.D. \\
\hline C18:0 & 41.58 & 13.51 & 41.57 & 25.63 & 36.89 & 20.13 & N.D. & N.D. & N.D. & N.D. & N.D. & N.D. \\
\hline $16: 4 \omega 1$ & 0.59 & 0.19 & N.D. & N.D. & N.D. & N.D. & N.D. & N.D. & N.D. & N.D. & N.D. & N.D. \\
\hline iC16:0 & 0.48 & 0.16 & N.D. & N.D. & N.D. & N.D. & 1.77 & 5.22 & 0.00 & 10.78 & 2.65 & 6.15 \\
\hline $16: 1 \omega 7 t$ & 1.62 & 0.53 & 0.24 & 0.15 & 0.47 & 0.26 & N.D. & N.D. & N.D. & N.D. & N.D. & N.D. \\
\hline 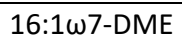 & 1.31 & 0.10 & N.D. & N.D. & 2.26 & 1.23 & N.D. & N.D. & 4.51 & N.D. & N.D. & N.D. \\
\hline 10:0-4-DME & 11.40 & 3.70 & 4.20 & 2.59 & 4.44 & 2.42 & N.D. & N.D. & N.D. & N.D. & N.D. & N.D. \\
\hline iC17:0 & 0.33 & 0.11 & N.D. & N.D. & N.D. & N.D. & N.D. & N.D. & N.D. & N.D. & N.D. & N.D. \\
\hline
\end{tabular}




\begin{tabular}{|c|c|c|c|c|c|c|c|c|c|c|c|c|}
\hline aC17:0 & 6.17 & 2.00 & 0.70 & 0.43 & 2.68 & 1.46 & 0.54 & 1.59 & N.D. & N.D. & N.D. & N.D. \\
\hline C17:0 & 5.32 & 1.73 & 2.64 & 1.63 & 2.95 & 1.61 & N.D. & N.D. & N.D. & N.D. & N.D. & N.D. \\
\hline $18: 2 \omega 6$ & 1.31 & 0.43 & N.D. & N.D. & 0.62 & 0.34 & 0.42 & 1.24 & N.D. & 6.99 & 4.99 & 11.58 \\
\hline $18: 1 \omega 9 t$ & 4.12 & 1.34 & 0.63 & 0.39 & 3.96 & 2.16 & N.D. & N.D. & N.D. & N.D. & N.D. & N.D. \\
\hline $18: 1 \omega 7 \mathrm{t}$ & 0.90 & 0.29 & 0.15 & 0.09 & N.D. & N.D. & 1.26 & 3.70 & 7.73 & 22.80 & 34.07 & 79.01 \\
\hline $18: 2 \omega 11$ & 0.68 & 0.55 & N.D. & N.D. & N.D. & N.D. & N.D. & N.D. & N.D. & N.D. & N.D. & N.D. \\
\hline 10Me18:0 & 0.53 & 0.82 & N.D. & N.D. & N.D. & N.D. & N.D. & N.D. & N.D. & N.D. & N.D. & N.D. \\
\hline 18:1w9t-ep & 31.67 & 0.22 & 31.48 & 19.41 & 26.64 & 14.54 & N.D. & N.D. & N.D. & N.D. & N.D. & N.D. \\
\hline 18:1w6c-ep & 0.45 & 19.96 & N.D. & N.D. & N.D. & N.D. & N.D. & N.D. & N.D. & N.D. & N.D. & N.D. \\
\hline 18:0w9-ox & 29.99 & 12.99 & 30.59 & 18.86 & 20.93 & 11.42 & N.D. & N.D. & N.D. & N.D. & N.D. & N.D. \\
\hline $20: 2 \omega 6 t$ & 12.57 & 4.08 & 6.19 & 3.82 & 4.96 & 2.71 & 0.23 & 0.66 & N.D. & N.D. & 0.99 & 2.30 \\
\hline $20: 1 \omega 9 t$ & 9.40 & 3.05 & 3.47 & 2.14 & 5.12 & 2.79 & 0.87 & 2.56 & 13.23 & N.D. & N.D. & N.D. \\
\hline c20:0 & 4.04 & 1.31 & N.D. & N.D. & 1.28 & 0.70 & 0.03 & 0.10 & N.D. & N.D. & 0.41 & 0.96 \\
\hline sum & 258.01 & 99.99 & 162.20 & 100.00 & 183.22 & 99.98 & 33.99 & 100.00 & 30.55 & 100.00 & 43.11 & 100.00 \\
\hline
\end{tabular}

Table 4. DGFA functional group biomarker distribution in the MSEEL-1, MSEEL-2, MSEEL-3, WV 6-1, WV 6-2, WV 6-3 samples.

\begin{tabular}{|l|l|l|l|l|l|l|}
\hline & MSEEL-1 & MSEEL-3 & MSEEL-3 & WV 6-1 & WV 6-2 & WV 6-3 \\
\hline normal sats & 45.97 & 51.95 & 59.47 & 59.49 & 13.44 & 67.16 \\
\hline mono-unsats & 5.47 & 2.77 & 5.21 & 17.92 & 66.39 & 32.84 \\
\hline term branched & 2.68 & 0.43 & 1.46 & 14.59 & 9.94 & N.D. \\
\hline Poly unsats & 5.25 & 3.82 & 3.05 & N.D. & N.D. & N.D. \\
\hline hydroxy & 0.47 & 0.00 & 0.00 & N.D. & N.D. & N.D. \\
\hline Oxiranes & 20.18 & 19.41 & 14.54 & N.D. & N.D. & N.D. \\
\hline Keto & 13.59 & 18.86 & 11.42 & N.D. & N.D. & N.D. \\
\hline Branched Sats & 0.82 & N.D. & N.D. & 8.00 & 10.23 & N.D. \\
\hline Dimethyl Esters & 5.56 & 2.77 & 4.85 & N.D. & N.D. & N.D. \\
\hline & & & & & \\
\hline
\end{tabular}


